\title{
Um Sistema para Leitura de e-mail, com Conversão Texto/Voz, utilizando Redes \\ Neurais
}

\author{
Dennys Peixoto Noronha
}

Orientadora:

Profa. Dra. Roseli Aparecida Francelin Romero

Dissertação apresentada ao Instituto de Ciências Matemáticas e de Computação I (MC-USP, como parte dos requisitos para obtenção do titulo de Mestre em Ciências de Computação e Matemática ('omputacional.

\section{USP - São Carlos \\ Julho/ 2001}

Data da Defesa:

$18 / 06 / 2001$

Visto do Orientador: 
Chegamos ao século XXI, e muitos elementos criados pela ficção científica começam a se tornar realidade. Foise $o$ tempo em que computadores falantes eram exclusividade de filmes e seriados de televisão.

Com computadores cada vez mais velozes e potentes, finalmente está se tornando viável o desenvolvimento de softwares capazes de interagir verbalmente com seus usuários, o que torna o computador mais agradável e prático de ser utilizado, além de fazê-lo parecer mais esperto e mais "inteligente". 


\section{Dedicatória}

À minha avó, Ezilda Rodrigues Peixoto, por ter sido sempre tão amável e carinhosa em vida, e por ter, lá de cima, ao lado de Deus, certamente me ajudado na conclusão deste projeto. 


\section{Agradecimentos}

Agradeço acima de tudo a Deus, que me dá força nas horas mais dificeis, me ajudando a superar todas os obstáculos impostos pela natureza da vida.

Agradeço pela orientação e pela amizade da professora Roseli Aparecida Francelin Romero, que foi de suma importância para o sucesso desta etapa de minha vida acadêmica.

Agradeço aos meus Pais José Adelino Soares Noronha e Maria de Nazaré Peixoto Noronha, pela confiança depositada em mim, pelo amor e carinho sempre presentes, e pela ajuda diária em todas as etapas de minha vida.

Agradeço a toda minha família, e especialmente às minhas irmãs Thais e Grace, e à minha tia e madrinha Marli, pelo incentivo em mim depositado, sempre mesclado com muito afeto e saudade.

Agradeço aos meus amigos: Alessandro e Daniel, por me aturarem durante 2 anos; Gedson, por estar sempre presente durante a fase de treinamento da Rede Neural do projeto; Luciana, Fabinho, Renato, Jorge, Laura, Renata, Indira, Sara e a todos os demais amigos em São Carlos, que direta ou indiretamente me ajudaram, suprindo em parte a ausência de minha familia e demais amigos distantes.

Agradeço aos professores, funcionários e alunos do ICMC-USP em geral, que através de discussões, comentários e orientações, contribuíram para a conclusão deste projeto. 


\section{Sumário}

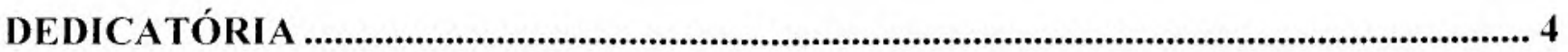

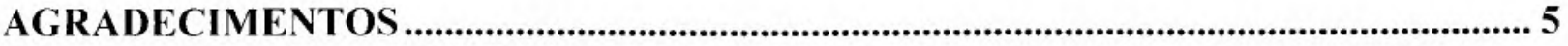

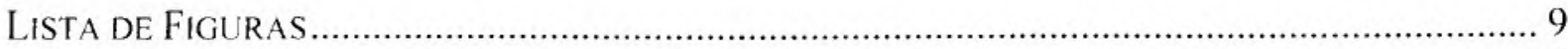

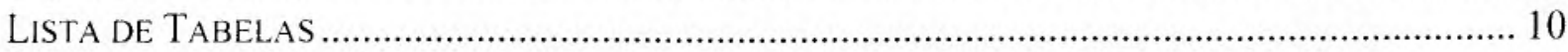

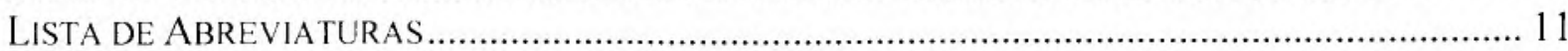

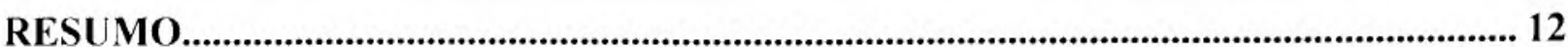

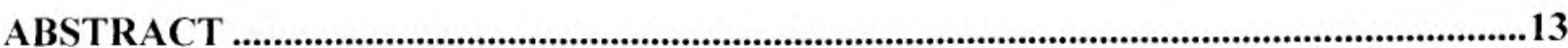

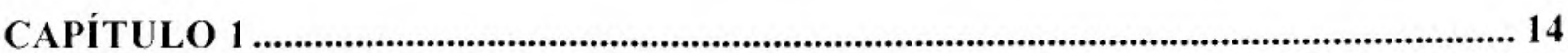

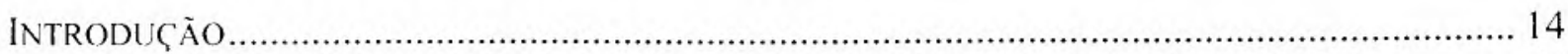

1.1 O uso da tecnologia de Conversão Texto/Voz .................................................... 16

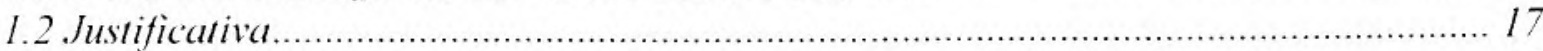

1.3 Objetivo

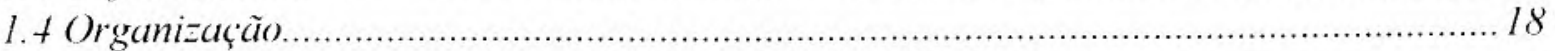

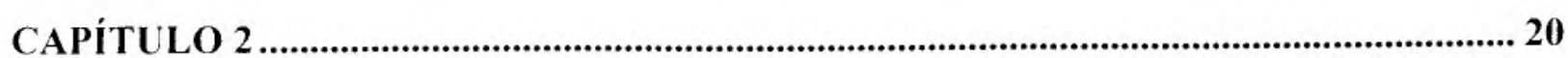

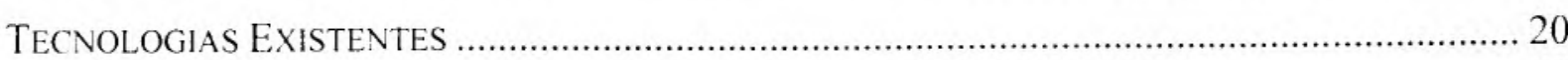

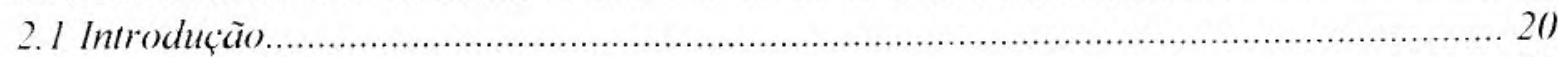

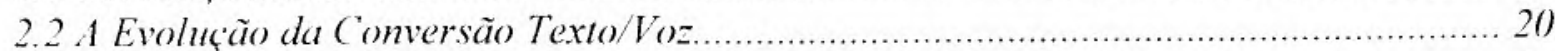

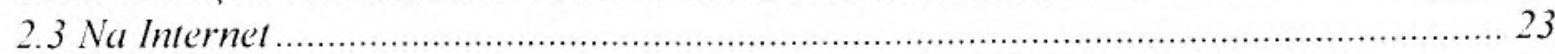

2. Tecnologias de Conversão Texto/ Voz em Português................................................. 24

2.4.1 Micropower Delta Talk ............................................................................................ 25

2.4.2 Elun "Text to Speech Engine V 3.0" "........................................................................ 26

2.5 Tecnologia de Conversão com Redes Neurais ...................................................... 27

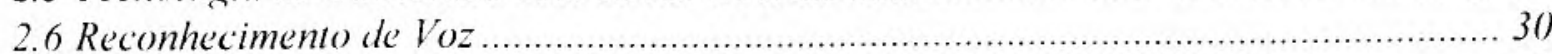

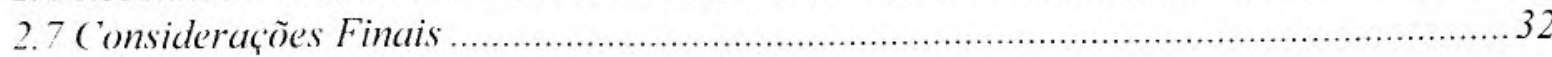

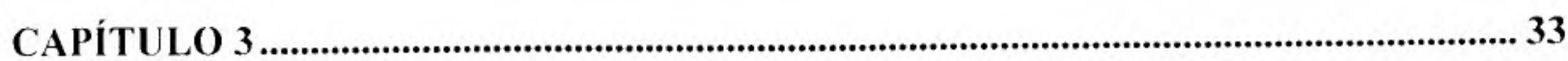

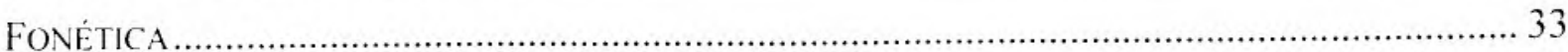

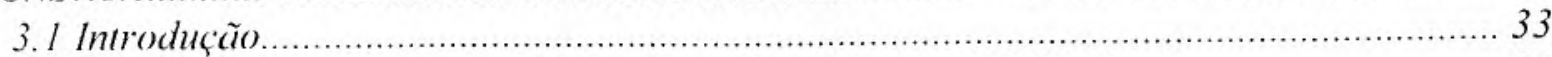

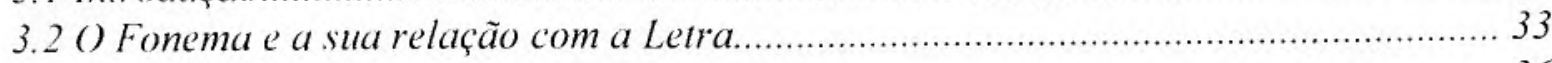

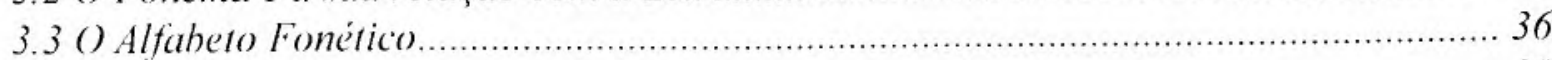

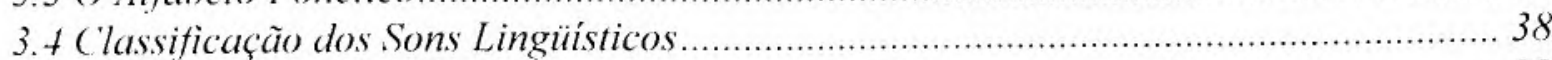

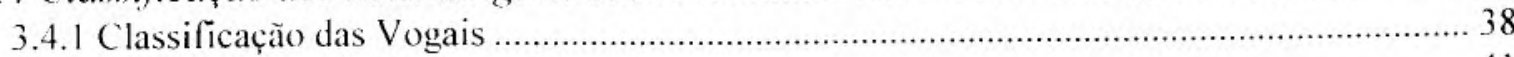

3.4.2 Classificação das Consoantes ....................................................................................... 4 I

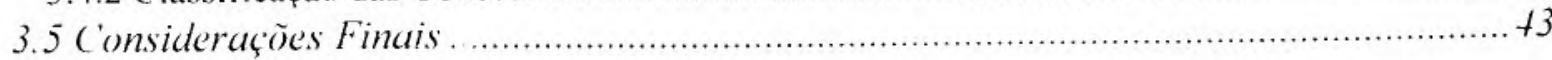




\section{CAPÍTULO 4}

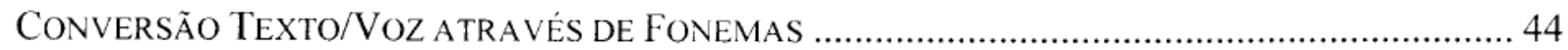

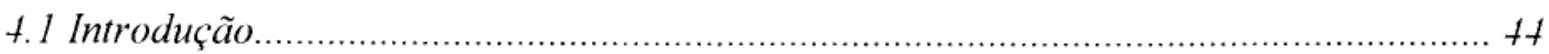

4.2 O Processo de Sintese de Voz a partir de Texto .............................................................. 4

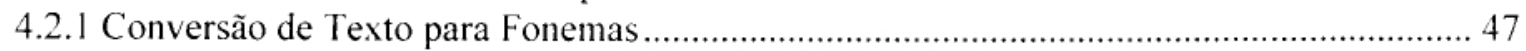

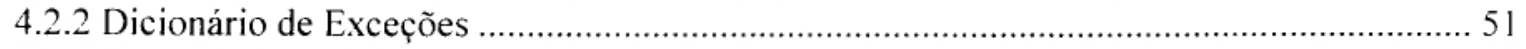

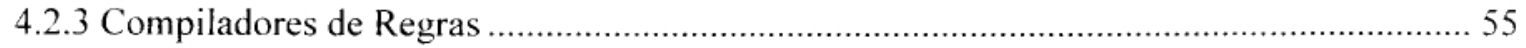

4.3 Conversão de Texto para Fonemas na Lingua Portuguesa ......................................... 57

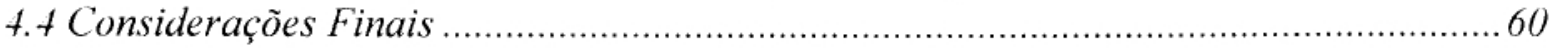

\section{CAPÍTULO 5}

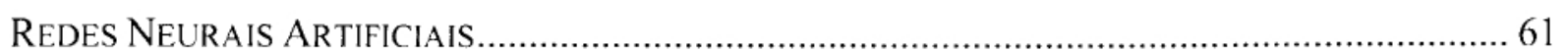

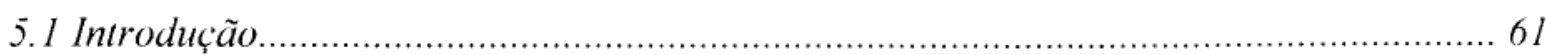

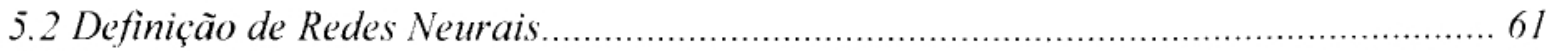

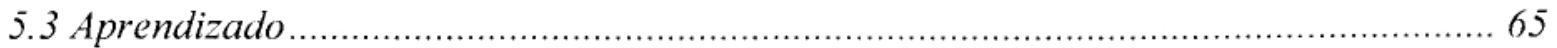

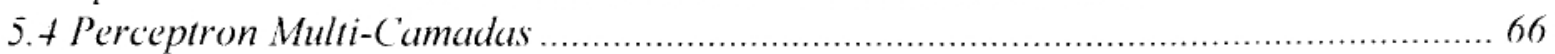

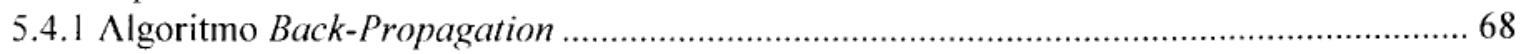

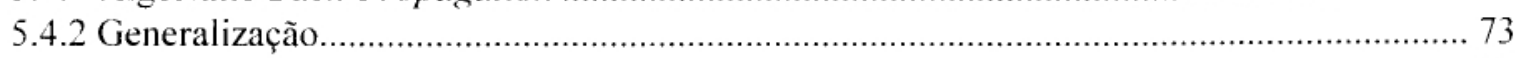

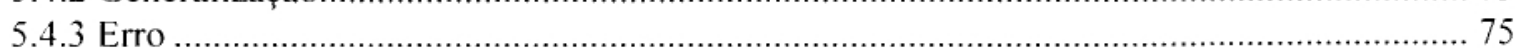

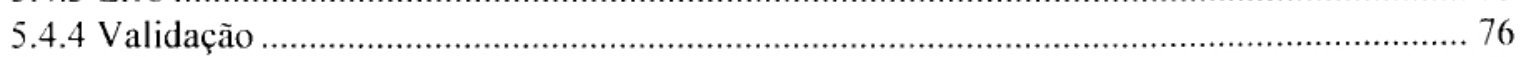

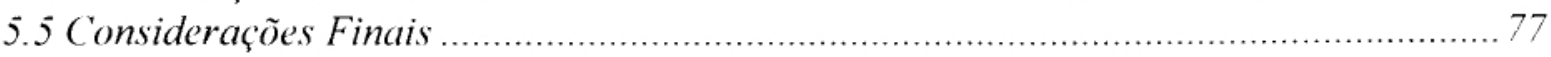

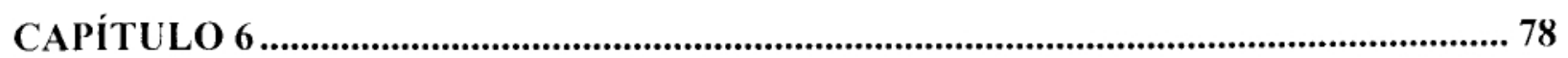

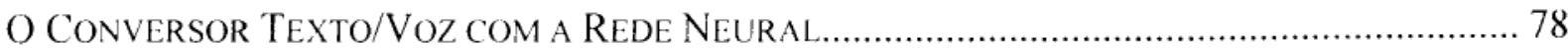

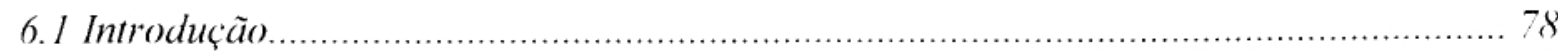

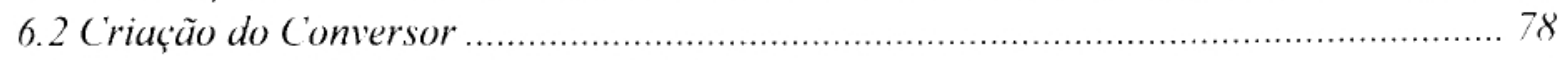

6.2.1 Arquivos digitais dos fonemas da Lingua Portuguesa .................................................... 79

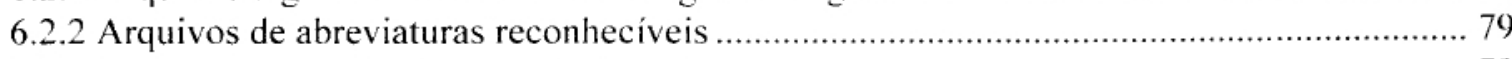

6.2.3 Software normalizador do texto de entrada .................................................................. 79

6.2.4 Software de transformação dos caracteres para fonemas e montagem do vocábulo digital 79

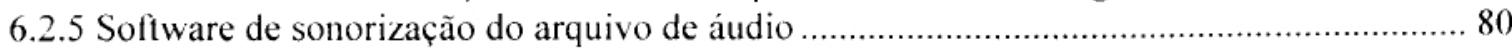

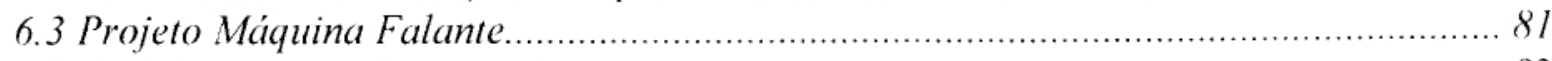

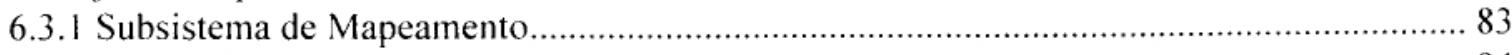

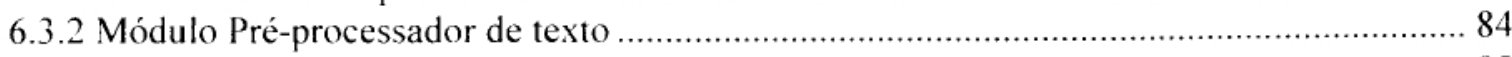

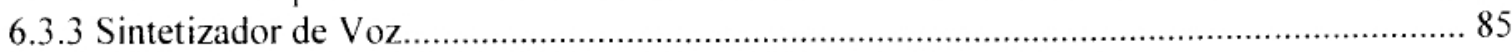

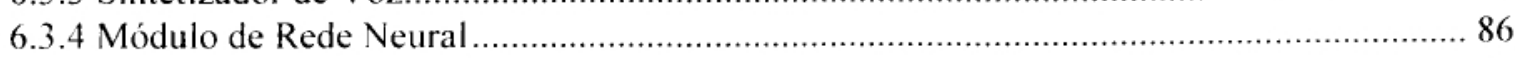

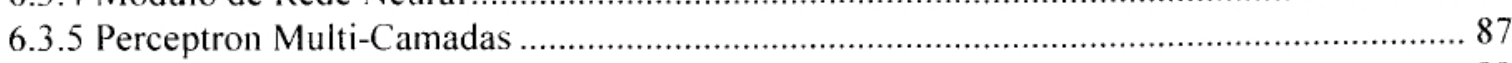

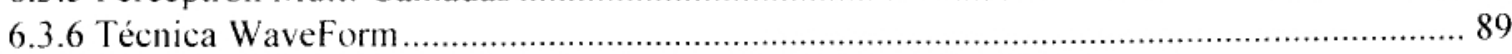

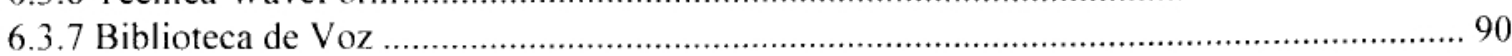

6.t Modificações realizadas no sistema Máquina Falante .............................................. 91

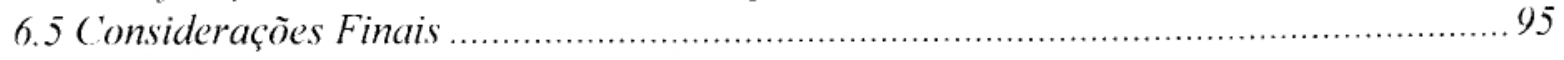




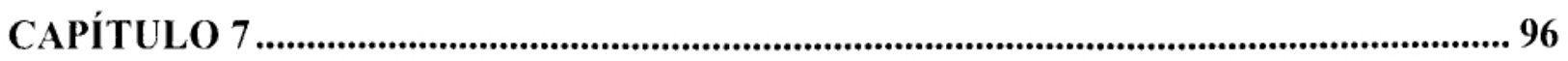

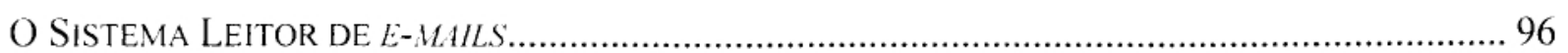

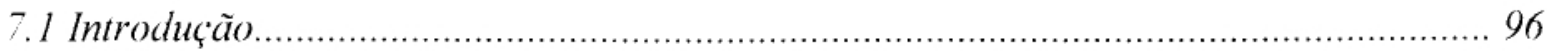

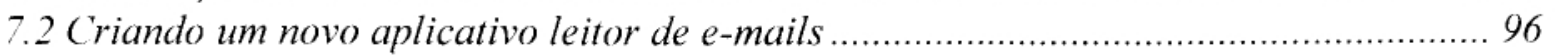

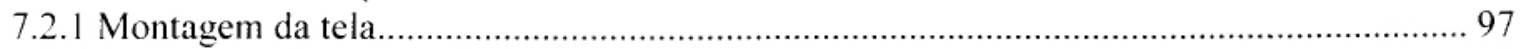

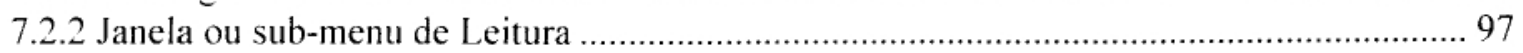

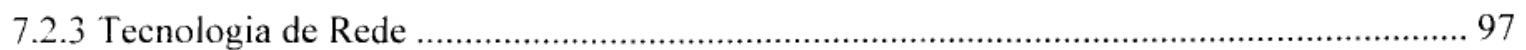

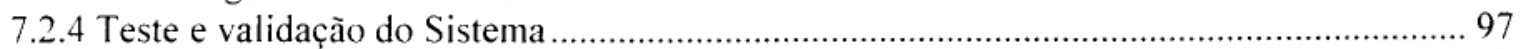

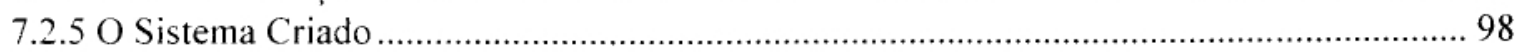

7.3 Adaptando o Conversor a um sistema leitor já existente ...................................... 102

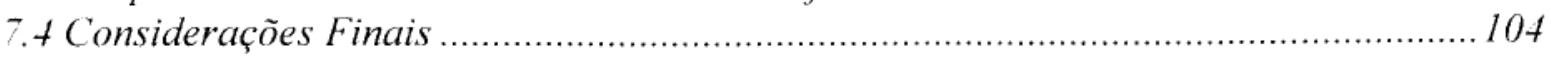

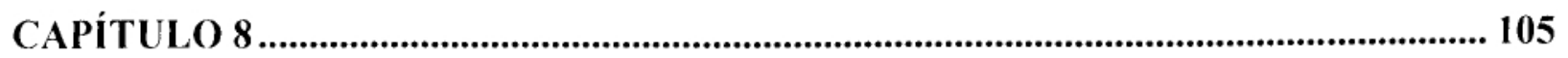

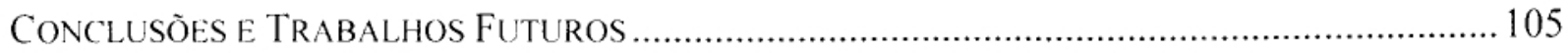

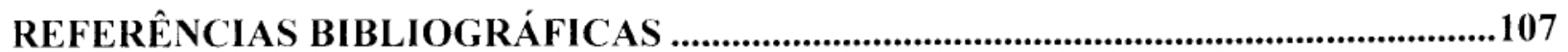

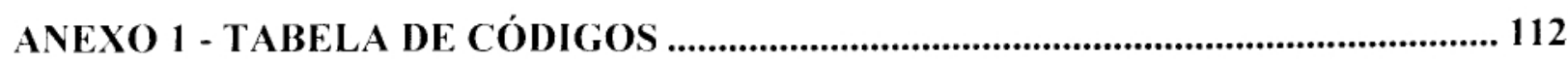

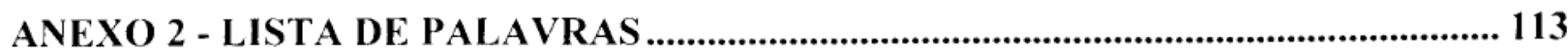

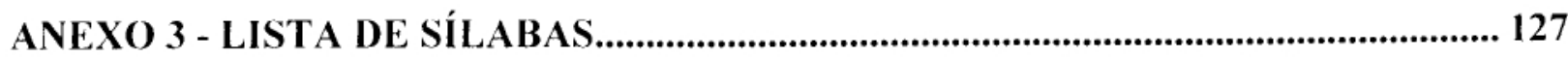




\section{Lista de Figuras}

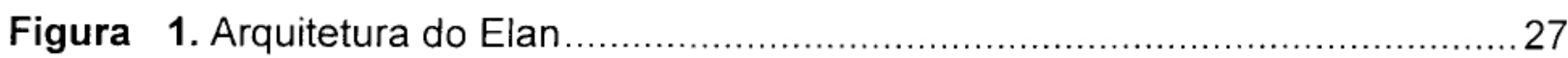

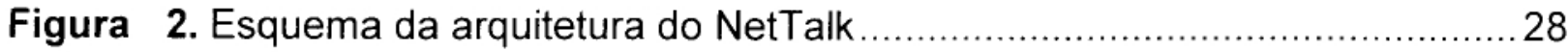

Figura 3. Diagrama esquemático do aparelho fonador humano ............................. 39

Figura 4. Elementos de um sistema de sintese de voz a partir de texto ................. 45

Figura 5. Freqüência acumulada de entradas em um corpus da Lingua Inglesa .....52

Figura 6. Sistema de conversão de letra para fonema ..........................................54

Figura 7. Diagrama de blocos do "Delta System" .................................................56

Figura 8. Modelo matemático de um neurônio ....................................................... 62

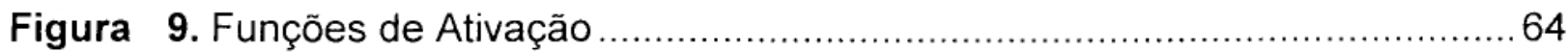

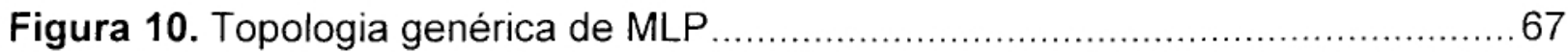

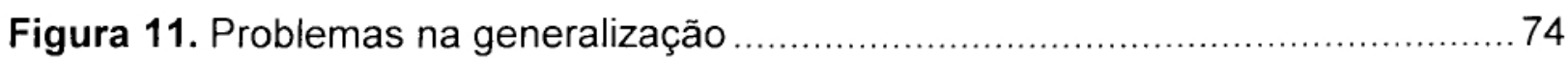

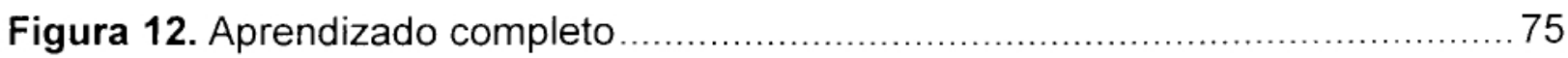

Figura 13. Visão Detalhada da Conversão Texto/Voz ............................................ 80

Figura 14. Visão Geral da Conversão Texto/Voz no "Máquina Falante" ................... 82

Figura 15. Dados produzidos no sistema Texto-Fonema-Voz ................................... 83

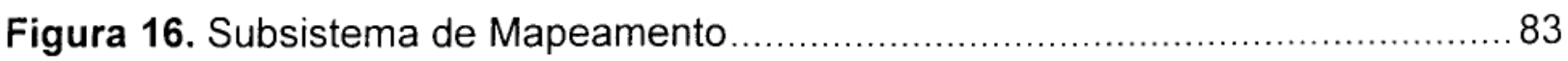

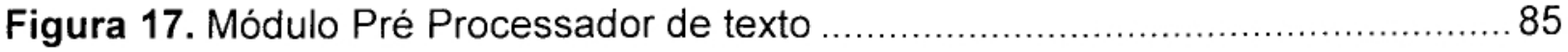

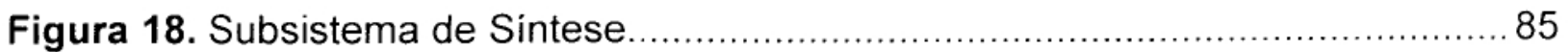

Figura 19. Dados importantes do subsistema de Síntese ..................................... 90

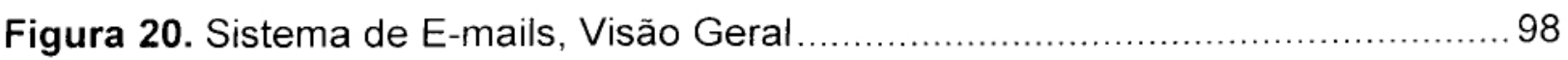

Figura 21. Sistema de E-mails, Janela de Conversão .......................................... 100

Figura 22. Sistema de E-mails, Janela de Conversão Automática.......................... 101

Figura 23. Integração com o Microsoft Outlook ..................................................... 103 


\section{Lista de Tabelas}

Tabela 1. Tecnologias de Conversão Texto/Noz ..................................................24

Tabela 2. Alfabetos fonéticos para a Língua Portuguesa........................................37

Tabela 3. Quadro de Fonemas Vocálicos .............................................................4 41

Tabela 4. Quadro de Fonemas Consonantais ....................................................43

Tabela 5. Regras de conversão Letras/Fonemas para o Inglês, com alfabeto IPA. . 48

Tabela 6. Algumas regras para conversão fonética da letra "x" .............................59

Tabela 7. Características da Rede Neural do Máquina Falante ..............................87

Tabela 8. Resultados da topologia da Rede Neural do Máquina Falante ................88

Tabela 9. Resultados de Generalização do Máquina Falante ................................... 88

Tabela 10. Caracteristicas da Rede Neural do sistema .......................................... 92

Tabela 11. Estudo da melhor arquitetura da Rede Neural ..................................... 93

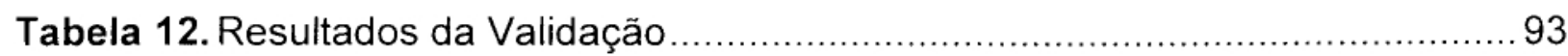

Tabela 13. Resultados obtidos para a topologia escolhida …..................................93

Tabela 14. Resultados de Generalização .............................................................. 93

Tabela 15. Resultados para topologia escolhida (generalização) ..............................95 


\section{Lista de Abreviaturas}

API

Application Program Interface

DEPES Development Environment for Pronunciation Expert Systems

PDS Processamento Digital de Sinal

FPGA Field Programmable Gate Array

GUI Graphical User Interface

IPA International Phonetic Alphabet

MLP Multi-Layer-Perceptron

NRL Naval Research Laboratory System

PLN Processamento de Linguagem Natural

RNA Redes Neurais Artificiais

SCYLA Speech Compiler for your Language

SRS Speech Research System

TTS Text to Speech 


\section{Resumo}

A proposta deste trabalho consiste no desenvolvimento de um sistema leitor de e-mails com conversão de texto para voz, em português, tendo em seu resultado, uma voz próxima àquela falada por nós humanos e não uma voz simplesmente sintetizada.

Para isso, foi criada uma tecnologia de Conversão Texto/Voz, que utiliza Redes Neurais e opera com um banco de fonemas da língua portuguesa. A adaptação desta tecnologia, a um sistema leitor de e-mails, propõe um software específico à leitura de e-mails, com Conversão Texto/Noz para a língua portuguesa.

Esta tecnologia de conversão pode auxiliar os deficientes visuais, e também aqueles que não possuem tal deficiência, como um usuário comum, que tem como lucro a leitura automática de sua caixa postal, enquanto o mesmo realiza tarefas paralelas, sem que estas sejam interrompidas, conseguindo assim um ganho de tempo considerável, o que nos dias de hoje é fundamental.

É válido ressaltar que o desenvolvimento deste trabalho proporciona um enriquecimento aos sistemas de correio eletrônico atuais, através do acréscimo de novas funções, tais como, leitura automática de e-mails, leitura de e-mails novos, entre outras que poderão vir a existir, seguindo a técnica proposta.

Este trabalho também tem outras vantagens, devido ao fato de abrir as portas para outras interfaces, possibilitando efetuar a migração desta técnica de Conversão Texto/Noz criada, para outras aplicações nos mais variados niveis de interação com o usuário; tornando possivel, por exemplo, a leitura agradável em editores de textos como o Microsoft Word; o agendamento de tarefas com lembretes sonoros; a leitura de programas educacionais para jovens, crianças e adultos, facilitando o entendimento da língua; a utilização de sistemas de telefonia com integração de voz; e ainda outras atividades alternativas. 


\section{Abstract}

The aim of this work consist in the development of an e-mail reader system with text/voice conversion, in Portuguese, obtaining as a result, one voice closer than human voice and no one voice simply sintetized.

For this, one technique of text/voice conversion that uses Neural Networks and phonemes of the Portuguese Language has been developed. The adaptation of this technique for an e-mail reader system proposes a software specific for the e-mail reading, with text/voice conversion in Portuguese.

This technique can help visual deficients and other users, such as a common user that can turn on the automatic reading of his/her mail box while he/she accomplishes tasks in parallel, without having to interrupt them, getting one considerable gain of time, fundamental, in our days.

It's worth to mention that the development of this work provides to the current email system improvements by adding new functions, such as, e-mail automatic reading, new e-mail reading, among others, based on the proposed technique.

This work has also other advantages, due to the fact to be easily adaptable to other interfaces, enabling the migration of the text/voice conversion to other applications in the different user interaction levels. This makes possible, for example, a nice reading in text editor as Microsoft Word; scheduling of tasks with sound notes; the reading of educational programs for youngs, kids and adults, making easier the understanding of the language; the telephony system utilization with voice; and other alternative activities. 


\section{Capítulo 1}

\section{Introdução}

A Conversão de texto para voz é uma área em grande desenvolvimento atualmente. Com o advento da multimidia e a necessidade de se facilitar a comunicação homem-máquina, a técnica de conversão de texto para voz começou a ser bastante difundida no âmbito da informática.

Dados estatísticos de Chaponis, citados por YOUNG e FALLSIDE (1989), mostraram que a comunicação da informação através da voz, em situações de interação homem-máquina, é em média, duas vezes mais eficiente do que qualquer outra forma de comunicação. A maior eficiência da comunicação verbal, apoiada na crescente evolução das técnicas de processamento de sinais digitais, tem feito com que sistemas de compreensão da fala e sintese de voz difundam-se cada vez mais, como meios de entrada e saída de informaçōes em computadores.

Atualmente os sistemas de compreensão da fala estão restritos a algumas aplicações especiais, enquanto que os sistemas de síntese de voz vêm sendo largamente utilizados.

Dentre esses sistemas, aqueles capazes de sintetizar voz a partir de texto apresentam particular importância, pois são capazes de produzir voz a partir de um texto de entrada, unindo a eficiência do armazenamento de dados na forma escrita com a comunicação através da fala.

Essa possibilidade de armazenar informações na forma escrita, fornecendo saídas através de voz, amplia o uso de computadores para diversas aplicações, dispensando a necessidade de treinamento ou equipamentos especiais para os usuários. Tais sistemas permitem, por exemplo, acesso a bancos de dados através de telefone, como os sistemas de consulta de saldo bancário, atualmente bastante difundidos, e abrem perspectivas para transformar os atuais sistemas de correio eletrônico em correio por voz. 
Merecem destaque ainda, as facilidades advindas do uso desses sistemas para pessoas portadoras de deficiências vocais e visuais, através de máquinas de auxílio à fala e máquinas de leitura para cegos (ALLEN, 1973).

Allen (ALLEN, 1976) divide o processo de conversão de texto para voz em duas etapas distintas. Primeiro o texto de entrada deve ser analisado, determinando-se sua estrutura lingüistica, constituída basicamente por fonemas formadores das palavras que serão faladas. Os fonemas são as unidades mais simples da Língua, aos quais correspondem os sons elementares que entram na constituição das sílabas e dos vocábulos. Nesta etapa inicial, é importante a análise das pausas, da acentuação das palavras e sinais de pontuação para simular as características da prosódia da fala, que são o acento, o ritmo e a entonação. Finalmente, as informações obtidas na etapa anterior são combinadas para produzir voz.

Percebe-se assim que a primeira etapa na conversão de texto para voz depende fundamentalmente de características lingüísticas de cada idioma, sendo a conversão de palavras para fonemas uma etapa básica para o desenvolvimento do processo.

Nesse sentido, procurando viabilizar futuros projetos de conversão de texto irrestrito para voz, este trabalho trata especificamente da conversão de palavras para fonemas na Língua Portuguesa.

É notável que a tecnologia de Conversão Texto/Noz está em grande crescimento nos dias de hoje, e que este crescimento já pode ser considerado necessário para o mundo atual da informática, onde cada vez mais se trabalha com múltiplas plataformas, no intuito de diminuir o tempo gasto na realização das mais diversas tarefas.

O fato de poder contar com uma ferramenta de Conversão Texto/Noz, é de grande utilidade para conferir entradas de dados, textos e planilhas. Poder-se-ia apertar um botão e o computador falaria todos os dados, enquanto o usuário apenas acompanharia a leitura, detectando muito mais facilmente qualquer erro nos dados digitados. Além disso, a clareza de um texto é muito melhor avaliada quando o mesmo é lido em voz alta. 


\section{$1.1 \mathrm{O}$ uso da tecnologia de Conversão Texto/Voz}

Existem inúmeras alternativas para se utilizar a tecnologia de Conversão Texto/Noz, e entre elas, podem ser citadas várias vantagens em relação ao chamado modo tradicional de leitura e apresentação, conforme pode ser observado a seguir:

- Em aplicações de bancos de dados, podem ser criadas opções de leitura de relatórios, onde o usuário economizaria e otimizaria seu tempo, dedicando-se a outras atividades enquanto escuta o relatório gerado pelo seu software.

- Será possivel oferecer ajuda on-line falada, no lugar de obrigar o usuário a ler textos para aprender a utilizar seu produto.

- Usar voz no lugar de caixas de diálogo para alertar o usuário sobre eventos ocorridos, também é uma forma muito interessante de utilizar a tecnologia de Conversão Texto/Voz. Por exemplo, ao contrário do sistema apresentar na tela uma mensagem "Impressão Concluída", o usuário ouviria a mensagem, o que é muito mais prático e agradável. (Isto já acontece com as impressoras da linha Lexmark)

- Utilizar voz para criar apresentações e versões de demonstração de produtos rapidamente, facilmente e com muito pouco custo, o que além de tudo, impressionará possiveis interessados no produto.

- Oferecer dicas de utilização de softwares, faladas e sensiveis ao contexto. Por exemplo, se uma opção de auto-explicação estiver ativada em seu software, ao ativar uma determinada janela o usuário poderia ouvir a explicação de como deve proceder paì utilizá-la. Este é um recurso fantástico para tornar um produto mais fácil de usar e de ser aprendido.

- Criar aplicações educacionais, especialmente para crianças em fase de alfabetização. Neste caso, a criança aprenderá inclusive a dicção das palavras, que poderão ser associadas a figuras, para tornar o ambiente mais interessante ao tipo de usuário citado. 
Contudo, é necessário reconhecer que a tarefa de fazer com que o computador "fale" como nós humanos, não é uma tarefa simples, e por isto o desenvolvimento de pesquisa nesta área se justifica por si só.

\subsection{Justificativa}

O desenvolvimento de sistemas de sintese de voz para várias línguas tem contribuido poderosamente para aumentar a capacidade de comunicação de pessoas com deficiências da voz, com vantagens óbvias de um ponto de vista social sobre outros meios de apoio baseados na visualização de mensagens.

Um problema essencial encontrado é o da velocidade de geração das mensagens. Esta é sempre consideravelmente mais lenta do que a falada pelo ser humano.

Outro problema está associado com o desempenho dos sintetizadores e Conversores Texto $\mathrm{Noz}$ em geral. Na realidade, contrariando a idéia, durante algum tempo veiculada, de que a síntese de voz a partir de texto já não constituia um problema para ninguém, são ainda inúmeras as questões que se colocam tanto em termos gerais como do desenvolvimento de aplicações para fins específicos.

Um exemplo disto está no relativo insucesso de muitos produtos desenvolvidos para outras línguas, pelo menos em parte, explicável pela falta de qualidade das vozes sintetizadas que ainda estão longe de poderem ser confundidas com vozes naturais, sendo necessário normalmente um periodo de adaptação às suas caracteristicas, para que se torne inteligivel, sobretudo se a informação fornecida for nova e inesperada.

\subsection{Objetivo}

O objetivo deste trabalho é o desenvolvimento de um Leitor de E-mails, utilizando um sistema de Conversão Texto/Noz, gerado por uma junção de fonemas, treinados por uma Rede Neural, fazendo com que o retorno de áudio seja o mais próximo possivel ao linguajar humano. 
Para isto, utilizou-se uma biblioteca de sons, contendo sílabas da língua portuguesa, e ainda os arquivos chamados de elementares, onde cada um destes corresponde a um fonema, e são utilizados quando a sílaba desejada não está gravada em arquivo. A biblioteca conta ainda com 26 arquivos com os nomes das letras, para o sistema poder soletrar letras isoladas no texto.

O projeto abre perspectivas extremamente interessantes e motivadoras, que poderão vir a ser exploradas em pesquisas futuras e aplicadas inclusive na área da lingüística, desenvolvendo aplicações adequadas às necessidades de pessoas com alguns tipos de deficiência, como a visual.

\subsection{Organização}

O presente trabalho, está organizado da seguinte forma.

No capítulo 2, são apresentadas as principais tecnologias de Conversão Texto/Noz existentes no mercado atual, dando ênfase àquelas tecnologias de conversão em português como o Delta Talk e o Elan, e as tecnologias que usam Redes Neurais, que é o caso do NetTalk, sem deixar de citar várias outras tecnologias de Conversão Texto/Noz existentes em outros idiomas. Também é apresentada neste capitulo uma introdução sobre alguns conceitos de Conversão Voz/Texto, através do Reconhecimento de Voz.

No capítulo 3, alguns conceitos de Fonética da Lingua Portuguesa, que são usadas no processo de Conversão Texto/Noz, são introduzidos, para fornecer uma compreensão maior do projeto desenvolvido.

No capitulo 4, as diversas tecnologias de Conversão Texto/Noz, via fonemas, existentes no mercado, são apresentadas, de maneira conceitual, para poder servir como parâmetro de comparação com a tecnologia utilizada no Leitor de e-mails proposto.

No capítulo 5, em caráter introdutório, é apresentada a funcionalidade de uma Rede Neural, pois ela é a base deste trabalho. 
No capitulo 6, apresenta-se a metodologia de criação do Conversor Texto/Noz, o projeto "Máquina Falante" e a Rede Neural Artificial utilizada no projeto ressaltandose as alterações realizadas.

No capítulo 7, detalha-se o Sistema Leitor de E-mails, apresentando as duas interfaces geradas para a utilização do Conversor Texto/Noz, assim como as tecnologias utilizadas para sua criação, finalizando o capítulo com uma comparação entre o Sistema Leitor de E-mails, criado especificamente para tal função, e o uso desta tecnologia adaptada a uma plataforma já existente.

Finalmente, no capitulo 8 são apresentados as conclusões e os trabalhos futuros, que podem ser realizados seguindo a mesma linha de pesquisa.

São encontradas em anexo a este projeto, as tabelas de Códigos utilizadas na Conversão Texto/Noz, assim como o algoritmo de Back-Propagation e as listas de Palavras e Silabas utilizadas no Projeto. 


\section{Capítulo 2}

\section{Tecnologias Existentes}

\subsection{Introdução}

Neste capitulo, são citadas as tecnologias de Conversão Texto/Noz existentes no mercado atual, dando ênfase àquelas tecnologias de conversão em português, como o Delta Talk e o Elan, e as tecnologias que usam Redes Neurais, que é o caso do NetTalk, sem deixar de citar várias outras tecnologias de Conversão Texto/Noz existentes em outros idiomas. É citada também neste capítulo a tecnologia de Conversão Voz/Texto, através do Reconhecimento de Voz.

Existe uma grande variedade de programas de Conversão Texto/Noz em inglês, como as existentes no Universal Translator 2000, no Willow Talk e no Winamp Talking, e ainda é possivel encontrar esta tecnologia em vários outros idiomas, como francês, japonês, alemão, italiano, etc..., conforme será apresentado ainda neste capitulo.

\subsection{A Evolução da Conversão Texto/Voz}

A partir da década de 60, principalmente após 1965, o estudo de sistemas de sintese de voz a partir de texto teve um grande impulso, caracterizado por intensas pesquisas na área (ENDRES, 1983). Tratava-se de uma época de pioneirismo, marcada por dúvidas sobre viabilidade dos sistemas, e na qual iniciou-se o desenvolvimento das primeiras regras de conversão de texto para fonemas.

O início dos anos 70 marcou um novo periodo, com o aperfeiçoamento dos sintetizadores e dos algoritmos de conversão de texto para fonemas. Dois centros de pesquisas sobressaíram nessa área, o "Bell Laboratories" pertencente à "American Telegraph \& Telephony - AT\&T", e o "Massachussets Institute of Technology -MIT" (UMEDA, 1976). 
Já no final da década de 70 e início dos anos 80 , foram apresentados os primeiros protótipos de sistemas de sintese de voz a partir de texto com vocabulário ilimitado, com destaque para o "MITalk", desenvolvido no MIT durante a década de 70 , sob a supervisão de Jonathan Allen (KAPLAN e LERNER, 1985).

Ainda nessa época, surgiram os primeiros sistemas comerciais com vocabulário ilimitado, os quais vêm sendo continuamente aprimorados desde então.

KLATT (1987) fez uma ampla descrição cronológica sobre a evolução de equipamentos vendidos comercialmente. O primeiro sistema comercial com vocabulário ilimitado foi uma máquina de leitura para deficientes visuais, lançado em 1976, pela "Kurzweil", baseado no "chip Votrax SC-01", que era capaz de produzir voz a partir de material impresso. Dois anos depois, em 1978, surgiu o conversor de texto para voz "Type-in-Talk", da Votrax, baseado também no mesmo "chip". Entretanto, havia falta de inteligibilidade da voz gerada por esses dois sistemas.

Em 1982, a "Speech Plus Inc." lançou o "Prose-2000", sistema de conversão de texto para voz baseado no "MITalk". No mesmo ano, a "Street Eletronics" lançou o "Echo", sistema de baixo custo baseado no "chip TMS-5220", da "Texas Instruments".

Em 1983, a "Digital Equipment Corporation - DEC" lançou o "DECtalk", que teve origem no conversor de texto para voz "Klattalk", também desenvolvido no MIT por Dennis Klatt.

Ainda em 1983, a "Infovox" colocou no mercado o sistema "SA 201/PC", capaz de sintetizar voz a partir de textos em inglês, francês, espanhol, alemão, italiano, suéco e norueguês, desenvolvido a partir das pesquisas de Rolf Carlson no "Royal Institute of Technology of Stockholm".

$\mathrm{Na}$ segunda metade da década de 80, a "Berkeley Speech Technologies" apresentou o sistema "Text-to-Speech - T-T-S", (O'MALLEY, 1990) na Universidade da Califórnia. Ainda nessa época, a AT\&T lançou o sistema "Conversant", capaz de sintetizar voz a partir de textos em inglês, francês e espanhol.

Desde então, esses sistemas vêm sofrendo constantes atualizações com a finalidade de aumentar a inteligibilidade e a naturalidade da voz produzida, e também, suportar novos idiomas. Por exemplo, um ano após o lançamento do "Prose 2000", já havia uma implementação para aceitar textos em espanhol (OLABE et al., 1983), e em 
1989, o "MITalk" produzia saída de voz a partir de textos em japonês e chinês (JAVKIN et al., 1989).

Diversas outras pesquisas vêm sendo realizadas em âmbito mundial, como o sistema de sintese de voz a partir de textos em Chinês (LEE et. Al., 1989) e o sistema para textos em Árabe (EL-IMAN, 1989).

Além desses estudos, outros sistemas de síntese de voz de baixo custo têm surgido no mercado, como as placas para microcomputador padrão PC-AT "Sound Blaster PRO" da "Creative Labs" e a "Mwave LS2000" da "IBM", acompanhadas do programa "Monolog" da "Creative Labs", capaz de fazer a conversão de textos em inglês para voz, com qualidade bastante aceitável.

No Brasil, estudos de sintese voz tiveram início na Escola Politécnica da Universidade de São Paulo - EPUSP, com o desenvolvimento de um sintetizador de voz para o Idioma Português, capaz de aceitar entradas na forma fonética do Português. (CAMPOS, 1980)

Esquivel, em 1984, apresentou um sistema de síntese de voz em tempo real a partir de texto, no qual sinais adicionais eram acrescentados ao texto para a correta pronúncia de determinados sons. (ESQUIVEL, 1994)

Na Universidade de Campinas - UNICAMP, estudos sobre síntese de voz a partir de texto irrestrito foram realizados posteriormente (EGASHIRA, 1992). Foram feitos trabalhos sobre pré-processamento de texto com a finalidade de permitir a correta elocução de números, abreviaturas e caracteres não alfabéticos.

Em 1994, passou a ser comercializado um produto de baixo custo para auxílio à deficientes visuais, o "Dosvox", desenvolvido na Universidade Federal do Rio de Janeiro. Esse produto é formado por um conjunto de programas, tais como editor de texto e calculadora, e é capaz de sintetizar voz a partir de texto utilizando um conjunto de regras simples de conversão de texto para fonemas. No entanto, esta técnica não faz uso de Redes Neurais.

Já em 1999, foram criados dois softwares de conversão Texto/Noz em português: Elan Informatique e Micropower Delta Talk, que serão apresentados na seção 2.4 . 
É interessante observar, que mesmo com a grande variedade existente deste tipo de tecnologia, ainda é pequeno o número de adaptações da Conversão Texto/Noz a sistemas leitores de e-mail. A única empresa que já opera com esse sistema em língua portuguesa do Brasil é a IBM, com o recente lançamento "IBM Via Voice Pro", cujas especificações da metodologia utilizada, ainda não foram liberadas ao público pela empresa.

\subsection{Na Internet}

A seguir, na Tabela 1, são apresentados alguns sites encontrados na Internet que trabalham com a tecnologia de Conversão Texto/Noz. Assim é possivel fazer uma comparação dos sistemas em diversos idiomas e não só os que utilizam a língua portuguesa como o Elan Informatique e o MicroPower Delta Talk, que são citados e especificados na próxima seção.

\begin{tabular}{|c|c|c|c|}
\hline Nome & Língua & URL & E-mail \\
\hline AT\&T Labs & Inglês & http://www.research.att.com projects/tts & mcb@research.att.com \\
\hline Babel Technologies & Inglês & http://tcts3.fpms.ac.be/babil/us & pagel@babe \\
\hline Babel Technologies & Francês & http://tcts3.fpms.ac.be/babil/french & pagel@babeltech.com \\
\hline Babel Technologies & Alemão & http:/tcts3.fpms.ac.be/babil/German & pagel@babeltech.com \\
\hline Bell Labs & Chinês & http:/www.bell-labs.com/project/tts/mandarin.html & online_service@ldc \\
\hline Bell Labs & Inglês & http:/www.bell-labs.com/project tts voices html & online_service $($ lddc \\
\hline$\overline{\text { Bell Labs }}$ & Alemão & http: www.bell-labs.com/project/ts german.html & online_service@ldc \\
\hline Bell Labs & Espanhol & http:/www.bell-labs.com/project/tts/spanish.html & online_service@ldc \\
\hline BT labs & Inglês & http:/www.labs.bt.com/innovate/speech/laureate/index.htm & online_service@ldc \\
\hline$\overline{\text { Centigram }}$ & Inglês & http 198.137.181.20/centigram/TruVoice index.html & online_service@ldc \\
\hline Edinburgh Festival & Inglês & http:/www.cstr.ed.ac.uk/projects/lestival userin.html & awbocstr.ed.ac.uk \\
\hline Elan Informatique & Português & http: $/ 194.98 .105 .37 /$ ttsdemo/default_br.asp & nsoumet@elan.fr \\
\hline Elan Informatique & Alemão & http: 194.98.105.37 ttsdemo default_de.asp & nsoumet $@$ elan.fr \\
\hline Elan Informatique & Inglês & http: 194.98.105.37/ttsdemo default_uk.asp & nsoumet@elan.fr \\
\hline Elan Informatique & Inglês & http: 194.98.105.37/ttsdemo/default_us.asp & nsoumet@elan.fr \\
\hline
\end{tabular}


"Um Sistema para Leitura de e-mail, com Conversão Texto/Voz, utilizando Redes Neurais"

\begin{tabular}{|c|c|c|c|}
\hline Elan Informatique & Francês & http:/194.98.105.37/ttsdemo/default_fr.asp & nsoumet@elan.fr \\
\hline Elan Informatique & Russo & http:/194.98.105.37/ttsdemo/default_ru.asp & nsoumet@elan.fr \\
\hline Elan Informatique & Espanhol & $\underline{\text { http://194.98.105.37/ttsdemo/default_sp.asp }}$ & nsoumet@elan.fr \\
\hline Epos & Teheco & http:/epos.ure.cas.cz/ & geo@acuni.cz \\
\hline German Festival & Alemão & http:/www.ims.uni-stuttgart.de/phonetik/synthesis/ & mochleraims uni-stuttgart do \\
\hline GTH-DIE-UPM & Espanhol & http//www-gth dic upm.cs/research/synthesis/ssnth-form-concat.html & online_service@ldc \\
\hline HADIFIX & Alemão & http:/asll.ikp.uni-bonn.de/-tpo/Hadiq.en.html & online_service@ldc \\
\hline MicroPower Delta Talk & Português & http:/www.micropower.com.br/ & dtalk@mp.com.br \\
\hline NTT labs. FLUET & Japonês & http:/www.hil-unet.ocn.ne.jp/fluet/f_04.html & online_service $a$ ldd \\
\hline OGI-Festival & Inglês & http://cslu.cse.ogi.edu/tts/demos/ & online_service@ldc \\
\hline OGl-Festival & Espanhol & $\underline{\text { http: } / \text { cslu.cse.ogi.edu/tts/demos/ }}$ & online_service@ldc \\
\hline Panasonic/STL & Inglês & htp_/_www.research.panasonic.com/ptist/stl_web_demo/demo.html & mick usisll resecarch panasmic com \\
\hline Samsung AIT - MagicVoice & Koreano & http:/ hci.sait.samsung.co.kr/mvoice & kimsig sait.samsung.co.kr \\
\hline$\overline{\text { Say }}$ & Inglês & http: wwwtios.cs.utwente.nl/say/form & online_service@ldc \\
\hline SVOX & Alemão & http:/www.tik.ee.ethz.ch/cgi-bin/w3svox & online_service $a$ ldc \\
\hline University Duisburg & Inglês & http:/www.fb9-ti.uni-duisburg.de/demos/speech.html & online_service $(0)$ ldc \\
\hline University Duisburg & Alemão & http: www.tb9-ti.uni-duisburg.de/demos/speech.html & online_serviceoldc \\
\hline
\end{tabular}

\section{Tabela 1. Tecnologias de Conversão Texto/Voz}

\subsection{Tecnologias de Conversão Texto/Voz em Português}

Nesta seção, são apresentadas as principais caracteristicas das tecnologias: Micropower Delta Talk e Elan "Text to Speech Engine V 3.0" que realizam conversão TextoNoz para a lingua portuguesa. 


\subsubsection{Micropower Delta Talk}

O Delta Talk (www.micropower.com.br) opera com um sintetizador de voz e possui as seguintes caracteristicas:

- Funciona com qualquer linguagem compatível com o Microsoft Windows. Versões em 16 e 32 bits estão disponíveis.

- Capacidade de cantar músicas (editor de melodias incluído).

- Multitarefa (fala enquanto outros programas continuam executando).

- Boa base de dados para a língua portuguesa, que garante a pronúncia correta da maioria das palavras, inclusive palavras homógrafas não homófonas (como por exemplo a palavra "olho" que é pronunciada com som fechado quando for substantivo: "o olho" e com som aberto quando for verbo: "eu olho") têm suas pronúncias determinadas com alto grau de acerto por análises lingüísticas do contexto onde elas estão.

- Módulo de processamento de linguagem natural (PLN), capaz de produzir automaticamente uma entonação e ritmos adequados ao texto dado.

- Módulo de processamento digital de sinal (PDS) de última geração, baseado na tecnologia Multiband-Resynthesis, garantindo alta inteligibilidade, fluidez e naturalidade à voz produzida.

- Permite total controle de velocidade, tonalidade e volume do áudio produzido. Vários modelos de voz podem ser utilizados para pronunciar diferentes trechos de um mesmo texto.

- Capacidade de uso de dicionário personalizado para converter texto em fonemas (para pronunciar corretamente palavras estrangeiras, por exemplo).

- Totalmente baseado em software, não há necessidade de qualquer outro hardware a não ser uma placa de som comum compativel com o Microsoft Windows. 
- Funciona em qualquer programa para Windows 95 e/ou 98, seus aplicativos Office 95 e/ou 97 ,

- Pronuncia as palavras digitadas letra por letra, palavra por palavra, linha por linha, parágrafo por parágrafo, ou todo o texto continuamente;

- Opera com tecnologia de síntese de voz em português (qualidade de áudio semelhante ao Juno e ao DOSVOX);

- Pronuncia as mensagens emitidas por vários aplicativos;

O Delta Talk é um software eficiente, porém não pode ser considerado eficaz, pois seu resultado não é aquele esperado ficando longe de uma voz semelhante a do ser humano, devido ao seu sistema único de sintese de voz.

\subsubsection{Elan "Text to Speech Engine V 3.0"}

O Elan "Text to Speech Engine V 3.0" (www.elan.fr), possui uma qualidade de áudio superior a do Micropower Delta Talk, pois o Elan não opera com um sistema de sintese de voz simplesmente e sim com um servidor de Sinteses, onde este processo é aperfeiçoado, porém ainda não pode ser considerado ideal.

O Elan possui as seguintes características básicas em seu funcionamento:

- Permite alteração das caracteristicas da voz quanto ao gênero, a velocidade, a tonalidade e ao idioma.

- Funciona em plataformas pré-determinadas como Outlook, ou Microsoft Word.

- Opera com sistema de som Sound Blaster ou compatível, suportando freqüências de 8,11 e $16 \mathrm{KHz}$ 
A arquitetura do Elan "Text to Speech Engine $V$ 3.0" pode ser demonstrada através da seguinte figura:

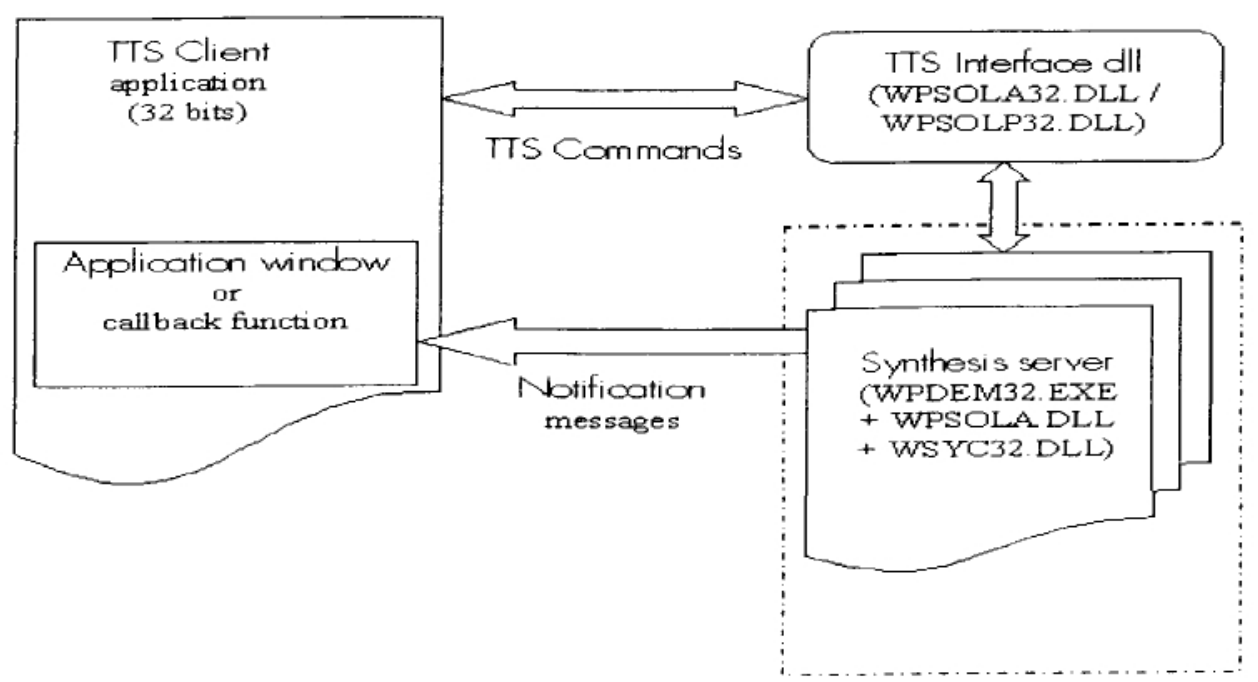

Figura 1. Arquitetura do Elan (www.elan.fr)

\subsection{Tecnologia de Conversão com Redes Neurais}

\section{Sistema NetTalk}

O sistema NetTalk (SEJNOWSKI \& ROSENBERG, 1987) tem um desempenho similar ao observado em um ser humano. O desempenho de um especialista em uma tarefa caracteriza-se pela rapidez e pelo pouco esforço para realizá-la. Porém, isto requer muito esforço para aprendê-la. Os autores salientam que a Rede Neural utilizada pode demorar a aprender, mas executa a transformação de texto em fonemas com rapidez e eficiência, inclusive de palavras que não apareciam na fase de aprendizado. Isto é possivel devido à capacidade de generalização do Perceptron Multi-Camadas (Multi-Layer Perceptron - MLP). Os seres humanos muitas vezes não percebem o tempo que demoraram a aprender uma determinada tarefa como a fala, e que toda vez que utilizam esse conhecimento, estão realizando um novo treinamento.

O processo de pronunciar uma palavra na língua inglesa representa bem estas características de conhecimento especializado. As regras de pronúncia não são 
facilmente modeladas devido às constantes exceções e inúmeras condições. A lingua inglesa possui a pronúncia irregular, como por exemplo: a vogal "a" na maioria das palavras terminadas por "ave" é uma vogal longa na sua duração, mas isto não acontece na palavra "have". Outro exemplo é a palavra "read" que depende do tempo verbal para ser pronunciada corretamente.

O modelo de Rede Neural utilizado no NetTalk é o MLP (RUMELHART, 1986). Como algoritmo de aprendizagem são utilizados: o algoritmo de Boltzmann e o algoritmo Back-Propagation, apresentado no capitulo 5.

A topologia da rede MLP do NetTalk (Figura 2) é formada por três camadas, sendo uma de entrada, uma de saída e uma intermediária. A camada de entrada é composta por 203 neurônios, representando uma janela do texto a ser convertido em fonemas. A camada intermediária é composta por 80 neurônios, número escolhido após alguns testes. A camada de saída é composta por 26 neurônios, que representam as articulações que formam os fonemas. As ligações sinápticas seguem o modelo padrão do MLP, todos os neurônios de uma camada conectam-se a todos os neurônios da camada anterior. Ao todo, a rede MLP do NetTalk possui 18.629 pesos.

Camada de Saída

Camada Intermediária

Camada de Entrada

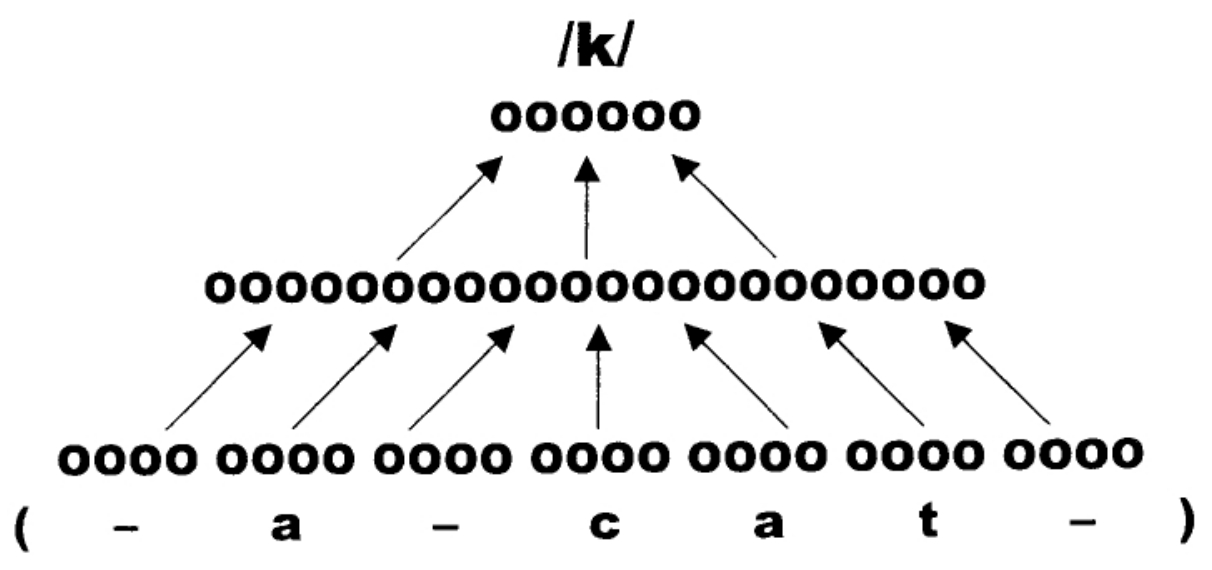

Figura 2. Esquema da arquitetura do NetTalk 
Esta rede recebe sete letras de um texto na língua inglesa e responde com o fonema correspondente à quarta letra desta janela. A janela percorre todo o texto, a cada passo avança um caractere no texto. Uma letra é mapeada para fonema e as outras seis contribuem para que este mapeamento seja correto. As letras adjacentes de uma determinada letra exercem uma influência na mesma. Quanto mais próxima esta letra adjacente está, maior é a sua influência. O conjunto contendo sete letras, composto de três letras anteriores, a letra a ser mapeada e três posteriores, foi escolhido devido a duas razões:

1) um número razoável de letras adjacentes que contribuem significativamente;

2) limitações computacionais que não permitem grandes números. Este número interfere significativamente na quantidade de pesos da rede.

Além disso, Sejnowski e Rosenberg basearam-se em um gráfico que demonstra a influência que uma letra recebe de suas vizinhas. Um gráfico análogo a este não está disponivel para a língua portuguesa, desta forma, as análises e deduções foram realizadas a partir da estrutura silábica. (SEJNOWSKI \& ROSENBERG, 1987)

Cada letra da janela é representada por um vetor de 29 entradas, sendo 26 referentes ao alfabeto e três à pontuação e limites de palavra. Apenas uma entrada deste grupo de 29 entradas é ativada. O fonema, por sua vez, é representado por um conjunto de 26 neurônios de saida. Na saída temos uma combinação, onde cada saída representa uma característica articulatória, ou melhor, um item na descrição de cada fonema.

O formato proposto no NetTalk é sensivel aos problemas de combinações entre os neurônios da camada de saída. Representar as articulações beneficia a portabilidade com a interface de sintese da voz, que pode ser um módulo independente. O uso de representação das articulações, utilizado na saída da rede, seria fortemente justificado se, para casos de variações de fonemas para uma mesma letra, elas tivessem combinações de saidas semelhantes, ou seja, fossem distintas por apenas uma única característica na classificação fonética.

No sistema de Conversão Texto/Noz utilizado neste trabalho, os neurônios representam os próprios fonemas da língua portuguesa. As articulações são 
representadas através dos fonemas, pois cada fonema é correspondente a um único som.

O aprendizado da Rede Neural é feito com dois conjuntos distintos de dados: um referente a palavras e sua transcrição fonética correspondente, contida em "Miriam Webster's Pocket Dictionary", e outro referente a uma transcrição informal da fala continua de uma criança. Sejnowski e Rosenberg comentam que é difícil trabalhar com o aprendizado da fala contínua.

No aprendizado da rede MLP do NetTalk foram utilizadas apenas mil das 20.012 palavras contidas no dicionário citado. A rede absorveu boa capacidade de exceções, pois estas mil palavras são, na sua maioria, as mais irregulares. A melhor topologia testada para este aprendizado foi a que continha 120 neurônios na camada intermediária, com $98 \%$ de acerto para este conjunto de mil palavras.

A capacidade de generalização da rede foi testada utilizando todo o dicionário, e a configuração com 120 neurônios na camada intermediária obteve $77 \%$ de acerto.

\subsection{Reconhecimento de Voz}

É válido ressaltar que o processo inverso, isto é, a Conversão Voz/Texto, entendida como Reconhecimento de Voz, é uma área que atualmente tem crescido muito no Brasil.

Os programas de Reconhecimento de Voz permitem que um usuário possa comandar o computador através de comandos de voz. Alguns produtos que usam esta tecnologia, permitem também o sentido inverso, que é a Conversão do Texto para a Voz, trabalhada neste projeto.

Existe uma grande variedade de softwares de Reconhecimento de Voz no mercado e eles são diferenciados devido às características das tecnologias utilizadas. Estas tecnologias podem necessitar de pausas entre palavras ou permitir uma fala contínua, dependendo do aplicativo.

A seguir são listados alguns aplicativos que trabalham com Reconhecimento de Voz: 


\section{Creative Voice Assist}

Empresa: Creative Labs

Internet: $\quad$ http://Www.creaf.com

Sistema: $\quad$ Windows 95, Windows $3.1 x$

Demo: $\quad$ http://www.creaf.com/

Notas: $\quad$ Comandos por $\mathrm{Voz}$

\section{DragonDictate ${ }^{\circledR}$ for Windows}

Empresa: Dragon Systems®, Inc., 320 Nevada St., Newton, MA 260

Internet: $\quad$ http://www.dragonsys.com

Sistema: $\quad$ Windows 95

Demo: $\quad h t t p: / / w w w . d r a g o n s y s . c o m$

Notas: $\quad$ Compativel com as placas de som mais comuns. O Utilizador pode controlar o ponteiro do mouse, ditar texto e navegar no windows através de comandos de voz.

Kurzweil VoicePad, ver 1.0

Empresa: Kurzweil Applied Intelligence, Inc., 411 Waverly Oaks Rd., Waltham, MA 02154

Internet: $\quad$ http://www.kurzweil.com

Sistema: $\quad$ Windows 95

Demo: $\quad$ http://www.kurzweil.com

Notas: $\quad$ Reconhecimento independente do utilizador. Permite comandar o windows e ditar texto.

\section{Voice Type Simply Speaking Gold}

Empresa: $\quad I B M$

Internet: http://www.software.ibm.com/is/voicetype/uk_menu.htm/

Sistema: $\quad$ Windows 95

Info: $\quad$ http.//www.software.ibm.com/is/voicetype/uk_menu.html

Notas: $\quad$ Comandos por Voz 


\section{Microsoft Voice Comand Speech SDK, ver 3.0}

Empresa: Microsoft

Internet: $\quad$ http://www.microsoft.com

Sistema: $\quad$ Windows 95

Demo: $\quad$ http://www.microsoft.com

Notas: $\quad$ Permite comandar o computador por voz e ditar texto.

Recentemente, a empresa belga Lernout and Hauspie lançou dois novos produtos de reconhecimento de voz para o Microsoft Word: Voice Xpress e Voice Xpress Plus.

Estes produtos permitem ao usuário do sistema criar e editar textos no processador de texto Microsoft Word, em inglês, falando de uma forma natural até 140 palavras por minuto.

Outro software que vai adotar essa tecnologia é o Windows NT5, pois já vai trazer o uso de reconhecimento de voz incluído no sistema. A versão do Windows posterior ao NT5, prevista ainda para 2001, usará reconhecimento de voz como principal forma de interagir com o usuário.

Outra empresa que também adota essa tecnologia é a Intel, que está integrando reconhecimento de voz na CPU.

\subsection{Considerações Finais}

Neste capítulo, foram apresentadas as tecnologias de Conversão Texto/Noz existentes no mercado, para vários idiomas, destacando-se aquelas existentes para a Lingua Portuguesa, tais como o Ellan e o DeltaTalk. Foram apresentadas também algumas técnicas para conversão voz/texto. 


\section{Capítulo 3}

\section{Fonética}

\subsection{Introdução}

Neste capítulo, é apresentada, em caráter introdutório, a Fonética da Língua Portuguesa, que é usada no processo de Conversão Texto/Noz.

Antes de entrarmos diretamente em Conversão Texto/Noz, é necessário ter a idéia da constituição básica da linguagem portuguesa, que é a plataforma para este projeto.

A Linguagem é formada por segmentos chamados de Palavras, as quais são subdivididas em Sillabas e Fonemas. Silabas são sons pronunciados em uma única expiração e Fonemas são sons capazes de estabelecer distinção entre duas silabas.

O objetivo é utilizar uma seqüência de texto que se aproxime de uma fala humana compreensivel e para isso o nível hierárquico ideal é o que tem como base o fonema, por possuir menor utilização de memória e maior nível de universalização em relação à língua.

\subsection{O Fonema e a sua relação com a Letra}

A Fonética é a área da ciência que estuda minuciosamente os sons da fala em suas múltiplas realizações, não apresentando portanto, preocupação com nenhuma das linguas em especial. Através dos fonemas, podemos diferenciar palavras compostas pela mesma seqüência de letras, porém com significado diferenciado, como por exemplo em Réis e Reis ou em Pós e Pôs. Todo som capaz de estabelecer distinção significativa entre duas palavras de uma língua, sem apresentar significado próprio, recebe o nome de fonema.

Os fonemas são as unidades básicas de uma Lingua, e têm a propriedade de mudar o sentido de umá palavra quando uma unidade é substituída por outra. Por 
exemplo, na série de palavras dia, fia, mia, pia, tia e via, a distinção entre as palavras ocorre apenas pelo elemento consonântico inicial, que caracterizam unidades sonoras distintas, correspondendo cada uma delas a um fonema diferente.

Entendidos como uma unidade de som no início do século XIX, os fonemas são hoje considerados como unidades mentais, abstratas, das quais o som é a sua realização física. O fonema é uma unidade da Língua e os sons ou fones são unidades da fala (CALLOU \& LEITE, 1990).

Os fonemas são comuns a todos os indivíduos que falam a mesma Lingua, enquanto que os sons que os representam variam não apenas de um individuo para outro, como também, para um mesmo indivíduo de uma ação para outra.

Aos vários sons que correspondem ao mesmo fonema dá-se a denominação de variantes ou alofones. Por exemplo, os fonemas /d/ e /t/ apresentam em determinados dialetos do Português uma realização palatal diante do /i/, como nas palavras tia e dia e uma realização alveolar ou dental diante das outras vogais como nas palavras dado, docas, tela, tua (CALLOU \& LEITE, 1990).

Para distinguí-los dos sons realmente produzidos, os fonemas são normalmente representados entre barras obliquas $(/ /)$, enquanto que os sons são representados entre colchetes ([ ]). No caso da representação entre barras, a transcrição é dita fonológica e no caso da representação entre colchetes, a transcrição é fonética. A palavra dia por exemplo, é representada pelos fonemas /dia/ e pode ser pronunciada como [djia] (EGASHIRA \& VIOLARO, 1992).

Cada idioma tem seus próprios fonemas, que são elementos fônicos dotados de função representativa no sistema. De acordo com Callou e Leite, a Língua Portuguesa tem 26 fonemas segmentais (19 consoantes e 7 vogais) e um fonema suprasegmental, o acento, que não é um segmento e sim uma qualidade que se superpõe a certos segmentos. Formas como dívida e divida; sábia, sabia e sabiá, opõem-se entre si apenas pela posição do acento tônico.

Para que as seqüências fônicas de uma Lingua sejam reproduzidas na escrita, utilizam-se sinais gráficos representativos desses sons, que são as letras ou grafemas. No entanto, não há uma correspondência exata entre número de letras e o número de 
fonemas nos idiomas. Alguns exemplos podem ser encontrados em CEGALLA (1977) tais como:

- na Língua Portuguesa pode-se observar que uma mesma letra pode representar mais de um fonema, como por exemplo na seqüência de palavras exame, xale e próximo;

- um mesmo fonema pode ser figurado por mais de uma letra, como nas palavras casa, exilio, cozinha ou representado por um grupo de duas letras, os dígrafos, como nas palavras machado, mulher, unha, missa e carro;

- há ainda letras que por vezes não representam fonemas, funcionando somente como notações léxicas, como nas palavras campo [cãpo] e regue, na qual o u é insonoro, para não seja proferido reje;

- e também são utilizadas letras simplesmente decorativas, na medida em que não representam fonemas e não funcionam como notações léxicas, como em discipulo [dicipulo], hotel [otél] e exceção [esesão]; além de fonemas que, em certos casos, não são representados graficamente como em eram [érãu], falam [fálãu].

Há um sistema ortográfico que rege essa representação na línguagem escrita, sendo a ortografia vigente até hoje no Brasil, a oficialmente adotada nas normas do Vocabulário Ortográfico de 1943, com as alterações determinadas pela Lei n o 5.765 de 18 de dezembro de 1971 (FERREIRA, 1986).

Em (CALLOU \& LEITE, 1990), foi discutida a possibilidade de uma reforma ortográfica, que levasse em consideração a relação entre a pronúncia e a ortografia portuguesa do Brasil e de Portugal e que também procurasse aproximar o sistema de fonemas ao sistema de letras, como a substituição da letra "s" por "z" em palavras nas quais a letra "s" representa o som [z] (casa, mesa) e de "ss", "c", "ç" e "x" por "s" para representarem o som [s] (posso, cedo, laço, próximo).

No entanto, ainda segundo esses autores, esse sistema integrado letra-fonema parece ser inviável, pois em um país com a dimensão do Brasil qualquer tentativa de aproximação seria precária e deixaria a desejar, já que deveriam ser levadas em consideração todas as diferenças regionais, sócio-culturais e até mesmo individuais. 
Os autores citam ainda que, quanto mais um idioma desenvolve-se, mais o sistema ortográfico afasta-se do sistema fonológico, como ocorre com os idiomas inglês e francês. Ainda com relação à simplificação abordada anteriormente, a representação do som [s] sempre pela letra "s" e do som [z] sempre pela letra "z" esbarra na questão das palavras homófonas como coser/cozer, expiar/espiar, cessão/sessão/seção, além de palavras como aterrisar e subsídios, para as quais existem normalmente duas pronúncias, aterri[s]ar e aterri[z]ar, sub[s]ídios e sub[z]ídios.

Assim, considerando-se todos esses argumentos, a convivência com o sistema ortográfico atual parece inevitável, pelo menos a curto e médio prazo.

\subsection{O Alfabeto Fonético}

Para simbolizar na escrita a pronúncia real de um som utiliza-se um alfabeto especial, conhecido como alfabeto fonético. A finalidade da transcrição fonética e portanto do alfabeto fonético é justamente a transcrição e a leitura de um som em qualquer idioma por uma pessoa treinada. Assim, esse alfabeto deve apresentar convenções inequívocas e de maneira explícita. Algumas dessas convenções tornaram-se bastante difundidas, como por exemplo, as propostas no "International Phonetic Alphabet - IPA" pela Sociedade Internacional de Fonética. Esse alfabeto, no entanto, emprega caracteres pouco comuns em máquinas de escrever e computadores, o que dificulta sua utilização (CALLOU \& LEITE, 1990).

A Tabela 2, a seguir, apresenta o alfabeto fonético baseado nos símbolos IPA, e outros dois possíveis alfabetos para a Língua Portuguesa, sendo um deles baseado em letras maiúsculas, utilizando até dois caracteres e outro, que será adotado neste trabalho, utilizando apenas um único caractere. 


\begin{tabular}{|c|c|c|c|}
\hline $\begin{array}{c}\text { Símbolos } \\
\text { IPA }\end{array}$ & $\begin{array}{l}\text { Símbolos } \\
\text { com } 1 \text { ou } 2 \\
\text { caractéres }\end{array}$ & $\begin{array}{l}\text { Símbolos } \\
\text { com } 1 \\
\text { caracter }\end{array}$ & Exemplos \\
\hline $\mathrm{a}$ & A & $\mathrm{a}$ & pá, gato \\
\hline $\mathrm{e}$ & $E$ & $\mathrm{e}$ & vê, medo \\
\hline$\varepsilon$ & $\mathrm{EH}$ & é & pé, ferro \\
\hline $\mathrm{i}$ & I & $\mathrm{i}$ & vir, bico \\
\hline $\mathrm{o}$ & $\mathrm{O}$ & $\mathrm{O}$ & avô, morro \\
\hline 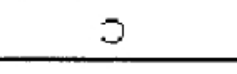 & $\mathrm{OH}$ & ó & avó, cola \\
\hline $\mathrm{u}$ & $\mathrm{U}$ & $\mathrm{u}$ & tu, bambu \\
\hline à & $\mathrm{AN}$ & $\tilde{\mathrm{a}}$ & lã, cama \\
\hline $\mathrm{m}$ & M & $\mathrm{m}$ & mar, a migo \\
\hline$n$ & $\mathrm{~N}$ & $\mathrm{n}$ & nada, cano \\
\hline$\eta$ & $\mathrm{NH}$ & $\bar{n}$ & vinha, caminho \\
\hline $\mathrm{b}$ & $\mathrm{B}$ & $\mathrm{b}$ & bravo, ambos \\
\hline $\mathrm{p}$ & $P$ & $\mathrm{p}$ & pai, caprino \\
\hline d & D & $\mathrm{d}$ & dar, andar \\
\hline$t$ & $\mathrm{~T}$ & $t$ & tu, canto \\
\hline$g$ & $\mathrm{G}$ & $g$ & frango, agrado \\
\hline $\mathrm{k}$ & $\mathrm{C}$ & $\mathrm{k}$ & casa. que \\
\hline f & $\mathrm{F}$ & $\mathrm{f}$ & filho, afiar \\
\hline $\mathrm{v}$ & $\mathrm{V}$ & $\mathrm{v}$ & vinho, uva \\
\hline$s$ & $\mathrm{~S}$ & $\mathrm{~s}$ & saber, posso \\
\hline $\mathrm{z}$ & Z & Z & bazar, casa \\
\hline ! & $X$ & $x$ & chover, xarope \\
\hline 3 & $\mathrm{~J}$ & $\mathrm{j}$ & já, jarra \\
\hline 1 & $\mathrm{~L}$ & 1 & lado, veludo \\
\hline 1 & $\mathrm{~L}$ & $\perp$ & alto, fuzil \\
\hline$\lambda$ & $\mathrm{LH}$ & $\mathrm{L}$ & filho, pilha \\
\hline$r$ & $\mathrm{R}$ & $\mathrm{r}$ & caro, cores \\
\hline $\mathrm{r}$ & $\mathrm{R}$ & $\mathrm{h}$ & mar, carta \\
\hline $\mathrm{R}$ & RR & $\mathrm{R}$ & carro, roda \\
\hline
\end{tabular}

Tabela 2. Alfabetos fonéticos para a Língua Portuguesa. 
$\mathrm{Na}$ Lingua Portuguesa os fonemas /i/ e / $\mathrm{u} /$, quando formam silaba com outra vogal, são chamados semi-vogais e normalmente transcritos como [j] e [w], como em [rej] e [mew] (CUNHA \& CINTRA, 1985).

No entanto, um ditongo pode ser considerado como junção de duas vogais de menor duração com transições suaves entre as suas freqüências que formam (CAMPOS, 1980).

Em posição final de sílaba ou palavra, a consoante "l" pode ser pronunciada como [u] ou [w], como em alto e Brasil (CUNHA e CINTRA, 1985). Por essa razão, quando encontrado nessas posições o "l" é associado ao símbolo [l]. E nessa mesma situação a letra " $r$ " é associada ao símbolo [h], conforme indicado anteriormente na Tabela 2.1.

É comum utilizar uma apóstrofe (') para indicar a silaba ou vogal tônica na transcrição, como em ['bo-la] ou [b'ola].

\subsection{Classificação dos Sons Lingüísticos}

Para entender os parâmetros envolvidos na produção da voz, é importante ser compreendido também o funcionamento do aparelho fonador (KLATT, 1987). Por esse motivo ainda hoje o aparelho fonador é um tópico de ativas pesquisas na área de fonética acústica e articulatória e pode ser visualizado na Figura 3.

A classificação dos sons da Lingua Portuguesa foi discutida em detalhes por diversos autores, como em CUNHA \& CINTRA (1985) e CALLOU \& LEITE (1990). Apesar de algumas divergências, é de consenso entre os autores a existência de duas classes de sons, as vogais e as consoantes, as quais serão destacadas a seguir.

\subsubsection{Classificação das Vogais}

As vogais são normalmente classificadas seguindo quatro critérios:

1- quanto à região de articulação

2- quanto ao timbre 
3- quanto ao papel das cavidades bucal e nasal

4- quanto à intensidade

Os três primeiros critérios são fundamentalmente de base articulatória e o último de base acústica.

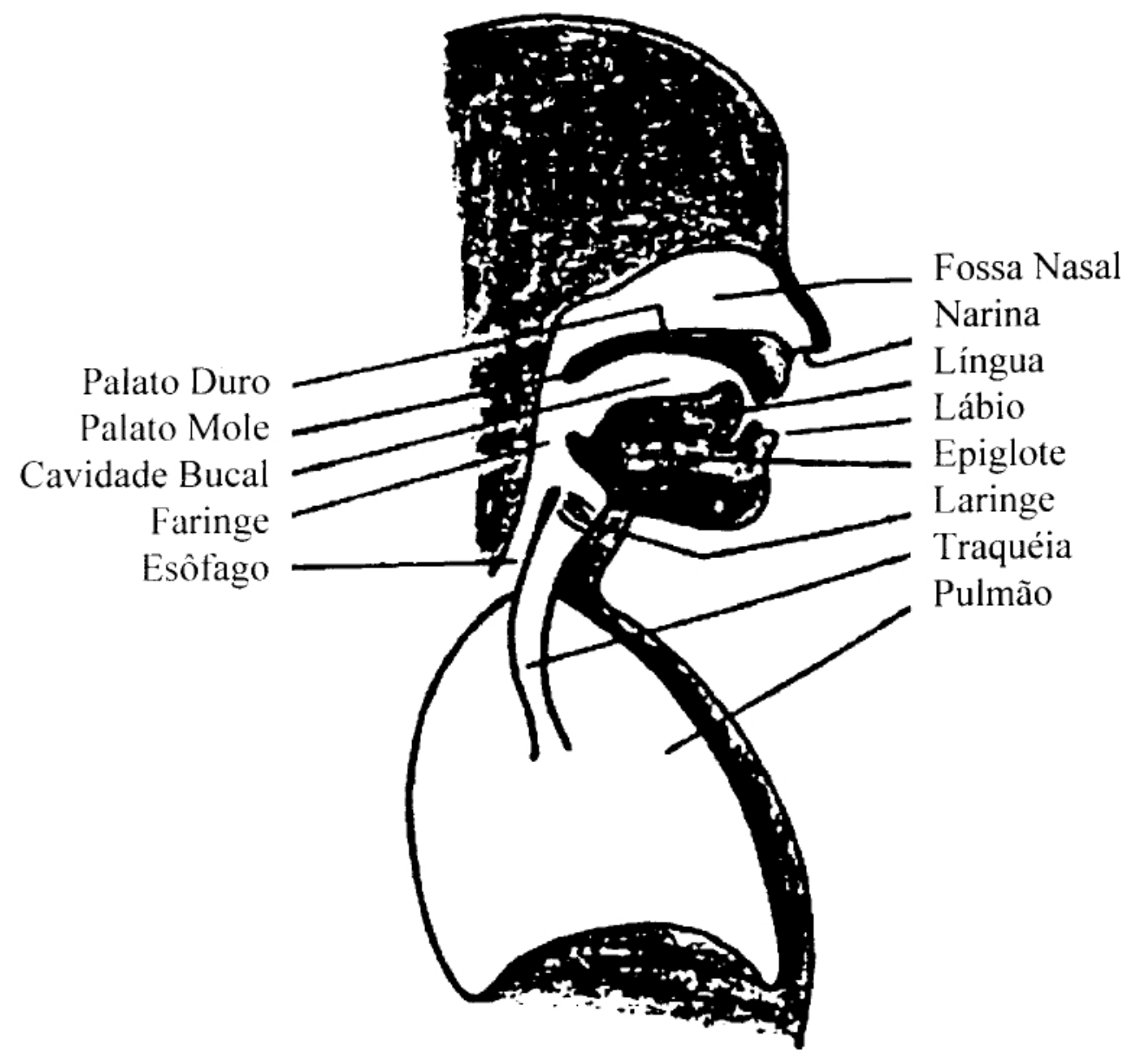

Figura 3. Diagrama esquemático do aparelho fonador humano

Classificação quanto à Região de Articulação: diz respeito ao ponto ou parte em que se dá o contato ou aproximação dos órgãos que cooperam para a produção dos fonemas, no caso das vogais, a língua e o palato. Produz-se a vogal média [a] mantendo-se a língua baixa, quase em posição de descanso, e a boca entreaberta.

A passagem da vogal a para as vogais anteriores ([e], [é], [i]) levanta-se gradualmente a parte anterior da língua em direção ao palato duro, ao mesmo tempo 
em que se diminui a abertura da boca. Para emitir as vogais posteriores ([o], [ó], [u]), eleva-se a parte posterior da língua em direção ao véu palatino, arredondando progressivamente os lábios.

Classificação quanto ao Timbre: refere-se ao maior ou menor grau de abertura dos lábios. Essa abertura é máxima para a vogal [a] e mínima para as vogais [i] e [u].

Classificação quanto ao Papel das Cavidades Bucal e Nasal: depende da posição da úvula durante a passagem de ar pelo trato vocálico.

Quando a corrente sonora é impedida de ressoar na cavidade nasal devido à posição levantada da úvula, tem-se a produção das vogais orais ([a], [e], [é], [i], [o], [ó], [u]).

Quando as fossas nasais são acopladas à cavidade bucal através do abaixamento da úvula, parte da corrente sonora ressoa na cavidade nasal, produzindo as vogais nasais ([ã], [ē], [ï], [ö], [u]).

Classificação quanto à Intensidade: é uma qualidade física da vogal que depende da força expiratória e da amplitude da vibração das cordas vocais. As vogais que se encontram nas silabas pronunciadas com maior intensidade chamam-se tônicas e caracterizam-se, no idioma Português, por um reforço da energia expiratória.

As vogais que se encontram em sílabas não acentuadas denominam-se átonas. No idioma Português normal do Brasil, as vogais [é] e [ó] não aparecem em posição atona, assim como as vogais nasais.

A Tabela 3 resume a classificação das vogais da Lingua Portuguesa, que basicamente se caracterizam por possuirem:

1) Maior abertura das articulações,

2) Maior qualidade de vibrações nas cordas vocais e

3) São os únicos que configuram o ápice (centro) da sílaba. 


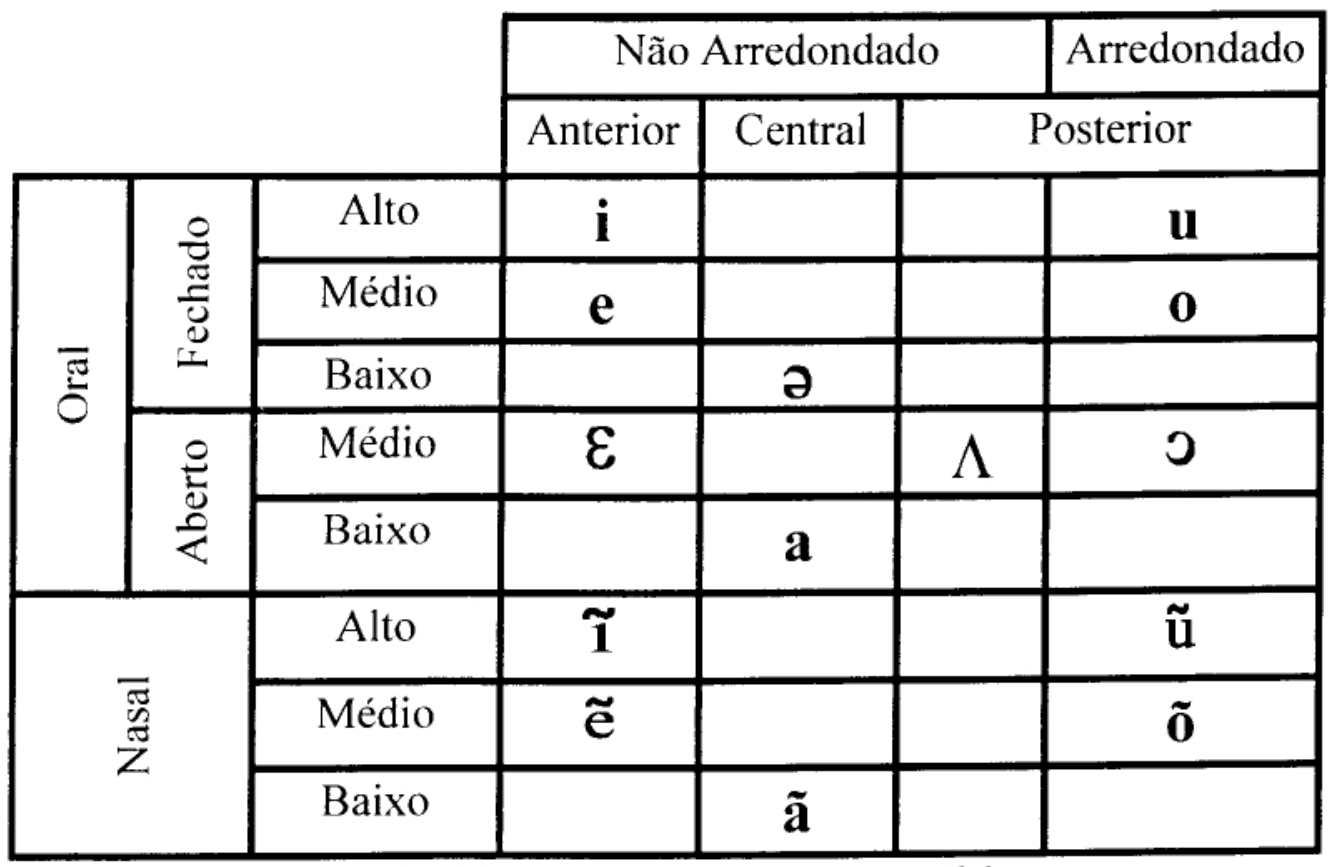

Tabela 3. Quadro de Fonemas Vocálicos

Do ponto de vista da fonética acústica não há razão para considerar [ã], [ë], [õ], e [ü] fonemas distintos, pois seus espectros apresentam uma parte inicial idêntica ao das vogais que o iniciam, seguidos de uma parte muito semelhante a todos eles, que caracteriza o [m] final desses sons. Por isso, podem ser tratados como o encontro de dois fonemas, com transições suaves entre duas configurações do trato vocálico (CAMPOS, 1980).

No Brasil, nas silabas átonas, ocorre a chamada "neutralização", na qual as vogais anteriores "e" e "i", quando em posição final absoluta, são reduzidas a uma única vogal [i], como na palavra tarde $\rightarrow$ [tardi] e as vogais posteriores "o" e "u", quando nessa situação também são reduzidas a uma única vogal [u], como no caso da palavra povo $\rightarrow[$ povu].

\subsubsection{Classificação das Consoantes}

São dezenove as consoantes da Língua Portuguesa e tradicionalmente classificadas em função de quatro critérios de base articulatória, ou seja, quanto ao 
modo de articulação, quanto ao ponto de articulação, quanto à função das cordas vocais e quanto ao papel das cavidades bucal e nasal.

Classificação quanto ao Modo de Articulação: refere-se à maneira pela qual os fonemas consonantais são articulados. Vindo da laringe, a corrente de ar chega à boca, onde encontra obstáculos totais ou parciais da parte dos órgãos bucais. Se o fechamento dos lábios ou a interrupção da corrente de ar é total, temos as consoantes oclusivas ([p], [t], [k], [b], [d], [g]); se o fechamento for parcial, são produzidas então as consoantes constritivas.

No segundo caso, dependendo de como a corrente expiratória escapa, as consoantes podem ser:

- fricativas: são produzidas quando o trato vocálico é excitado por um fluxo de ar turbulento, que se forma quando a corrente expiratória passa pela constrição ([f], [s], $[\mathrm{x}],[\mathrm{v}],[\mathrm{z}],[\mathrm{j}])$.

- vibrantes: são caracterizadas pelo movimento vibratório rápido da língua ([r]) ou da úvula ([R]), que provocam breves interrupções da passagem da corrente expiratória.

- laterais: são caracterizadas pela passagem da corrente expiratória pelos dois lados da cavidade bucal, em virtude de um obstáculo formado no centro desta pelo contato da língua com os alvéolos dos dentes ([l]) ou com o palato ([L]).

Classificação quanto ao Ponto de Articulação: diz respeito ao lugar onde os órgãos fonadores entram em contato para a emissão do som, podendo ser bilabiais ([p], [b], [m]), labiodentais ([f], [v]), linguodentais ([t], [d], [s], [z]), alveolares ([l], [r], [n]), palatais $([x],[j],[L],[\tilde{n}])$ ou velares $([k],[g],[R])$.

Classificação quanto à Função das Cordas Vocais: se durante a produção das consoantes a corrente de ar produzir vibração das cordas vocais tem-se uma consoante sonora; caso contrário, a consoante será surda. 
Classificação quanto ao Papel das Cavidades Bucal e Nasal: quando o ar sai exclusivamente pela boca, as consoantes são ditas orais. Quando o ar penetra nas fossas nasais pelo abaixamento da úvula, as consoantes são ditas nasais ([m], [n], [ñ]).

A Tabela 4, a seguir, resume a classificação das consoantes para a Língua Portuguesa.

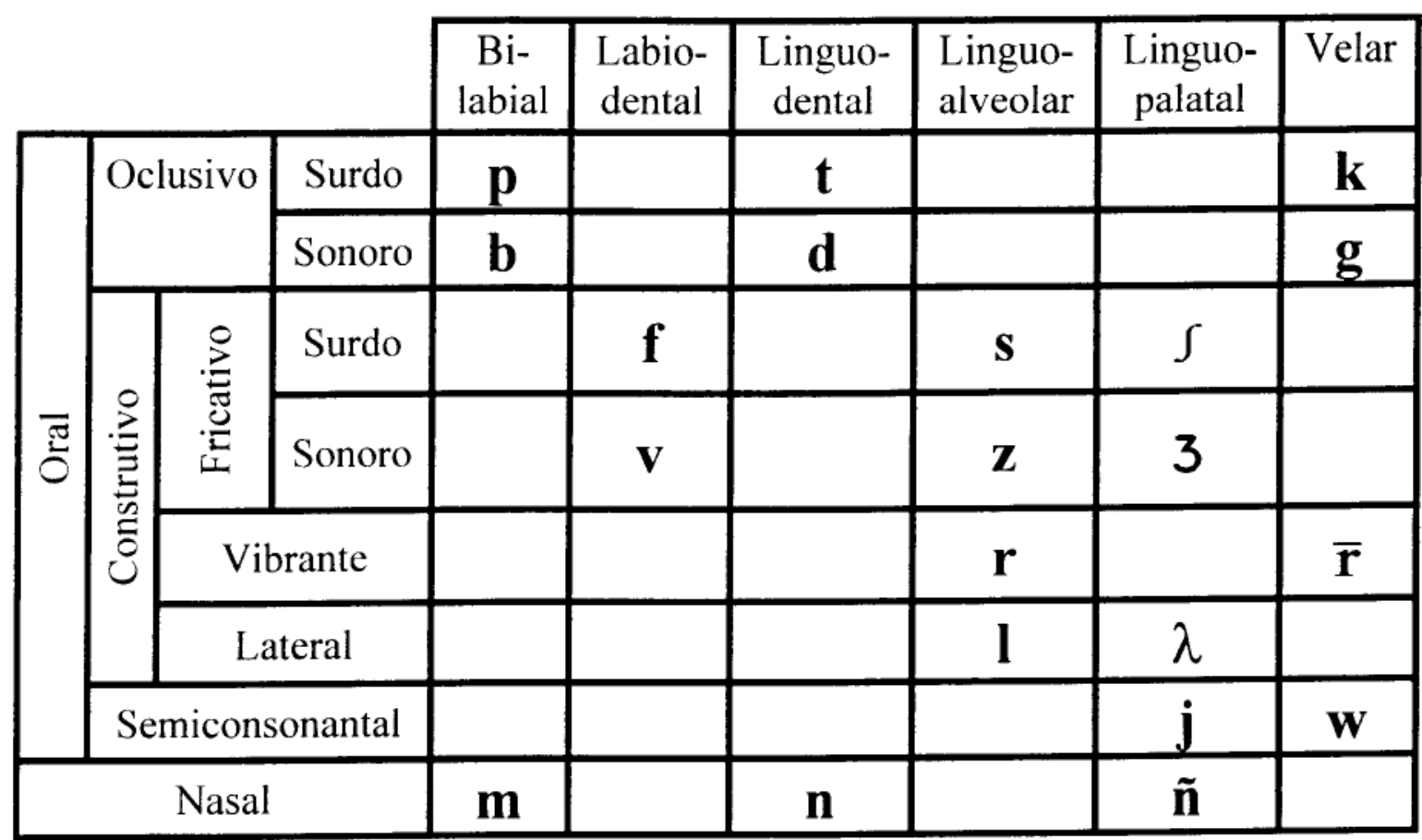

Tabela 4. Quadro de Fonemas Consonantais

\subsection{Considerações Finais}

Neste capitulo, foi apresentada a Fonética da Língua Portuguesa, que é usada no processo de Conversão Texto/Noz, para fornecer uma base de entendimento sobre a plataforma do projeto leitor de e-mails, que são os fonemas. 


\section{Capítulo 4}

\section{Conversão Texto/Voz através de Fonemas}

\subsection{Introdução}

Neste capitulo, são apresentadas as diversas Tecnologias de Conversão Texto/Noz, que utilizam fonemas, existentes no mercado, tanto para a língua inglesa quanto para a língua portuguesa.

\subsection{O Processo de Síntese de Voz a partir de Texto}

O processo de síntese de voz a partir de texto puro e simples, sem o uso de Redes Neurais, pode variar bastante de acordo com o idioma utilizado.

$\mathrm{Na}$ língua inglesa, inicia-se com o processamento lingüistico para a determinação da estrutura fonológica das sentenças dos textos de entrada. Essa estrutura, constituída essencialmente pelos fonemas que formam as palavras, é analisada para a determinação dos parâmetros acústicos que serão utilizados posteriormente no controle do sintetizador de voz, o qual produzirá a fala.

Este processo constitui uma tarefa ampla e complexa, e pode ser dividido em várias etapas, conforme indica a Figura 4 , a seguir.

Inicialmente, o texto de entrada contendo abreviações, acrônimos, datas, caracteres não alfabéticos e sinais de pontuação, deve sofrer um pré-processamento para que seja utilizado nas fases seguintes. 


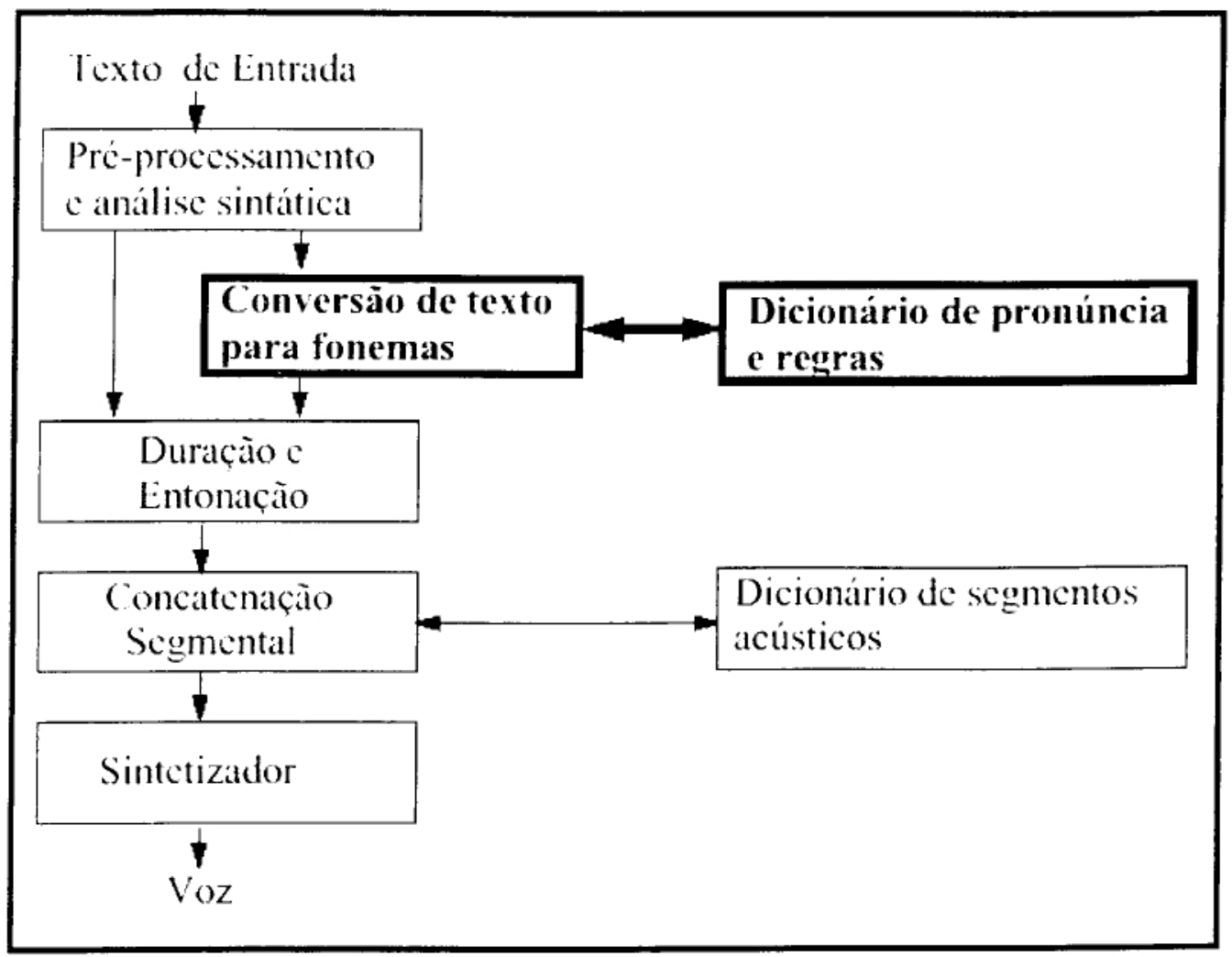

Figura 4. Elementos de um sistema de sintese de voz a partir de texto.

Hirschberg (HIRSCHBERG et al., 1990) comenta a respeito das dificuldades relativas a esse processo, na medida em que podem ocorrer muitas ambigüidades, como por exemplo, um "ponto" pode ser usado em uma abreviação ou no final de uma sentença.

Além disso, números constituem uma séria dificuldade; 1/2 por exemplo, pode ser uma data ou uma fração e também muitas abreviaturas comuns podem ter múltiplos sentidos, como nas seguintes sentenças, "Dr. Jones lives on Jones Dr." (Doctor Jones lives on Jones Drive) e "St. James St." (Saint James Street), citadas em (O'MALLEY, 1990).

Uma análise sintática simples é necessária para a pronúncia de determinadas palavras, como "object" e "desert", as quais em Inglês são acentuadas na primeira sílaba em caso de substantivo ou na segunda sílaba, em caso de verbo. A análise 
sintática é importante também para determinar a correta entonação de uma sentença, como por exemplo, para fazer com que uma palavra seja pronunciada com maior destaque em relação à outra. (HIRSCHBERG et al., 1990)

Na maioria dos sistemas as palavras são divididas em palavras de função, como as preposições e os artigos, e palavras de conteúdo, como substantivos e verbos. Normalmente, as palavras de conteúdo são pronunciadas com maior destaque, como na frase "Cat likes to eat mice", cujas palavras grifadas são pronunciadas com maior ênfase em relação à palavra "to".

A etapa seguinte à análise sintática consiste em determinar os fonemas correspondentes ao texto de entrada, tarefa executada normalmente através de um dicionário e de um conjunto de regras de conversão de letras para fonemas (ATAL \& RABINER, 1986).

A conversão de uma palavra para a sua correspondente forma fonética neste caso, inicia-se com a sua busca no dicionário, o qual contém informações fonéticas sobre algumas palavras. Caso não seja encontrada, a palavra deve ser submetida à aplicação de um conjunto de regras para a obtenção dos fonemas a partir de suas letras.

Na lingua portuguêsa, VIANA et al. (1991) realizaram essa etapa da transcrição fonética através de dois conjuntos de procedimentos independentes porém capazes de operarem sobre os mesmos niveis de estruturas de dados. A cadeia segmental foi percorrida da esquerda para a direita e a transcrição fonética realizada palavra por palavra, ao nivel da forma de citação. Seguindo o Alfabeto SAM_PA, a frase "Ele disse à Antonia que vinha amanhã" foi inicialmente transcrita como "ela d"isa a a tonj6 ka v"inha amaj"a e depois foram tratados os encontros vocálicos e consonantais em fronteira de palavras obtendo-se el dis a tonja $k$ vïJ amaJa .

Cabe ressaltar nesse exemplo, algumas diferenças quanto à pronúncia do Português falado em Portugal e no Brasil, como no caso da palavra ele, que em Portugal pronuncia-se [el] e no Brasil [eli] ou na palavra que, a qual é pronunciada como [k] em Portugal e [kê] no Brasil, o que evidencia mais uma vez a necessidade de regras fonéticas e fonológicas próprias para cada país. 
As informações fonéticas e sintáticas são utilizadas posteriormente para determinação da prosódia da mensagem, através das características de ritmo, acentuação, entonação e expressas como resultado combinado de parâmetros de duração, intensidade e "pitch". (LAPORTE, 1989)

Cada sílaba em uma sentença tem uma duração especifica, geralmente diferente das sílabas vizinhas, que determinam o ritmo da fala. $A$ intensidade caracteriza o volume do som da fala, que em uma sentença varia entre valores baixos e altos. O mesmo acontece com os valores de "pitch", os quais definem a entonação de uma sentença. A partir dessas características, são determinados os parâmetros acústicos da sentença a ser pronunciada, eventualmente com base em um dicionário de segmentos acústicos, e finalmente a voz é produzida por um sintetizador.

\subsubsection{Conversão de Texto para Fonemas}

Várias tentativas iniciais foram feitas com a finalidade de prever a pronúncia de palavras a partir das letras que as compunham, com base na hipótese de que uma letra ou par de letras poderia ser convertido para o fonema apropriado caso fosse examinado o contexto, ou vizinhança, na qual a palavra estava inserida. Para cada letra, as regras deveriam ser ordenadas de modo que as primeiras tratariam dos casos mais complexos, e o último caso corresponderia à tradução fonética "default" (KLATT, 1987).

Partindo deste principio, Ainsworth (AINSWORTH, 1973) apresentou uma tabela para conversão de letras para fonemas para o Inglês Britânico a partir de um conjunto de 159 regras, que estão apresentadas na Tabela 5. 
"Um Sistema para Leitura de e-mail, com Conversão Texto/Voz, utilizando Redes Neurais"

\begin{tabular}{|c|c|c|c|c|c|c|c|}
\hline Letras & Fonemas & Letras & Fonemas & Letras & Foncmas & Letras & Fonemas \\
\hline$-(a)-$ & a & (ough) & $a u$ & (g)et & $\rho$ & $-(\mathrm{C}$ (ic) & $a$ \\
\hline - (are) & $a$ & (oulnd & $\mathbf{U}$ & clow) & $\mathrm{gu}$ & $V($ (ic) & $\mathrm{ii}$ \\
\hline (a) $\mathrm{E}$ & $\varepsilon \mathrm{Ei}$ & (ou) & au & $h($ ow $)$ & $a u$ & (i) & II \\
\hline (ar) & $a$ & (oor) & 10 & $n$ (ow) & $\mathrm{au}$ & (i) & $\mathrm{dz}$ \\
\hline (a) sk & $a$ & $(00) \mathrm{k}$ & $\mathrm{U}$ & v(ow) & $a_{\mathrm{u}}$ & $-(k) n$ & 1 \\
\hline (a)st & $a$ & ffoo)d & $\mathrm{u}$ & row) & $a_{u}$ & (k) & $\mathrm{k}$ \\
\hline (a)th & $a$ & $(00) \mathrm{d}$ & $\mathrm{U}$ & (ow) & au & (le)- & $\mathrm{al}$ \\
\hline (a) $\mathrm{ft}$ & $a$ & $f(00) t$ & $\mathrm{U}$ & $g(0)-$ & $\mathrm{au}$ & (1) & 1 \\
\hline (ai) & $\mathrm{ci}$ & $\mathrm{s}(00) \mathrm{t}$ & $\mathrm{U}$ & $n(0)-$ & $a u$ & $(\mathrm{~m})$ & $\mathrm{m}$ \\
\hline (ay) & $\mathrm{Ei}$ & $w(00)$ & 0 & stor- & au & $(\mathrm{n}) \underline{\underline{E}}$ & $n$ \\
\hline (aw) & 3 & $(00)$ & $\mathrm{u}$ & (0)- & $\mathrm{u}$ & (n) & $\mathrm{n}$ \\
\hline (au) & 0 & $\operatorname{sh}(00)$ & $\mathrm{u}$ & (o) & 0 & (or) & 3 \\
\hline$(\mathrm{al}) 1$ & 0 & (oo) & $\mathrm{au}$ & $(\mathrm{ph})$ & 1 & $(0) \mathrm{E}$ & $\mathrm{au}$ \\
\hline (a)ble & $\mathrm{Ei}$ & $\begin{array}{l} \\
\end{array}$ & a & (psy) & sai & (oa) & $\mathrm{au}$ \\
\hline (a)ngSUF & $\mathrm{Ei}$ & $V(t(c) d-$ & a & (p) & $\mathrm{p}$ & (their) & व \\
\hline (a) & $\mathrm{c}$ & V(re)d- & ? & $(q)$ & $\mathrm{kw}$ & (th)r & $\theta$ \\
\hline (b) & $\mathrm{b}$ & (c) r- & 2 & (r)- & i & (th) & a \\
\hline (ch) & $\mathrm{t} \mathrm{t}$ & where) & $\varepsilon z$ & (rho) & $\mathrm{rau}$ & (t)ion & $i$ \\
\hline (ck) & $k$ & hicre) & 13 & (r) & $\mathrm{r}$ & (t) & 1 \\
\hline (c)y & $\mathrm{s}$ & w(ere) & 3 & (sh) & ij & (u)pon & $\overline{i n}$ \\
\hline (c)c & $\mathrm{s}$ & (ere) & ir: & $(\mathrm{ss})$ & $\mathrm{s}$ & $(\mathrm{u}) \mathrm{V}$ & $\mathrm{u}$ \\
\hline (c)i & $\mathrm{s}$ & (ec) & ii & (sch) & $\mathrm{sk}$ & (u) $)^{\circ}-$ & $\overline{B A}$ \\
\hline (c) & $\mathrm{k}$ & (car) & ir & Xv(s) & $z$ & $r(u)$ & $\mathrm{iu}$ \\
\hline (d) & $\mathrm{d}$ & (ca) & 1 & $V(s)-$ & $z$ & I(u) & $\mathrm{u}$ \\
\hline Vc(c)- & $i$ & (c)ver & $\mathcal{E}$ & (s) & $\mathrm{s}$ & (u) & $\mathrm{ju}$ \\
\hline th(c)- & a & (cye) & $\mathrm{ai}_{\mathrm{i}}$ & (there) & aca & (v) & $\mathrm{V}$ \\
\hline$-(C(c)-$ & $i$ & (c)E & ii & (g) & $\mathrm{dz}$ & $(w) r$ & 1 \\
\hline$-(c(c) d-$ & $\varepsilon$ & (clci) & 1 & (gh) & $g$ & (wh)o & $h$ \\
\hline (o)hld & a & (ci) & $a_{i}$ & (g) & 9 & (wha)t & wo \\
\hline$(0 y)$ & 20 & (c) $\mathrm{r}$ & 3 & $w(h)$ & ! & (wa) & Wo \\
\hline (10)ing & $8 \mathrm{u}$ & $(c 0)$ & 1 & (ha) & hav & (wo) $\mathrm{r}$ & 143 \\
\hline (oi) & 20 & (cw) & ju & (h) & hi & $(w)$ & $w$ \\
\hline y(ou) & $\mathrm{u}$ & (c)u & i & -(i) & $a i$ & $(x)$ & $\mathrm{ks}$ \\
\hline (ouis & $A$ & (c) & 3 & (i)ty & 1 & $-(y)$ & ii \\
\hline roughit & 2 & $(f)-$ & $\mathrm{v}$ & (i) $\mathrm{E}$ & $\mathrm{di}$ & $V(y)$ & 1 \\
\hline$b$ (ough) & $a_{u}$ & (f) & $\mathrm{f}$ & (ir) & 3 & $-(c(y)$ & $\mathrm{Cl}_{1}$ \\
\hline troughis & f & $(g)$ & $\mathrm{dz}$ & (igh) & $\mathrm{di}$ & $(y) \mathrm{E}$ & $a i$ \\
\hline clough) & of & (g)es- & $\mathrm{dz}$ & tion & 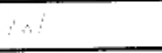 & (y) & 1 \\
\hline rrough) & $f$ & (g)SLF & (g) & (i)nd & $8 \mathrm{i}$ & (z) & 7 \\
\hline rough) & $u$ & (g)i & $\mathrm{dz}$ & (i)ld & $a \mathrm{i}$ & & \\
\hline
\end{tabular}

Tabela 5. Conversāo de Letras para Fonemas, para o Inglês Britânico, com alfabeto IPA. 
De acordo com esta tabela, nos casos onde a tradução de uma letra era ambígua e não houvesse um contexto que pudesse orientar a aplicação de determinada regra, o fonema mais comum era substituido. Algumas palavras foram consideradas exceções e incluidas em regras individuais.

Esse conjunto de regras foi testado em três textos com mil palavras cada um, sendo uma passagem de um livro sobre fonética, um trecho de um romance e um artigo sobre politica, nos quais foram detectadas respectivamente $8 \%, 11 \%$ e $11 \%$ das palavras com erros de transcrição fonética, sendo a maioria dos erros devido à conversão das vogais.

Baseado neste sistema, foi implementado um conjunto de regras para o Inglês Americano, que foi utilizado no "Naval Research Laboratory System - NRL". O sistema desenvolvido em três versões respectivamente com 182, 264 e 319 regras, foi testado em um conjunto de palavras mais freqüentes de um corpus da Lingua Inglesa (ELOVITZ et al., 1976).

Os resultados mostraram que o desempenho do conjunto de regras era sensivel ao nivel do vocabulário ao qual era aplicado, sendo que a taxa de erros na transcrição fonética de palavras aumentava com o decréscimo de sua freqüência de utilização. Para o conjunto das mil primeiras palavras mais freqüentes, a última versão de regras apresentou $3,9 \%$ de palavras transcritas erroneamente, enquanto que para as 5000 primeiras palavras de maior ocorrência esse indice aumentou para $7,2 \%$. A esses dois conjuntos de palavras corresponderam respectivamente $1,4 \%$ e $2,4 \%$ de acertos na transcrição de fonemas, visto que em alguns casos o mesmo erro de transcrição repetiu-se em mais de uma palavra.

No entanto, os critérios usados para aceitação da transcrição de uma palavra nesses sistemas eram bastante subjetivos, levando-se em consideração que se.procurava obter uma transcrição "aceitável", sem especificação de onde o nível "aceitável" situava-se entre o "perfeito" e o "compreensível". Por exemplo, no "NRL System" a troca de uma vogal acentuada por uma não acentuada não foi considerada um erro, mas, um "problema de acentuação" (ELOVITZ et al., 1976).

Um dos primeiros algoritmos de boa qualidade para trabalhar com conversão de letra para fonema, o algoritmo de Hunnicut, foi desenvolvido na década de 70 e 
utilizado no "MITalk" e no "DECtalk" (KLATT, 1987). Esse algoritmo era bem mais complexo e executava em uma primeira fase a eliminação dos afixos (prefixo e sufixo) da palavra. Em seguida, fazia a conversão das consoantes e finalmente as vogais eram transcritas. Aproximadamente 15 prefixos e 50 sufixos foram detectados e posteriormente, aproximadamente 500 regras foram aplicadas.

Em testes realizados com palavras extraidas aleatoriamente de um dicionário, esse algoritmo atingia em média um índice de $65 \%$ de palavras transcritas corretamente .

Allen (ALLEN, 1976) descreveu vários exemplos de transcrição fonética de palavras usando as regras de Hunnicut, com alfabeto IPA. Na palavra "table" por exemplo, não há afixos e as consoantes [t] e [b] são traduzidas diretamente. A letra [l] é seguida por um [e] final e é precedida por um [b]; nesse caso, ela é silábica, sendo indicada por / / (duas barras). Nesse ponto começa o processo de conversão de vogais.

A seqüência [ble] forma o contexto à direita de [a]. Todas as vogais, com exceção do [e], se estiverem na primeira silaba de uma palavra, são longas quando seguidas por uma seqüência de consoantes não vocálicas $+[l]+[e]$ em final de palavra. Essa regra é suficiente para converter [a] para /e/. Finalmente, a letra [e] por estar no final da palavra é muda, resultando a transcrição final /teb /.

A palavra "subversion", por sua vez é submetida primeiro à remoção dos afixos sub-e -ion. Em seguida são convertidas as consoantes e ao mesmo tempo em que é feita a conversão das vogais, adicionam-se os afixos novamente, os quais são transcritos diretamente resultando em / $\mathrm{b}-\mathrm{v} \mathrm{r}-\mathrm{n} /$.

Vários outros algoritmos foram então apresentados, com destaque para o de Berstein, citado em KLATT (1987), que examina as palavras da direita para a esquerda, atingindo um índice de $85 \%$ de acertos com palavras aleatórias extraídas de um dicionário.

Klatt aponta ainda, como uma das principais razões para as falhas desses algoritmos, o fato de que a conversão de uma vogal depende em parte da acentuação, como por exemplo, o "e" de "permit", que é realizado como ( $p$ ' rmite, como em "her") ou como (perm'it, como em "dinner"). 
No primeiro caso o acento está na primeira sílaba e a palavra é um substantivo significando autorização, permissão; no segundo caso, o acento está na segunda sílaba e a palavra é um verbo significando permitir. Esse mesmo autor comenta ainda que freqüentemente a análise correta de uma palavra requer a detenção dos limites dos seus morfemas, que são as menores unidades de uma Lingua com significado. De fato, qualquer algoritmo de conversão baseado somente em regras terá problemas em palavras compostas, como o "th" em "hothouse" ou o "e mudo" em "houseboat".

\subsubsection{Dicionário de Exceções}

Levando-se em consideração que apenas a conversão de letras para fonemas não é suficiente para uma transcrição fonética absolutamente correta de todas as palavras de uma Lingua, a alternativa é a utilização de um dicionário de exceções, que contenha palavras que falhem a essas regras. Por exemplo, a letra "f" sempre é pronunciada como /f/, exceto em of (/ v/) (ALLEN, 1976).

A vantagem da elaboração de um dicionário de exceções advém do fato de que um pequeno número de palavras repete-se inúmeras vezes em um texto aleatório

Um dicionário com apenas 150 palavras, chega a cobrir $50 \%$ das palavras de um texto. (HIRSCHBERG et al., 1990) No entanto, a utilização de um dicionário contendo todas as palavras de uma Língua é inviável. O gráfico da Figura 4, construido a partir de um corpus da Língua Inglesa com mais de um milhão de palavras, contendo aproximadamente 50.000 palavras diferentes, mostra a freqüência acumulada de palavras no corpus em função do número de diferentes palavras, ordenadas pela sua freqüência no corpus (KLATT, 1987).

Pode-se observar que um dicionário de duas mil palavras abrange mais de $70 \%$ das palavras dos textos, enquanto que com dez mil palavras atinge $90 \%$. Entretanto, uma extrapolação aproximada do número de palavras necessárias para aumentar essa abrangência de $90 \%$ para $93 \%$ em um texto aleatório, mostra que seriam necessárias aproximadamente 40.000 palavras adicionais, conforme indica a linha tracejada na Figura 5, que apresenta a freqüência acumulada de entradas em um corpus da Lingua Inglesa, em função do número de diferentes palavras, sempre ordenadas por sua freqüência (KLATT, 1987). 


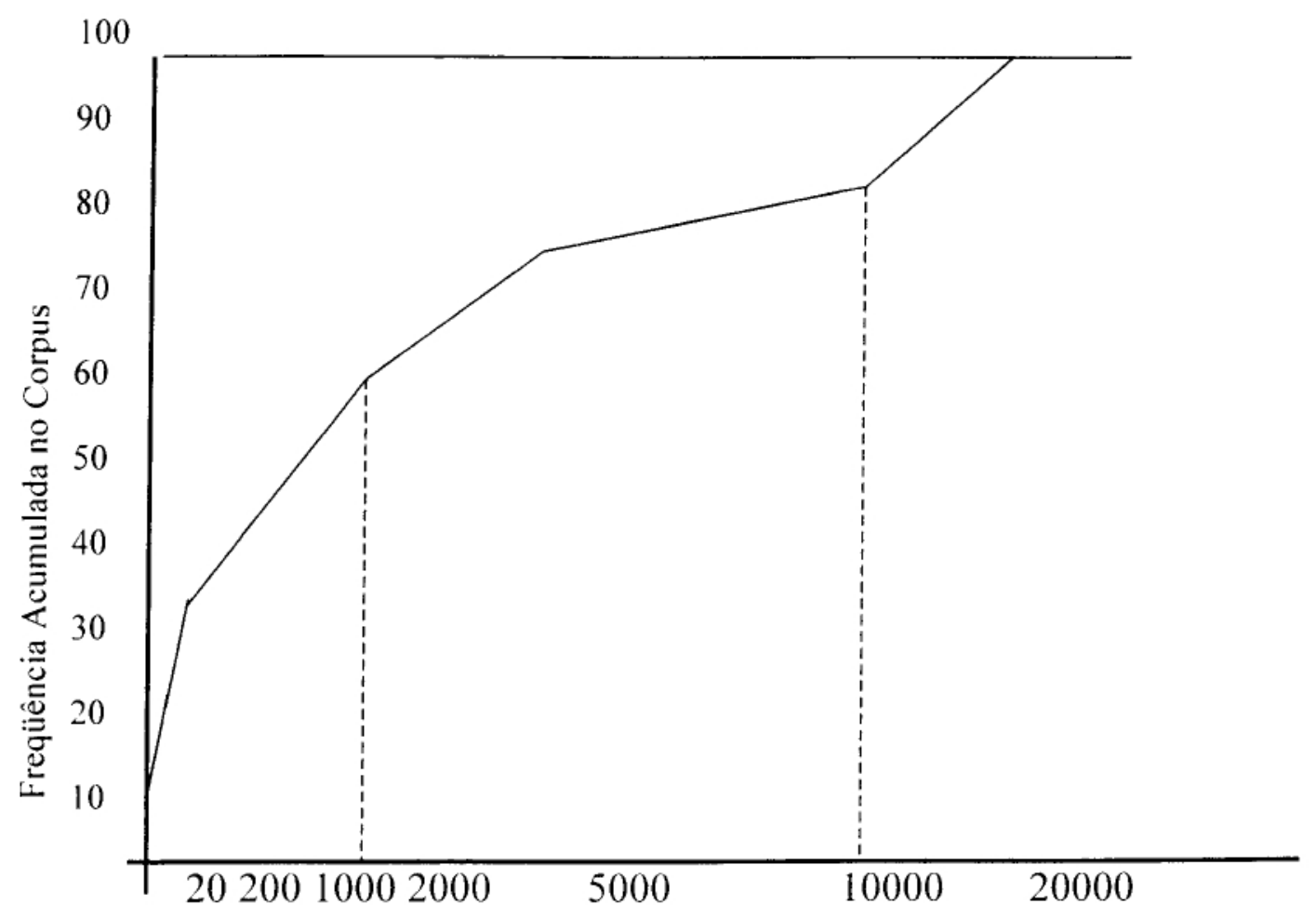

Número Acumulado de Palavras Diferentes ordenadas pela Freqüência

Figura 5. Freqüência acumulada de entradas em um corpus da Língua Inglesa

Essas considerações sugerem que um sistema hibrido, contendo um conjunto de regras de conversão de letras para fonemas e um dicionário de exceções, é uma solução adequada à conversão de textos em fonemas, pois um dicionário de exceções de tamanho moderado pode reduzir deficiências de um conjunto de regras de conversão de letras para fonemas.

Para Klatt, o tamanho de um dicionário necessário para obter um certo nivel de acerto na conversão de um texto está extremamente relacionado ao desempenho do conjunto de regras de conversão. Klatt cita como exemplo o sistema "Prose-2000", com um dicionário de exceções de 3.000 palavras e um conjunto de regras de conversão de letras para fonemas de Bernstein, com nivel de acerto de $85 \%$, resultando em um sistema com um nível de acerto total superior a $97 \%$, apenas 1 palavra em 33 em um texto aleatório conteria um erro de conversão de fonemas ou de acentuação.

Uma alternativa para aumentar a abrangência de um dicionário de exceções é a utilização de um dicionário de morfemas, que correspondem às menores unidades de 
um idioma com significado. Nesse caso, é necessária também a utilização de um conjunto de regras para dividir as palavras nos morfemas que a compõem.

Uma das principais vantagens de utilização de dicionário de morfemas é a possibilidade de a partir de um conjunto de 12.000 morfemas representar mais de 100.000 palavras da Língua Inglesa, sendo portanto, uma maneira econômica de armazenar um grande número de palavras. Além disso, os morfemas são estáveis com o tempo, podendo ser formadores de novas palavras (KLATT, 1987).

Segundo Allen (ALLEN, 1976), na Língua Inglesa existem em média menos que dois morfemas por palavra. Esses morfemas incluem os prefixos (con-, be-, mini-), sufixos derivacionais, que afetam o significado da palavra (-dom, -ness, -ship, -al), e sufixos inflexionais, que afetam o conteúdo gramatical da palavra (-s, -ed, -ing). Além disso, existem dois tipos de radicais, os radicais livres, que podem ser empregados isoladamente como em "snow", "boat" e "house", e os radicais combinados, que necessariamente são empregados ligados a um outro morfema adjacente (-turb, ceive, crimin-).

Todas as palavras em Inglês são formadas por combinações dessas unidades, através do processo de composição, no qual dois radicais são concatenados, como nas palavras "houseboat" e "snowplow"; e através do processo de afixação, no qual prefixos e sufixos são adicionados aos radicais, como nas palavras "enable" e "receive".

As regras de decomposição de palavras em morfemas devem dividir as palavras em seus respectivos morfemas, e também eleger dentre as decomposições possiveis, a mais adequada, pois existem palavras que podem ser separadas em morfemas de modos diferentes. Por exemplo, a palavra "scarcity" pode ser separada como scarce + ity ou scar + city, preferindo-se neste caso a primeira opção por ser a derivação afixional mais comum do que a composição (KLATT, 1987).

Allen (ALLEN, 1976) utilizou a divisão de palavras em morfemas no algoritmo de conversão de texto para fonemas, utilizado no "MITalk", conforme apresentado na Figura 6, a seguir. 


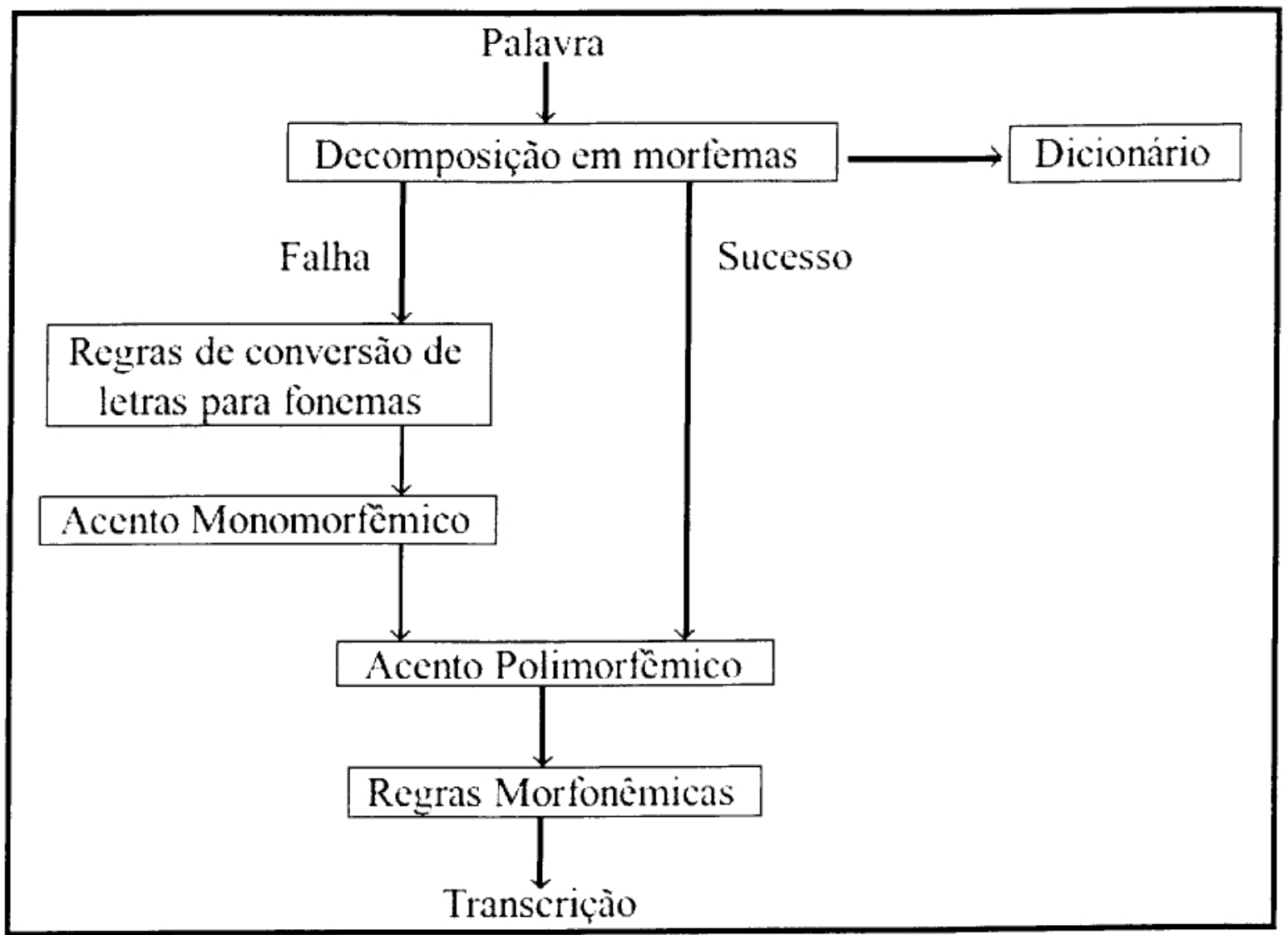

Figura 6. Sistema de conversão de letra para fonema

Inicialmente a palavra a ser transcrita é procurada no dicionário ou decomposta em uma seqüência de morfemas do dicionário. Caso não haja sucesso nessas tentativas, a palavra é submetida à um conjunto de regras de conversão de letras para fonemas.

No caso do "MITalk" esse conjunto é composto por uma implementação das regras propostas por Hunnicutt (KLATT, 1987), determinando-se a tonicidade de cada morfema separadamente (acento monomorfêmico).

A etapa seguinte seria determinar a tonicidade da palavra, considerando o efeito conjunto de todos os morfemas (acento léxico polimorfêmico).

Por exemplo, as palavras "photograph", "photography" e "photographic", embora comecem com o radical photo, têm acento respectivamente na primeira, segunda e terceira silabas (/'fout græfl, If 't gr fil e /fout 'græfik/). 
Finalmente, são feitos os acertos finais para correção dos fonemas devido aos efeitos de concatenação dos morfemas. Para o caso de palavras terminadas em -ed, a conversão do sufixo depende da última letra do morfema que está sendo modificado.

Caso o sufixo -ed seja precedido por /t/ ou /d/, será transcrito como /d/, como nas palavras "persuaded" e "stated"; se estiver precedido por /p/, /k/,/s/, /f/, /q/, /o/ ou ///, será transcrito como /t/, como em "stoped" e "walked". Nos demais casos, será transcrito apenas como /d/, como nas palavras "measured" e "doomed".

Outro algoritmo baseado na decomposição em morfemas foi desenvolvido por Coker, em 1985, com 43.000 morfemas da Língua Inglesa, sendo usado posteriormente no sistema "Conversant" de conversão de texto para voz (HIRSCHBERG et al., 1990).

\subsubsection{Compiladores de Regras}

O crescente interesse em sistemas de sintese de voz a partir de texto tem sido acompanhado por uma tendência de aumento na flexibilidade de sistemas de sintese por regras. Esses sistemas têm evoluído de programas específicos para determinada Língua, para sistemas onde linguagens especiais de programação permitem expressar regras em qualquer idioma, as quais podem ser modificadas facilmente. São os chamados compiladores de regras (HERTZ, 1982).

Essa técnica foi utilizada por Carlson no desenvolvimento do "Infovox", capaz de sintetizar voz em sete idiomas (KLATT, 1987).

Hertz (HERTZ, 1982) desenvolveu, na Universidade de Cornel, o "Speech Research System - SRS", com uma linguagem especial de programação, que permitia a construção de regras de: modificação de texto, conversão de texto para fonemas, modificação de seqüências de fonemas e de conversão de fonemas para parâmetros acústicos a serem utilizados por sintetizadores.

As regras de modificação de texto foram as primeiras a serem aplicadas, sendo responsáveis por modificar o texto de entrada, acrescentando informações necessárias às fases seguintes. 
A etapa seguinte correspondia à aplicação das regras de conversão de letras para fonemas nas palavras isoladas do texto, que produziam uma seqüência de fonemas correspondentes ao texto de entrada.

Finalmente, foram gerados os parâmetros acústicos para a produção da voz, a partir das entradas da etapa anterior.

A partir da experiência adquirida com o "SRS", foi desenvolvido o "Delta System" (HERTZ, 1985), com capacidade para combinar regras com um dicionário fonético, no qual foram armazenadas palavras que constituiam exceções às regras.

A Figura 7 mostra o diagrama de blocos dos componentes do sistema, que inclui um conjunto de regras aplicáveis ciclicamente ou não, seqüencialmente ou simultaneamente, da esquerda para direita ou da direita para esquerda, em sílabas ou morfemas, entre outras caracteristicas.

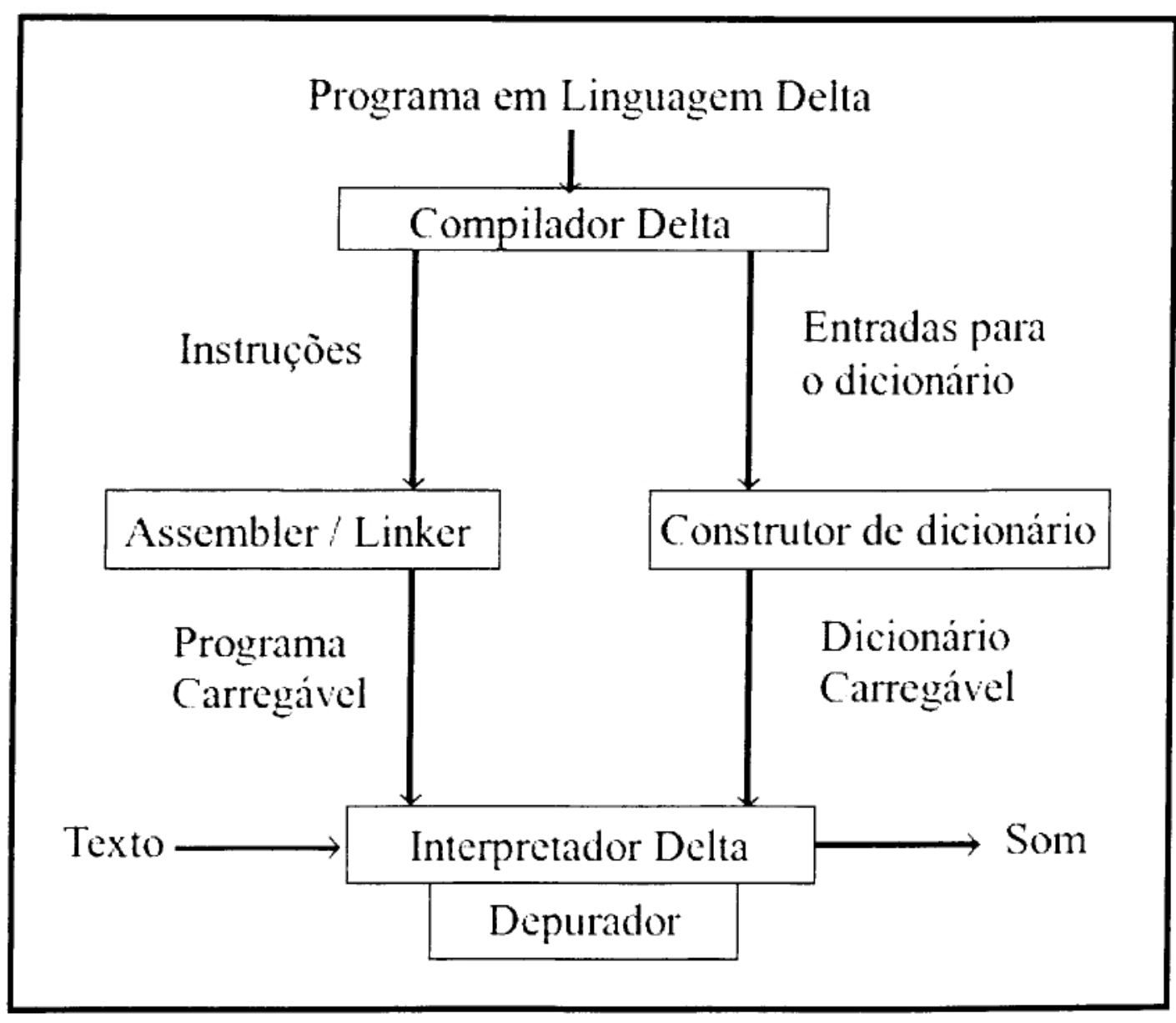

Figura 7. Diagrama de blocos do "Delta System" 
O sistema pode ser executado em microcomputadores PC ou Maclntosh e foi desenvolvido em linguagem $\mathrm{C}$, sendo constituído por cinco módulos. O compilador opera sobre um programa escrito em Linguagem Delta, contendo as regras de conversão e entradas para o dicionário. As regras são convertidas em instruções para o "interpretador Delta" e são transformadas em um programa carregável pelo módulo "assembler/linker". Em seguida, o módulo "construtor de dicionário" produz um dicionário carregável, que juntamente com o programa anteriormente gerado, podem ser carregados e executados pelo "interpretador Delta", que utilizando essas informações, produz a transcrição fonética do texto de entrada, a qual pode ser usada para a sintese de voz.

Vários outros sistemas semelhantes surgiram posteriormente, como 0 "Development Environment for Pronunciation Expert Systems - DEPES" , desenvolvido por VAN COILE (1989) e utilizado na criação de um conjunto de regras para o idioma Holandês e o "Speech Compiler for your Language - SCYLA", adotado por VIANA et al.(1991) para o desenvolvimento de regras para o idioma Português, em estudos realizados no Centro de Lingüística da Universidade de Lisboa.

\subsection{Conversão de Texto para Fonemas na Língua Portuguesa}

A conversão pura e simples, de texto para fonemas no idioma Português, de maneira análoga a que ocorre na Língua Inglesa, deve ser executada em vários passos para que possa ser bem sucedida.

Partindo-se do texto de entrada, é necessária a realização de um préprocessamento para eliminar abreviaturas, siglas, números e caracteres não alfabéticos, expandindo-os para as correspondentes palavras. Da mesma forma que acontece na língua inglesa, podem ocorrer ambigüidades, como no caso dos caracteres "1" e "2", que podem ser escritos respectivamente como um ou uma, e dois ou duas (EGASHIRA \& VIOLARO, 1992).

Foi recomendado ainda para essa fase de normalização que os caracteres acentuados fossem codificados em dois caracteres, como por exemplo, o á seria transformado em a' e o $̧$ tornar-se-ia c (OLIVEIRA et al, 1994). 
Esse procedimento possibilitaria que textos escritos em computadores de fabricantes diferentes, que utilizassem extensões de códigos ASCll distintos, pudessem ser tratados nas etapas seguintes alterando-se apenas o módulo de préprocessamento de texto.

A análise sintática é necessária não apenas para determinar a correta entonação do "pitch", mas também, para determinar a correta pronúncia de palavras como g[ó]sto, verbo, e g[o]sto, substantivo.

Em estudos realizados em um corpus da Língua Portuguesa, VIANA et al. (1991) verificaram que essas palavras, denominadas homógrafas heterófonas, ou seja, com a mesma grafia porém com pronúncias diferentes, constituiam cerca de $3 \%$ do corpus de teste.

$\mathrm{Na}$ conversão de letras para fonemas, na Lingua Portuguesa, um dos principais problemas encontrados pelos diversos autores, refere-se à transcrição das letras "e" e "o", quando pertencem à sílaba tônica de uma palavra, podendo ser pronunciadas respectivamente como [e] ou [é] e [o] ou [ó].

Poder-se-ia tentar formular algumas regras que mesmo não sendo adequadas a todas as situações, abrangeriam a maioria dos casos. No entanto, Egashira (EGASHIRA, 1992) comenta que seria necessário o acesso a medidas estatísticas de associação ortográfico-fonética. Além disso, deve-se considerar ainda o caso das palavras homógrafas heterófonas, que somente podem ter suas pronúncias determinadas após análise sintática.

Por esse motivo, é indispensável um dicionário de exceções, que contenha a transcrição de palavras que falhem à aplicação das regras..O mesmo ocorre para a letra " $x$ ", que pode ser associada a quatro fonemas diferentes, $[x]$ na palavra xale; [ks] na palavra fixo; [s] na palavra texto e [z] na palavra exame.

A Tabela 6 apresenta algumas regras para a conversão fonética dos fonemas $[x],[z]$ e [s], porém, deve-se notar mais uma vez que essas regras não serão suficientes para atender a todos os casos, devendo-se utilizar um dicionário de exceções. 


\begin{tabular}{|c|l|l|}
\hline Fonema & \multicolumn{1}{|c|}{ Ocorrência } & \multicolumn{1}{c|}{ Exemplo } \\
\hline$[\mathrm{x}]$ & $\begin{array}{l}\text { Inicio de palavra } \\
\text { Depois de "n" } \\
\text { Depois de "ai", "ei" e "ou" }\end{array}$ & $\begin{array}{l}\text { xícara, xarope } \\
\text { enxame, enxofre } \\
\text { caixa, eixo, frouxo }\end{array}$ \\
\hline$[z]$ & Palavras iniciadas com"ex" seguido de vogal & exame, exercício, exótico \\
\hline$[s]$ & Seguido de consoante & texto, sexto \\
\hline
\end{tabular}

\section{Tabela 6. Algumas regras para conversão fonética da letra "x".}

Alguns aspectos referentes à nasalidade das vogais foram destacados em CALLOU \& LEITE (1990), ressaltando dificuldades na transcrição de vogais nasais quando estas não estão marcadas com til. A nasalização das vogais ocorre em três situações distintas, quando a vogal é acentuada seguida de consoante nasal ([m] ou [n]); sempre que a vogal for seguida por consoante nasal e outra consoante, e quando a vogal estiver antes de consoante nasal em final de vocábulo.

Entretanto, existem exceções a essa regra, a qual não é capaz de distinguir "c[ã]minha" substantivo, de "c[a]minha" verbo. Nesses casos, as duas alternativas devem estar presentes no dicionário de exceções e a seleção da transcrição adequada ser dependente de uma análise sintática do texto de entrada.

Cabe ressaltar ainda a questão do "acento secundário" de algumas palavras derivadas por sufixação. Os sufixos -(z)inha e -(z)inho ocasionam nos radicais a que são acrescentados um comportamento diferente da maioria dos outros sufixos, na medida em que permitem a manutenção da qualidade da vogal do radical, como na palavra av[ó]zinha. Esse aspecto contraria a generalização de que em posição prétônica neutraliza-se o contraste entre /e/:lé/ e /o/:/ó/. O mesmo comportamento é apresentado também pelos sufixos -mente, -íssimo e -issima (CALLOU \& LEITE, 1990). 
No caso de palavras com o sufixo -mente a determinação do "acento secundário" torna-se mais simples uma vez que esse sufixo não altera a palavra à qual está sendo acrescentado, e portanto, procede-se à verificação da palavra obtida através da eliminação do sufixo, como por exemplo no caso da palavra fortemente $\rightarrow$ forte+mente $\rightarrow$ f[ó]rte+mente.

No entanto, a determinação do "acento secundário" torna-se um processo mais complexo no caso de palavras com os sufixos -íssimo(a) e -inho(a), pois é comum a supressão ou a mudança da vogal final, como nas palavras belo $\rightarrow$ belíssimo, excelente $\rightarrow$ excelentíssimo, amarelo $\rightarrow$ amarelinho, verde $\rightarrow$ verdinho.

\subsection{Considerações Finais}

Neste capitulo, foram apresentadas as diversas Tecnologias de Conversão Texto/Noz, que utilizam fonemas, existentes no mercado, tanto para a lingua inglesa quanto para a língua portuguesa. 


\section{Capítulo 5}

\section{Redes Neurais Artificiais}

\subsection{Introdução}

Este capitulo tem a finalidade de apresentar, em caráter introdutório, a funcionalidade de uma Rede Neural, para que seja obtida uma base de entendimento de como será utilizada esta tecnologia no Conversor Texto/Noz.

\subsection{Definição de Redes Neurais}

As Redes Neurais Artificiais estão sendo estudadas há alguns anos com o objetivo de alcançar o mesmo desempenho do ser humano, principalmente nas áreas do reconhecimento de padrões (LIPPMANN, 1987). O cérebro humano utiliza dois diferentes métodos para o processamento de informação (LAU, 1992):

1) processamento seqüencial e lógico utilizando simbolos;

2) processamento paralelo realizado pela dinâmica da interação mútua dos neurônios.

Assim as principais características das Redes Neurais são: paralelismo massivo, informação distribuida, aprendizado e processamento não-linear. Esta técnica possui vários diferentes modelos para diferentes tipos de aplicações, principalmente em: reconhecimento, predição, aproximação de funções e classificação.

Redes Neurais é uma técnica que pode realizar de maneira mais eficiente certas tarefas em comparação a outras técnicas. Neste capitulo, são apresentados resumidamente, os principais fundamentos de Redes Neurais e um de seus modelos, utilizado no projeto de Conversão Texto/Noz. 
Uma Rede Neural (RN) é um conjunto de "processadores" simples distribuídos paralelamente e altamente interconectados, tendo a capacidade de armazenar qualquer conhecimento experimental e fazer o seu uso.

Este conhecimento é adquirido através de um aprendizado e é armazenado nas conexões entre os neurônios (pesos sinápticos).

Com as características de aprendizagem, conexionismo e memória distribuída, as Redes Neurais assemelham-se ao cérebro humano (HAYKIN, 1994) (LIPPMANN, 1987) (LAU, 1992).

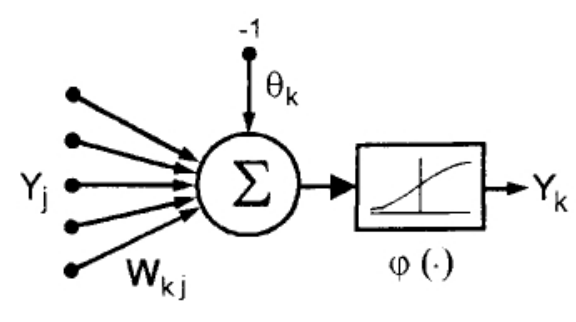

neurónio $k$

\section{Figura 8. Modelo matemático de um neurônio}

O modelo matemático do neurônio (Figura 8), unidade de processamento de uma Rede Neural, é composto basicamente por três componentes:

1) Conjunto de Conexões (ou sinapses), onde cada conexão tem associado um peso. Denotaremos o peso por: $\quad \mathbf{w}_{\mathrm{kj}}^{(\mathrm{c})}$, que representa uma conexão do j-ésimo neurônio da camada (c-1) para o k-ésimo neurônio da camada c. Uma conexão pode ser:
a) excitatória, quando $w_{\mathrm{kj}}^{(\mathrm{c})}>0$, ou
b) inibitória, quando $\mathrm{w}_{\mathrm{kj}}^{(\mathrm{c})}<0$.

Observação: quando não existe conexão, ${ }_{\mathrm{kj}}^{(\mathrm{c})}=0$.

2) Somador, faz o somatório dos valores de entrada multiplicados pelos seus respectivos pesos. Isto é: 
$\sum_{j} w_{k j}^{(c)} \cdot y_{j}^{(c-1)} \quad$, onde $y_{j}^{(c-1)}$ é a saída do neurônio j da camada (c-1) que está conectado ao neurônio k da camada c.

3) Função de Ativação (ou função de transferência) tem como entrada o resultado do somador e emite um sinal que corresponde à saída de um neurônio. A saída possui valores dentro dos seguintes intervalos típicos: $[0,1]$ ou $[-1,1]$.

Denominaremos aqui esta função por $\varphi(\cdot)$. Podem ser citados três tipos importantes de funções de ativação referenciadas nas Figuras 9.a, 9.b e 9.c, respectivamente como:

a) função limiar (thershold) ou degrau unitário;

b) função parcialmente linear;

c) função sigmoidal logística.

A função sigmoidal (1) é utilizada em redes que são submetidas a processos de aprendizados que utilizam derivadas, por exemplo Regra Delta Generalizada (RUMELHART, 1986). Sua derivada (2) é simples, simplificando o seu cálculo. A função sigmoidal logística tem resposta somente no intervalo $[0,1]$. O parâmetro $\lambda$ da função sigmoidal provoca o "efeito de aproximação com a função limiar", mostrado na Figuras 9.c, 9.d e 9.e. Para neurônios que tem ativação no intervalo $[-1,1]$, utiliza-se como função de ativação a tangente hiperbólica (3) que tem comportamento semelhante a sigmoidal logistica.

$$
\begin{aligned}
& \varphi(x)=\frac{1}{1+\exp (-\lambda \cdot x)} \quad 0<\varphi(x)<1 \\
& \varphi^{\prime}(x)=\lambda \cdot \varphi(x) \cdot[1-\varphi(x)] \\
& \varphi(x)=\tanh \left(\frac{\lambda \cdot x}{2}\right)=\frac{1-\exp (-\lambda \cdot x)}{1+\exp (-\lambda \cdot x)}-1<\varphi(x)<1
\end{aligned}
$$




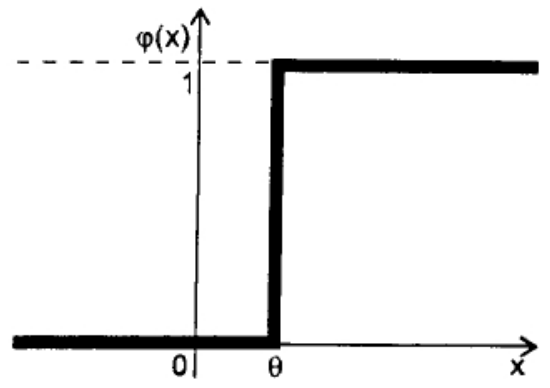

(a)

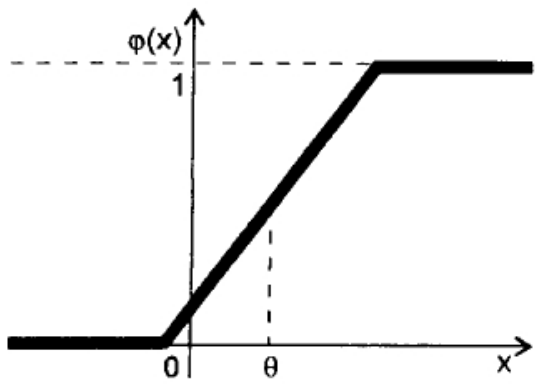

(b)

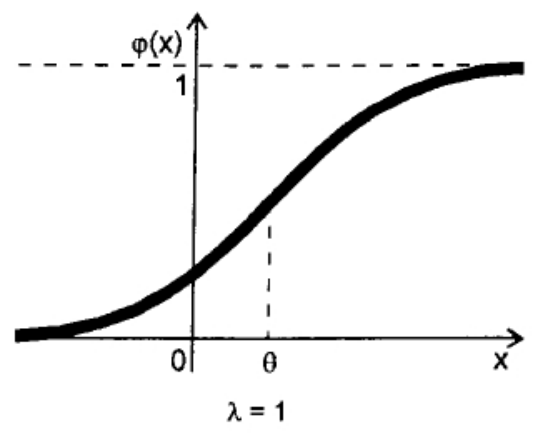

(c)

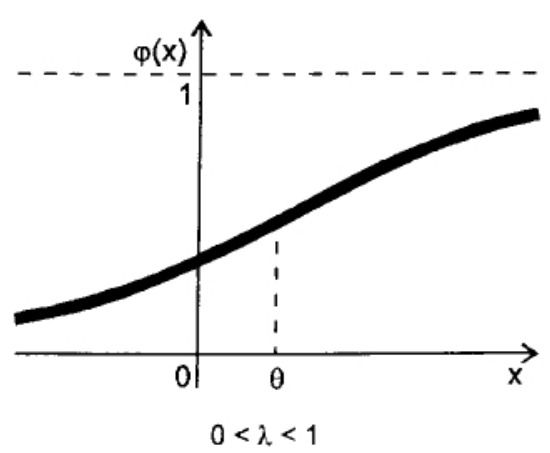

(d)

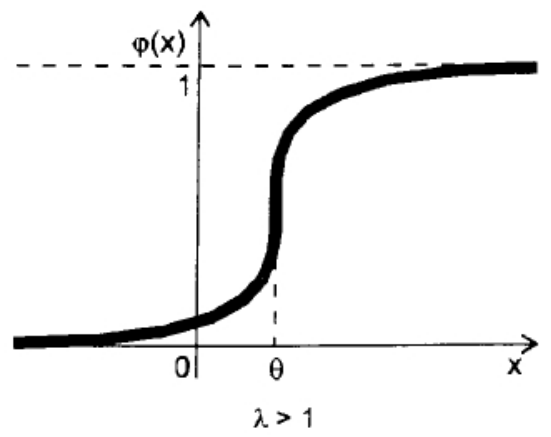

(e)

Figura 9. Funções de Ativação 
O neurônio pode ter um parâmetro $\theta$ denominado de limiar (threshold) que funciona como uma resistência, de sinal positivo ou negativo, para o sinal de ativação. Este limiar pode diminuir ou aumentar o resultado do somador.

\subsection{Aprendizado}

A característica mais importante das Redes Neurais é a capacidade de aprender. A Rede Neural recebe na sua entrada estímulos do ambiente exterior e responde produzindo uma saida, mas para que esta saida seja a resposta correta, a rede passa por um processo de aprendizado.

"Aprendizado é um processo pelo qual os parâmetros livres de uma Rede Neural são adaptados através de um processo contínuo de estímulo pelo ambiente no qual a rede é incorporada. O tipo de aprendizado é determinado pela maneira na qual as mudanças nos parâmetros são realizadas." (HAYKIN, 1994)

Esta definição determina a existência de três etapas distintas no aprendizado:

1) A Rede Neural é estimulada por um ambiente;

2) A Rede Neural muda com um resultado deste estímulo;

3) A Rede Neural responde de um novo modo ao ambiente, em função das mudanças que ocorreram na sua estrutura interna.

No processo de aprendizado os pesos sinápticos são os parâmetros livres que sofrem mudanças. O algoritmo utilizado no aprendizado da rede do sistema, é o denominado algoritmo Back-Propagation ou Regra Delta Generalizada (RUMELHART,1986). Este algoritmo é do tipo aprendizado supervisionado e pode ser observado na seção 5.4.1. 
Nos algoritmos de paradigma aprendizado supervisionado, a figura do professor é a característica típica que o diferencia dos demais. O professor sabe responder corretamente ao ambiente, ou seja ele conhece as saídas desejadas que a Rede Neural deve responder. No processo de aprendizado, a cada iteração a rede é estimulada pelo ambiente, fornecendo a ele, uma resposta. A saida que a rede produziu é comparada com a resposta desejada, fornecida pelo professor. O erro entre as duas respostas é a base para a mudança, ou correção, dos parâmetros livres da rede. A cada iteração a rede sofre uma nova correção. E esta seqüência - estimular, responder, comparar e corrigir - é repetida, até que as diferenças entre as respostas e os erros, sejam toleráveis (HAYKIN, 1994) (LAU, 1992).

Deste modo, através da correção dos parâmetros livres da Rede Neural, o professor transfere seu conhecimento à rede, tornando-a hábil à realização da tarefa a qual é destinada.

Este processo de aprendizado pode ocorrer de modo estático ou dinâmico. No modo estático, o aprendizado é executado até que o desempenho desejado da rede seja obtido. Isto ocorre quando os pesos obtidos são fixados em seus valores atuais, ou seja, a rede não é mais submetida ao aprendizado. No modo dinâmico, o aprendizado ocorre em tempo real de utilização da rede, tendo assim um processo contínuo de aprendizado (HAYKIN, 1994).

O modo estático foi adotado no processo de aprendizado do nosso projeto. Um motivo para utilizá-lo é que o usuário deseja um sistema que transforme texto em voz sem que ele faça qualquer alteração no sistema, ou seja, preste manutenção.

\subsection{Perceptron Multi-Camadas}

A rede Perceptron Multi-Camadas (Multi-Layer Perceptron - MLP), uma das Redes Neurais mais populares, é uma generalização do Perceptron, proposto por Rosenblatt (LIPPMANN, 1987).

A rede MLP possui três características que a distingue (HAYKIN, 1994):

1) Capacidade de não-linearidade intrínseca; 
2) Possui na sua topologia camadas intermediárias;

3) Alto grau de conectividade.

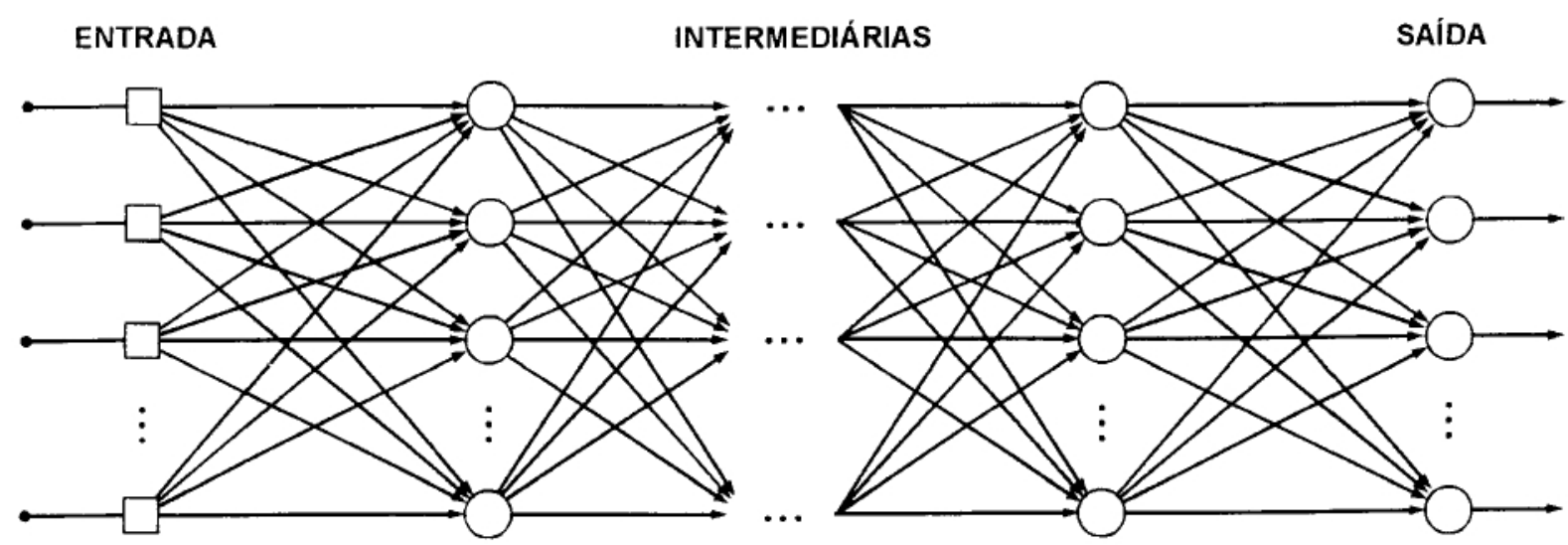

Figura 10. Topologia genérica de MLP

Considerando uma rede MLP como a mostrada na Figura 10, os neurônios da camada de entrada não modificam a sua entrada, apenas transferem-na para a sua saída, ou seja, $y_{j}^{(0)}(n)=x_{j}(n)$, onde $x_{j}(n)$ é a j-ésima componente da entrada de número n apresentada ao j-ésimo neurônio da camada de entrada (camada 0). A saída da rede é o conjunto da saída dos neurônios da camada de saída (camada C), ou seja, $o_{j}(n)=y_{j}^{(C)}(n)$

Podem existir, nesta topologia, inúmeras camadas intermediárias entre as camadas de entrada e saída. Todo neurônio da camada c envia uma saída para todos os neurônios da camada c+1 (a direita na Figura 10) e recebe uma entrada de cada neurônio da camada c-1 (a esquerda na Figura 10), através das conexões existentes entre as camadas. A cada conexão está associado um peso w. Não existem conexões entre neurônios da mesma camada. Nenhum neurônio recebe na sua entrada o seu próprio sinal de saída. $E$ também, não existe nenhuma forma de realimentação da saída da rede para a entrada da rede.

A rede MLP geralmente é usada para estabelecer um mapeamento entre dois conjuntos de dados. Desta forma, a cada entrada apresentada à rede, uma correspondente saída desejada deve também ser fornecida. O conjunto que contém 
todos os $\mathrm{N}$ pares de exemplos de entrada/saida é denominado conjunto de treinamento. Sendo fornecidas à rede as entradas e saídas, as variáveis restantes a serem determinadas são os pesos sinápticos.

\section{- Quantidade de Camadas Intermediárias}

A topologia do MLP pode conter várias camadas intermediárias. O Teorema da Aproximação Universal (HAYKIN, 1994) especifica que apenas uma camada intermediária é suficiente para que a rede MLP compute uma aproximação uniforme da função objetivo para um dado conjunto de treinamento.

Este teorema indica o número de camadas intermediárias - uma -, mas não especifica o número de neurônios desta camada.

\subsubsection{Algoritmo Back-Propagation}

O processo de aprendizado da rede MLP é do tipo aprendizado supervisionado, onde a partir de uma entrada apresentada à rede, ela produz uma saída, que é comparada com a saída desejada, gerando um erro de saída. Os pesos da rede são modificados baseado no erro que é propagado da saída para a entrada. Esta modificação tem a finalidade de minimizar o erro médio ou total, dependendo do critério adotado.

O erro quadrático $E(n)$, referente a cada par $n$ apresentado à rede, pode ser definido por: $E(n)=\frac{1}{2} \sum_{j=1}^{M} e_{j}^{2}(n)$ onde $e_{j}(n)=d_{j}(n)-o_{j}(n)$ é o erro do j-ésimo neurônio da camada ${ }^{2} \mathrm{j=1}$ de saída e $M$ é o número de neurônios na camada de saída. Este erro é a diferença entre a saída desejada $d_{j}(n)$ e a atual $o_{j}(n)$. O erro quadrático médio para o conjunto de treinamento é definido através da seguinte equação: $\quad E_{a v}=\frac{1}{N} \sum_{n=1}^{N} E(n)$ onde $N$ é o número de pares do conjunto de treinamento. 
A saída $y_{j}^{(c)}(n)$ do j-ésimo neurônio da camada c é dada em (4), onde $\theta_{j}{ }^{(c)}(n)$ é o limiar associado a este neurônio, utilizando a função sigmoidal (1) como função de ativação.

$$
y_{j}^{(c)}(n)=\varphi\left(\sum_{i} w_{j i}^{(c)}(n) \cdot y_{i}^{(c-1)}(n)-\theta_{j}^{(c)}(n)\right)
$$

A atualização dos pesos é definida por (5), onde se acrescenta uma correção para a próxima iteração. A correção do peso, definida por (6), é composta por uma fração da correção anterior e por uma fração do gradiente local do neurônio j multiplicada por sua entrada.

$$
\begin{aligned}
& w_{j i}^{(c)}(n+1)=w_{j i}^{(c)}(n)+\Delta w_{j i}^{(c)}(n) \\
& \Delta w_{j i}^{(c)}(n)=\alpha \cdot \Delta w_{j i}^{(c)}(n-1)+\eta \cdot \delta_{j}^{(c)}(n) \cdot y_{i}^{(c-1)}(n)
\end{aligned}
$$

De acordo com Rumelhart (RUMELHART, 1986), a Regra Delta Generalizada usando a função de ativação sigmoidal é dada em (7) para a camada de saída (camada C) e em (8) para uma camada intermediária (camada de 1 a C-1).

$$
\begin{aligned}
& \delta_{j}^{(C)}(n)=e_{j}(n) \cdot o_{j}(n) \cdot\left[1-o_{j}(n)\right] \\
& \delta_{j}^{(c)}(n)=y_{j}^{(c)}(n) \cdot\left[1-y_{j}^{(c)}(n)\right] \cdot \sum_{k} \delta_{k}^{(c+1)}(n) \cdot w_{k j}^{(c+1)}(n)
\end{aligned}
$$


A velocidade de aprendizado $\eta$ é a constante de proporcionalidade requerida pelo processo de aprendizado na mudança dos pesos com relação a $\partial \mathrm{E}(\mathrm{n}) / \partial \mathrm{w}$. Para este parâmetro do aprendizado onde $0<\eta<1$, quanto maior o seu valor, maior as mudanças nos pesos. Rumelhart sugere que se adote o maior valor possivel para o parâmetro velocidade de aprendizado, que não provoque oscilações nas mudanças dos pesos. Em geral, o valor de $\eta$ assume um valor fixado de forma empírica. Na maioria das vezes realizam-se vários aprendizados com valores diferentes de $\eta$.

Rumelhart (RUMELHART, 1986) sugere também que se acrescente um termo momentum $\alpha$, onde $0<\alpha<1$. Este parâmetro determina o efeito das mudanças anteriores nos pesos na direção das mudanças atuais. Isto significa fornecer uma memória ao processo de atualização dos pesos.

A aplicação da Regra Delta Generalizada envolve duas fases. Na primeira fase, uma entrada $\mathrm{n}$ é apresentada e propagada para frente (forward) através da rede, para calcular a saída $o_{j}(n)$ de cada neurônio da camada de saída. Esta saída é comparada com a saída desejada, resultando no gradiente local do erro $\delta_{j}^{(\mathrm{c})}$ (n) para cada neurônio da camada de saida.

A segunda fase envolve um sentido reverso (backward) através da rede, durante o qual o erro é propagado para o neurônio da camada anterior e as mudanças nos pesos são realizadas.

Por este motivo este procedimento - esquema de atualização dos pesos juntamente com a aplicação da Regra Delta Generalizada - é conhecido como Algoritmo Back-Propagation (BP). Pode-se dizer que, no sentido forward, a rede avalia a função erro e, no sentido backward, o seu gradiente.

Redes Multi-Camadas que usam a Regra Delta Generalizada são também conhecidas como Redes Multi-Camadas Feed-Forward.

A seguir, é apresentado o algoritmo Back-propagation. 
Passo 1. Inicialização dos pesos.

Passo 2. Apresentação das entradas e saídas desejadas.

$$
y_{j}^{(0)}(n)=x_{j}(n) \quad \text { e } \quad d_{j}(n)
$$

Passo 3. Calcular a saída atual.

$$
\begin{aligned}
& y_{j}^{(c)}(n)=\varphi\left(\sum_{i} w_{j i}^{(c)}(n) \cdot y_{i}^{(c-1)}(n)-\theta_{j}^{(c)}(n)\right) \\
& o_{j}(n)=y_{j}^{(C)}(n)
\end{aligned}
$$

Passo 4. Calcular o erro e o gradiente local.

$$
\begin{aligned}
& e_{j}(n)=d_{j}(n)-o_{j}(n) \\
& \delta_{j}^{(C)}(n)=e_{j}(n) \cdot o_{j}(n) \cdot\left[1-o_{j}(n)\right] \\
& \delta_{j}^{(c)}(n)=y_{j}^{(c)}(n) \cdot\left[1-y_{j}^{(c)}(n)\right] \cdot \sum_{k} \delta_{k}^{(c+1)}(n) \cdot w_{k j}^{(c+1)}(n)
\end{aligned}
$$

Passo 5. Atualizar os pesos.

$$
\begin{array}{ll}
\mathrm{w}_{\mathrm{ji}}^{(\mathrm{c})}(\mathrm{n}+1)=\mathrm{w}_{\mathrm{ji}}^{(\mathrm{c})}(\mathrm{n})+\Delta \mathrm{w}_{\mathrm{ji}}^{(\mathrm{c})}(\mathrm{n}) \\
\Delta \mathrm{w}_{\mathrm{ji}}^{(\mathrm{c})}(\mathrm{n})=\alpha \cdot \Delta \mathrm{w}_{\mathrm{ji}}^{(\mathrm{c})}(\mathrm{n}-1)+\eta \cdot \delta_{\mathrm{j}}^{(\mathrm{c})}(\mathrm{n}) \cdot \mathrm{y}_{\mathrm{i}}^{(\mathrm{c}-1)}(\mathrm{n}) \\
\begin{array}{cc}
\alpha \text { momentum } & \eta \text { velocidade de aprendizado } \\
0<\alpha<1 & 0<\eta<1
\end{array}
\end{array}
$$

Passo 6. Se erro inaceitável, então voltar para passo 2, senão fim.

$$
E_{a v}=\frac{1}{N} \sum_{n=1}^{N} E(n), \quad \text { onde } E(n)=\frac{1}{2} \sum_{j=1}^{M} e_{j}^{2}(n)
$$




\section{- Mínimo Local}

O Problema do Mínimo Local é descrito como a possibilidade do processo de aprendizado encontrar um mínimo local da função erro que está sendo minimizada. O problema existe quando o erro encontrado é maior que o erro admissivel (aceitável), e a RN não consegue encontrar um ponto com erro menor. Conseqüentemente, isto impossibilita que o algoritmo de aprendizado, que é do tipo "gradiente descendente", alcance o mínimo desejado, e assim, a rede não consegue mapear corretamente 0 conjunto de treinamento.

A única solução é reinicializar o aprendizado, alterando alguns dos parâmetros livres da rede, como a velocidade de aprendizado ou o momentum, ou apenas inicializando os pesos com outros valores.

\section{- Modo Padrão e Modo Batch}

Denominamos de ciclo, uma apresentação de todos os $\mathrm{N}$ pares do conjunto de treinamento no processo de aprendizado. Com relação à correção dos pesos em um ciclo, o aprendizado Back-propagation pode ser executado de dois modos:

1) Modo Padrão: neste modo, a correção dos pesos acontece a cada apresentação de um par do conjunto de treinamento. Ou seja, em um ciclo ocorrem $\mathrm{N}$ correções de pesos. Cada correção de pesos baseia-se somente no erro do par apresentado naquela iteração. A cada ciclo altera-se, aleatoriamente, a ordem de apresentação dos pares. Isto proporciona uma pesquisa estocástica no espaço dos pesos sinápticos (HAYKIN, 1994).

2) Modo Batch: neste modo, temos apenas uma única correção de pesos por ciclo. Primeiramente, todos os pares do conjunto de treinamento são propagados pela rede e o erro é calculado para cada par. Em seguida calcula-se o erro quadrático médio dos pares e utilizando este erro, $E_{a v}=\frac{1}{N} \sum_{n=1}^{N} E(n)$, faz-se as correções dos pesos. 
Do ponto de vista prático, prefere-se o modo Padrão ao invés do modo Batch, devido ao menor armazenamento de dados para o modo Padrão. Além disto, o modo Padrão, devido à pesquisa estocástica que realiza, é menos suscetível ao problema do Mínimo Local (HAYKIN, 1994).

\section{- Inicialização}

A inicialização dos pesos é feita de forma aleatória, recomendando-se que os valores dos pesos sejam de pequena magnitude e estejam distribuídos uniformemente (LIPPMANN, 1987). Na Rede Neural de nosso sistema, os pesos são inicializados com valores no intervalo $[-0,1 ; 0,1]$.

\section{- Critério de Parada}

O Critério de Parada do algoritmo Back-propagation não é bem definido (HAYKIN, 1994). Assim para considerarmos que o algoritmo convergiu, adotamos neste trabalho o seguinte Critério de Parada: o algoritmo Back-propagation, adotando-se o modo padrão, converge quando o erro quadrático médio por ciclo é suficientemente pequeno, ou seja, é menor que o erro admissível. O erro admissivel, portanto, é o valor do erro da rede que consideramos como aceitável.

\subsubsection{Generalização}

Generalização é uma das mais importantes características das Redes Neurais. O principal fator que determina uma ótima generalização é o conjunto de treinamento da Rede Neural, que deve ser muito bem escolhido. Este deverá expressar as características gerais do universo de discurso. Isto implica em dispor de vários exemplos de cada classe a ser treinada; que seria o ideal. A escolha dos exemplos deve estar sempre bem fundamentada na caracterização do universo de discurso. 
A Figura 11, a seguir, mostra a influência da escolha de exemplos na generalização da Rede Neural.

Se quiséssemos que a Rede Neural aproximasse a função da Figura 11.a, deveríamos escolher pontos que representassem esta função.

Nas Figuras 11.b, 11.c e 11.d, observamos três situações diferentes de resposta da Rede Neural.

Na Figura 11.b, a pouca quantidade de exemplos no treinamento fez com que a Rede Neural respondesse precariamente, ou seja, nota-se uma péssima aproximação da função desejada.

Na Figura 11.c, mesmo com mais exemplos, a função desejada não foi obtida. O motivo para este erro foi à escolha concentrada de exemplos, ocorreu uma particularização do universo.

Já, na Figura 11.d, temos uma boa aproximação, advinda de uma boa escolha e quantidade de exemplos, que é a mesma da Figura 11.c, quatro, porém bem distribuídos.

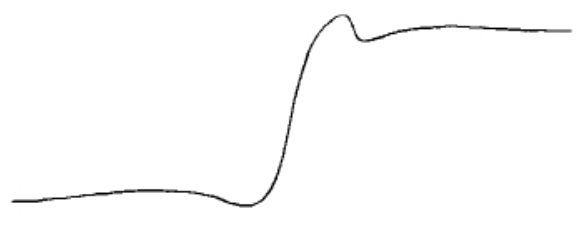

(a)

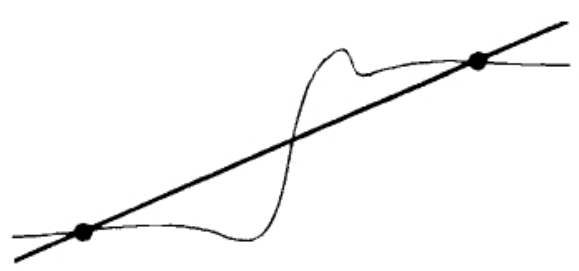

(b)

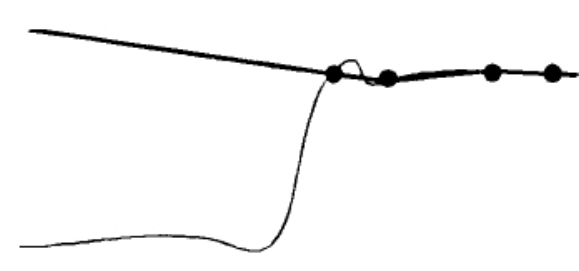

(c)

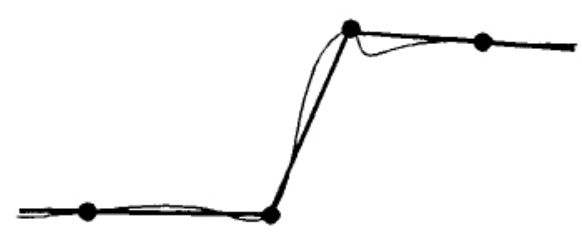

(d)

Figura 11. Problemas na generalização 


\subsubsection{Erro}

Um dos parâmetros livres a ser definido em Back-propagation é o valor do erro admissivel, que faz parte do Critério de Parada deste algoritmo. Qual será um valor aceitável de erro? A princípio podemos pensar que um erro de valor zero é o correto, pois assim a rede saberia fazer o mapeamento que the foi apresentado. Porém, a rede somente estaria apta a fazer o mapeamento das entradas contidas no conjunto de treinamento. Perderiamos toda a capacidade de generalização. Estariamos tornando a rede especialista em um conjunto pequeno do universo de mapeamento. Isto só é conveniente quando o conjunto de treinamento é composto por todo o universo de mapeamento (por exemplo, é o caso da operação lógica OU-Exclusivo, que possui apenas quatro possibilidades de entrada).

Podemos utilizar o seguinte procedimento para evitar este problema: inicia-se o aprendizado com um valor para o erro admissível e diminui-se até a generalização começar a degenerar. Este é o ponto ótimo do mínimo erro no aprendizado com a máxima generalização. Na Figura 12, observamos quando ocorre este ponto de mínimomáximo. Este procedimento aqui descrito será denominado de "refinamento do aprendizado".

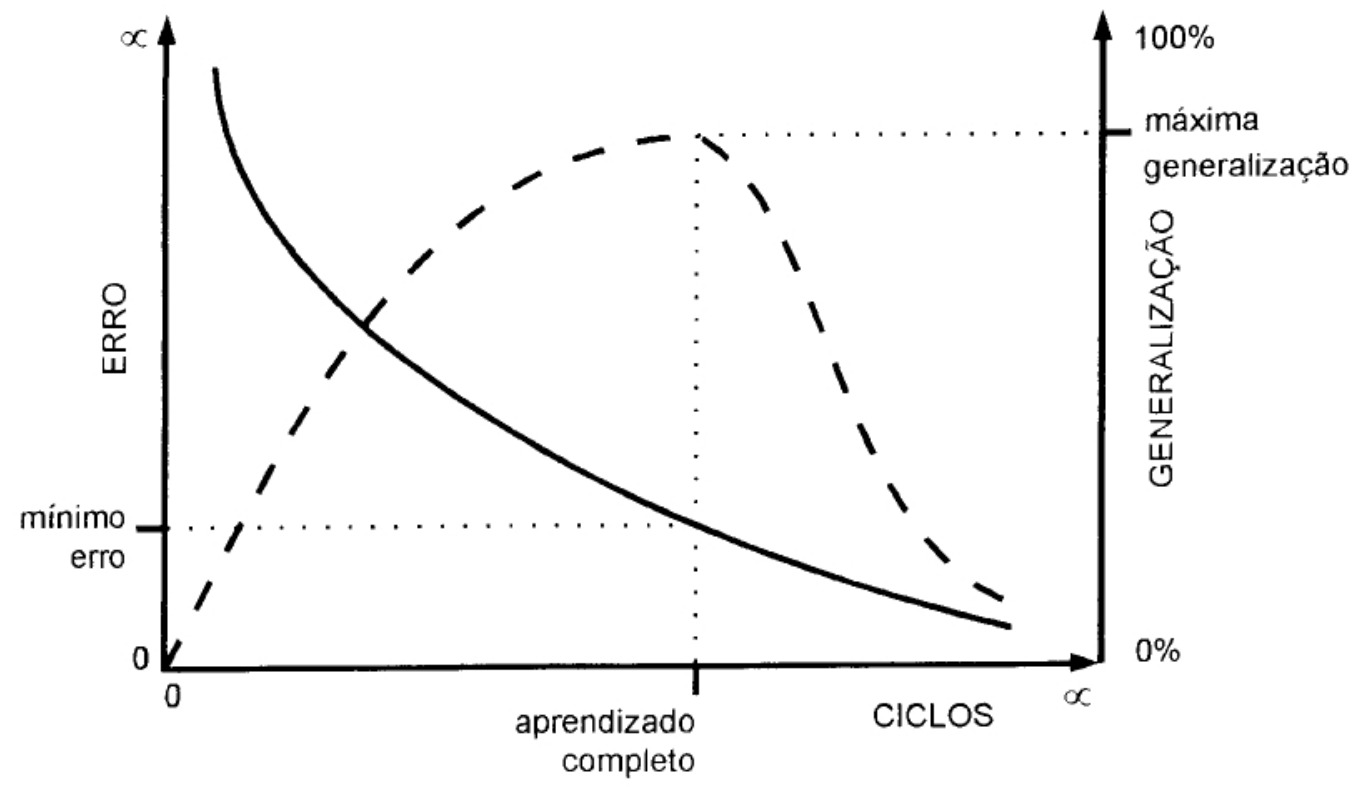

Figura I2. Aprendizado completo

A minimização do erro está sujeita à capacidade da rede de generalizar. 


\subsubsection{Validação}

A rede MLP e a algoritmo Back-Propagation possuem certos parâmetros livres que não possuem uma regra para determiná-los. Assim necessitamos de técnicas que auxiliem na determinação dos valores ótimos destes parâmetros.

\section{- Classificador Bayesiano}

Uma técnica de determinação da topologia "ótima", em especifico das camadas intermediárias, é a utilização do Classificador Bayesiano, citada em (HAYKIN, 1994). Comparando o resultado de classificação da Rede Neural com o resultado fornecido por este classificador, podemos determinar se a topologia é ou não aceitável, ou seja, ela deve responder de modo semelhante ao classificador.

Não utilizamos a técnica do Classificador Bayesiano, porque a sua implementação não é uma tarefa trivial para o nosso caso, uma vez que envolve cálculos de integrais dificeis de serem efetuados e não abordadas neste trabalho.

\section{- Validação Cruzada}

Outra técnica é utilizar a Validação Cruzada (HAYKIN, 1994). A Validação Cruzada consiste em dividir o conjunto de treinamento em dois subconjuntos distintos:

1) um subconjunto usado para o aprendizado da rede, denominado de subconjunto de treinamento;

2) um subconjunto usado na validação da rede, denominado de subconjunto de validação. O conjunto de validação corresponde a uma parte pequena do conjunto de treinamento, variando entre $10 \%$ a $20 \%$ de seu tamanho.

Além do conjunto de treinamento, deve existir também um conjunto denominado conjunto de teste.

O processo consiste em executar normalmente o aprendizado com o subconjunto de treinamento e em seguida testar a performance da rede com o subconjunto de validação. Após encontrar a topologia "ótima", a rede é novamente treinada com todo o 
conjunto de treinamento. Só então o conjunto de teste é utilizado para verificar a capacidade de generalização da rede. Estes resultados auxiliam na escolha da melhor topologia de rede, no aspecto de generalização.

\subsection{Considerações Finais}

Neste capitulo, uma descrição da técnica de Redes Neurais Artificiais foi realizada, focalizando conceitos importantes para o entendimento e ressaltando as características das Redes Neurais, em especial do Perceptron Multi-Camadas (MLP), que são importantes para o projeto desenvolvido.

O aprendizado é uma das características pela qual foi decidido fazer uso de Redes Neurais no mapeamento do Conversor Texto/Noz.

Um dos principais objetivos é o de aprender, a partir do conjunto de treinamento, o mapeamento Texto-Fonemas.

Outra característica da rede MLP - generalização - considerada importante na decisão de usar Redes Neurais, foi levada em consideração, que é a de permitir cobrir o vocabulário da língua portuguesa a partir de um pequeno e significativo subconjunto do universo de discurso. 


\section{Capítulo 6 \\ O Conversor Texto/Voz com a Rede Neural}

\subsection{Introdução}

Neste capitulo, é apresentada a metodologia de criação do Conversor Texto/Noz onde são apresentados os arquivos necessários para este tipo de técnica e os softwares utilizados para realizar a criação do conversor. É também comentado o funcionamento do processo de sonorização dos arquivos de áudio, fundamentais para a realização do conversor.

\subsection{Criação do Conversor}

Para o desenvolvimento deste projeto foi utilizado um sistema que realiza conversão de texto para voz através de fonemas utilizando Redes Neurais Artificiais (RNA). O banco de dados, ou mais especificamente, banco de fonemas, foi gerado durante o Projeto "Máquina Falante" (PROSDÓCIMO, 1996). No entanto, várias adaptações foram realizadas com a intenção de melhorar a saída de áudio do mesmo.

A utilização de RNA no mapeamento do sistema Conversor Texto/Noz, ocorreu devido, principalmente, a duas características básicas: o aprendizado, com o objetivo de absorver, a partir do conjunto de treinamento, o mapeamento Texto-Fonemas e a generalização que é responsável pela característica do MLP de permitir cobrir o vocabulário da língua portuguesa a partir de um pequeno e significativo subconjunto do universo de discurso.

Para a realização desta etapa, foi necessário inicialmente criar alguns arquivos e softwares detalhados a seguir. 


\subsubsection{Arquivos digitais dos fonemas da Língua Portuguesa}

São arquivos digitais de sons básicos, correspondentes aos 33 fonemas usados para representar os sons da fala na Lingua Portuguesa falada no Brasil. Estes fonemas foram gerados em formato WAV PCM com $11.025 \mathrm{~Hz}, 8$ Bit, Mono com o intuito de deixar os arquivos curtos e não causar demora no processo de conversão.

\subsubsection{Arquivos de abreviaturas reconhecíveis}

Esses arquivos são formados por uma lista linear contendo nós estruturados, onde cada abreviatura, de até 6 caracteres, pode ser interpretada por um software de normalização de texto, sendo este o responsável pela substituição do seu equivalente em extenso.

\subsubsection{Software normalizador do texto de entrada}

Processo responsável pela expansão de abreviaturas para a sua forma escrita extensa, assim como a expansão de números, quantias monetárias, datas e outros caracteres não alfabéticos, transformando-os em um arquivo padrão.

\subsubsection{Software de transformação dos caracteres para fonemas e montagem do vocábulo digital}

Tem como objetivo transformar os vocábulos do arquivo padrão em um conjunto de fonemas, a partir dos quais obtém-se os sons digitalizados correspondentes, que estão armazenados em forma de arquivo; montando-se então o vocábulo digital na forma de um arquivo de áudio. 


\subsubsection{Software de sonorização do arquivo de áudio}

Um vocábulo digital que é um arquivo de áudio (header + dados digitais) é enviado para um buffer em pacotes de 1 Kbyte e de lá para o /dev/audio, resultando na emissão sonora. Este processo é repetido até chegar ao final do arquivo de áudio, que contém o vocábulo.

Além da criação destes arquivos e softwares acima apresentados, é importante salientar os Módulos do Sistema de Conversão Texto/Noz. A estrutura básica de funcionamento é composta por: um Módulo Normalizador, um Módulo Fonemizador, um Módulo de Mapeamento e Montagem e ainda um Módulo de Sonorização que, trabalhando em conjunto, são responsáveis pela criação do arquivo de voz.

Todo este processo de Conversão Texto/Noz pode ser representado na Figura 13, apresentada a seguir.

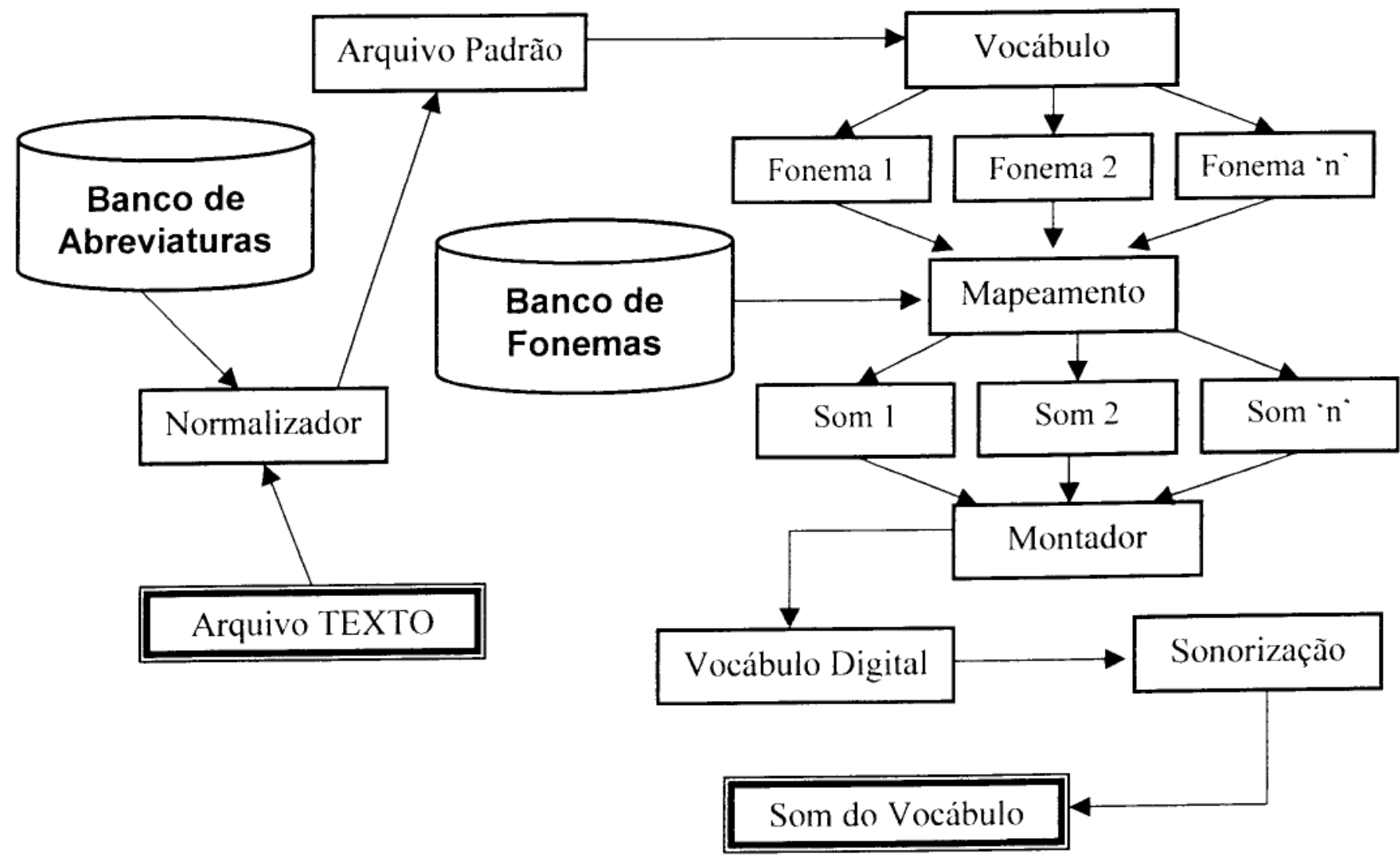

Figura 13. Visão Detalhada da Conversão Texto/Voz 
Em breves palavras, analisando superficialmente a figura acima, o processo de Conversão Texto/Noz pode ser descrito da seguinte forma:

A partir de um arquivo texto qualquer, este é submetido a um normalizador que com o auxílio de um banco de abreviaturas, caso necessário, gera o entendimento de seus fonemas que então são convertidos em um arquivo padrão, constituido por vocábulos. O vocábulo então é dividido em fonemas e estes fonemas são mapeados com o auxílio de um banco de fonemas previamente criado, retornando assim os sons correspondentes aos fonemas separados. Com o auxílio de um montador, é gerado o vocábulo digital da palavra inteira ou frase, sendo possível, com a sua sonorização, a audição do som do vocábulo digital.

\subsection{Projeto Máquina Falante}

Nesta seção, é apresentado o sistema "Máquina Falante", que é o sistema escolhido para realizar a tarefa de Conversão TextoNoz. Este sistema já vinha sendo desenvolvido junto ao LABIC - Laboratório de Inteligência Computacional do ICMC, e necessitava de algumas adaptações para que pudesse ser utilizado no Leitor de $E$ mails, proposto neste projeto. Optou-se por utilizar este sistema, pois ele tem a vantagem de fornecer uma voz mais próxima à humana e não uma voz sintetizada. (PROSDÓCIMO, 1996).

O Projeto Máquina falante é Composto por um Subsistema de Mapeamento, um Módulo Pré-processador de Voz e um Subsistema de Sintese, além do Módulo de Rede Neural, detalhados nesta seção.

As Linguagens usadas no projeto foram C ANSI, no módulo de Redes Neurais, e C++ para interface com sistemas GUI (Graphical User Interface)

Genericamente, a Conversão Texto/Noz no sistema Máquina Falante pode ser representada na Figura 14, onde temos um texto qualquer a ser convertido que é submetido a uma janela de texto para tirar a sujeira (ver seção 6.3.2) e então submetido a um mapeamento (ver seção 6.3.1) gerando o pacote de fonemas para ser, em seguida, submetido a um Sintetizador de voz (ver seção 6.3.3) gerando finalmente o som do texto convertido. 


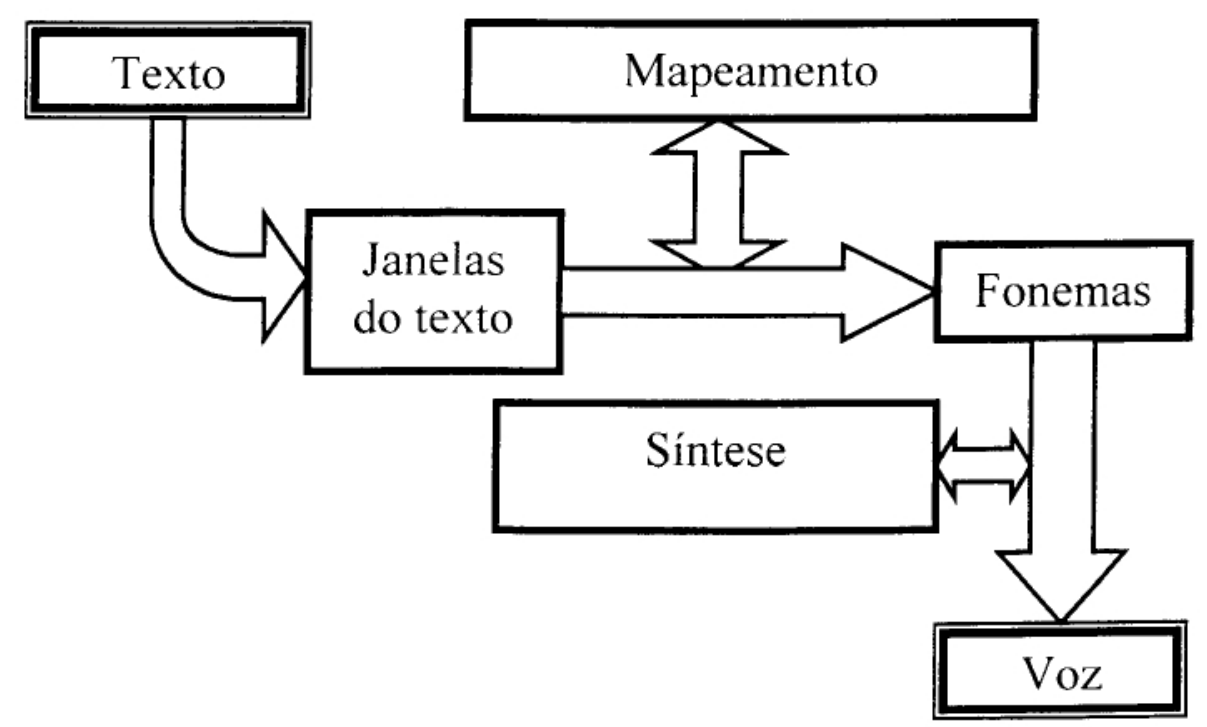

Figura 14. Visão Geral da Conversão Texto/Voz no "Máquina Falante"

É interessante ressaltar que os subsistemas de Mapeamento e Síntese são completamente separados.

Em sistemas operacionais multitarefas estes subsistemas podem ser implementados como processos distintos, sendo o processo correspondente ao subsistema de Mapeamento, um produtor, e o processo correspondente ao subsistema de Síntese, um consumidor.

A comunicação é unidirecional e a mensagem a ser trocada corresponde aos fonemas transcritos do texto a ser sintetizado. A troca de dados é feita através de um conjunto de dados, denominado Pacote de Fonemas, que contém todos os fonemas, ordenados, de uma palavra.

$O$ banco de fonemas contém também um fonema específico chamado pausa, gerada pelo espaço em branco, com a função de separador de palavras, determinando o fim do processamento de um Pacote de Fonemas.

$\mathrm{Na}$ Figura 15 é apresentado um exemplo que ilustra o uso de algumas informações básicas envolvidas no sistema. No exemplo, a frase "minha casa verde" é convertida em fonemas distintos, para que depois estes possam ser convertidos em seu áudio correspondente. 
minha casa verde

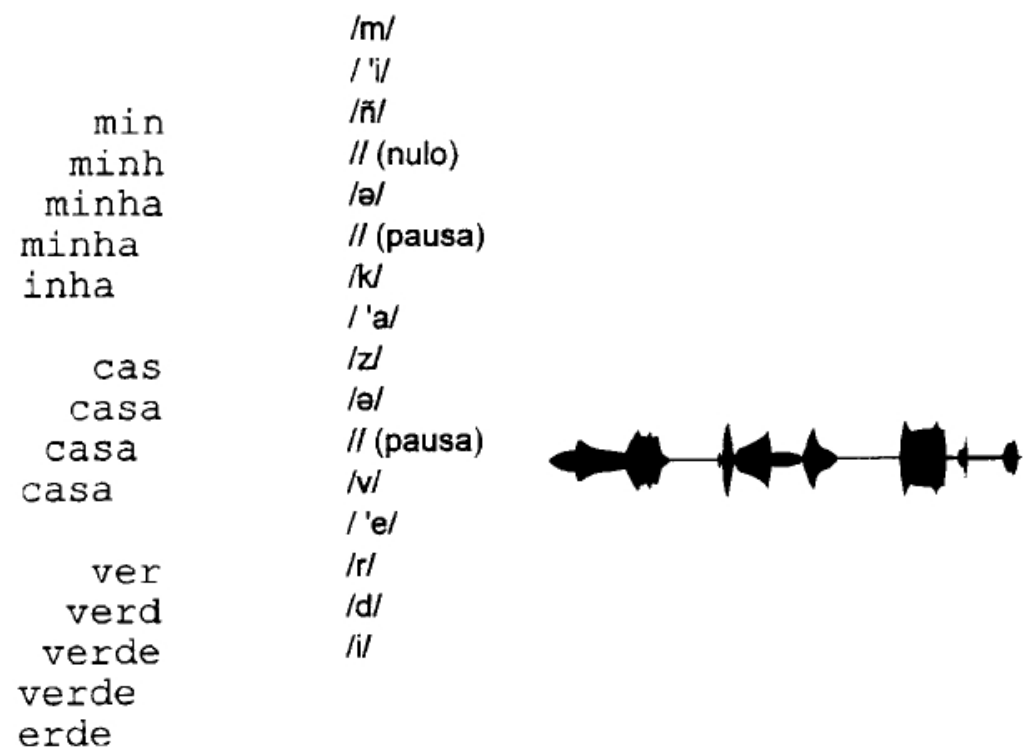

Figura 15. Dados produzidos no sistema Texto-Fonema-Voz

\subsubsection{Subsistema de Mapeamento}

O Subsistema de Mapeamento é constituído por dois módulos que são o Préprocessador de Texto e o módulo de Rede Neural.

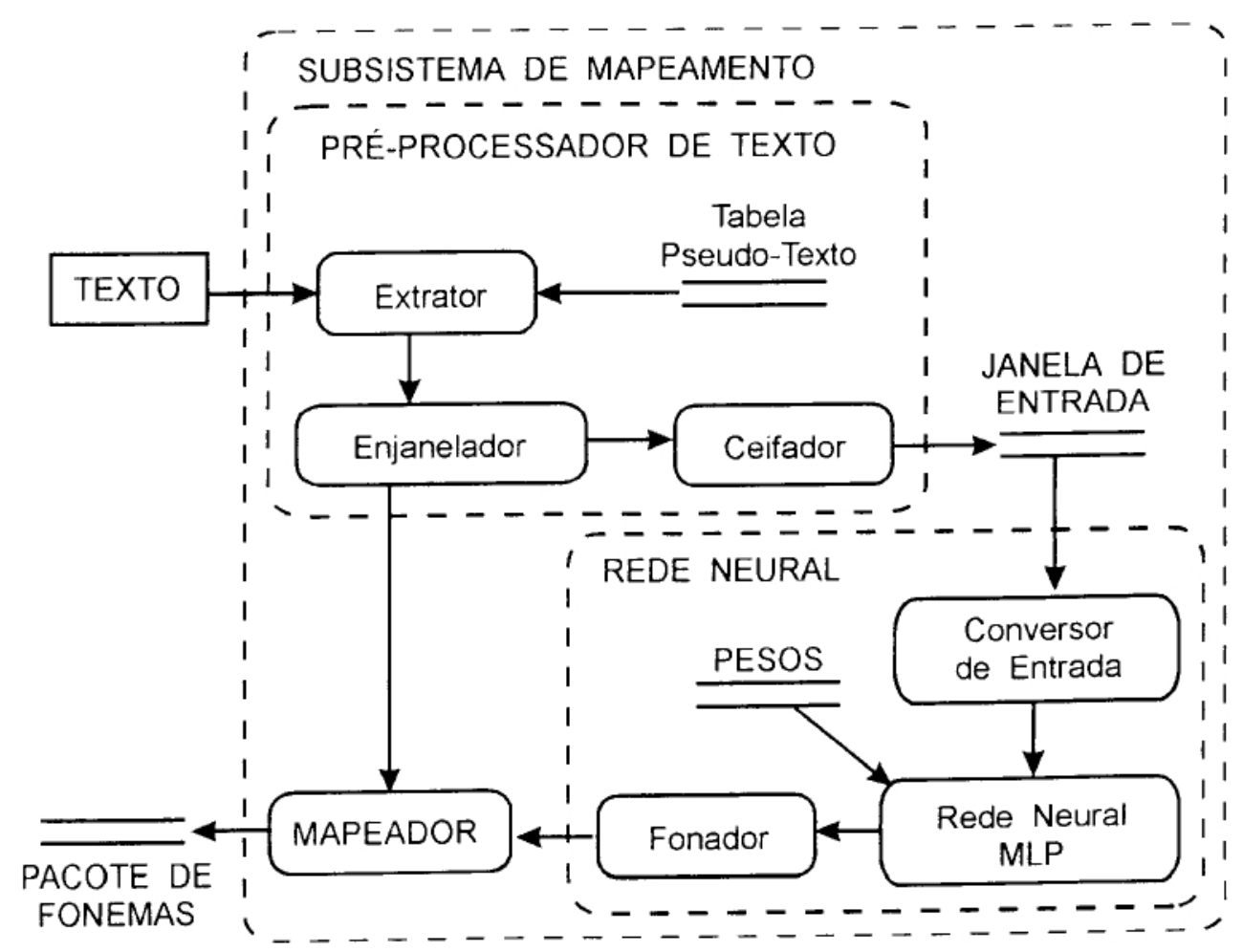

Figura 16. Subsistema de Mapeamento 
Este subsistema possui uma rotina chamada Mapeador, que controla os dois módulos gerando os Pacotes de Fonemas.

O Mapeador recebe um fonema do módulo ou um fonema específico, chamado pausa, oriundo do módulo Pré-processador de texto, que é responsável por definir o fim de um pacote e o término do mapeamento de uma palavra texto.

Mapeador: responsável por controlar os módulos gerando o pacote de fonemas.

Fonador: fornece a resposta do módulo RN determinando o neurônio mais ativado na camada de saída, comparando o valor de saída com o valor do limiar.

Conversor de Entrada: converte a informação da janela de entrada para ativar os neurônios da camada de entrada do MLP. Gera a entrada do MLP ativando os neurônios desta camada.

Janela de Entrada: cada letra da janela de entrada é representada por um conjunto de 34 neurônios. Como cada janela contém 6 letras tem-se um total de 204 neurônios na camada de entrada da rede.

Ceifador: transforma as janelas sujas geradas pelo enjanelador em Janelas Limpas.

Enjanelador: comanda o módulo Pré-processador de texto. Cria efetivamente as janelas que contem as letras que são mapeadas. Está apto para identificar o espaço em branco no texto informando diretamente à rotina Mapeador, o "Fonema Pausa".

Extrator: extrai um caracter do texto. Faz conversões de algarismos numéricos ou símbolos em texto. Contém Informações sobre o arquivo texto.

\subsubsection{Módulo Pré-processador de texto}

Janela de Entrada: cadeia de letras que constitui, após a conversão de formato, a entrada da Rede Neural.

Letra Central: é a letra pertencente à janela de entrada que deverá ser mapeada para fonema. Não necessariamente é a letra do centro da chamada janela.

Janela Limpa e Suja: as janelas ditas limpas são aquelas que possuem apenas letras que formam a palavra à qual a letra central pertence, enquanto que as janelas ditas sujas são compostas por todas as letras possíveis. 
As janelas usadas como entrada da rede são as limpas, pois as sujas trariam informações redundantes para a Rede Neural.

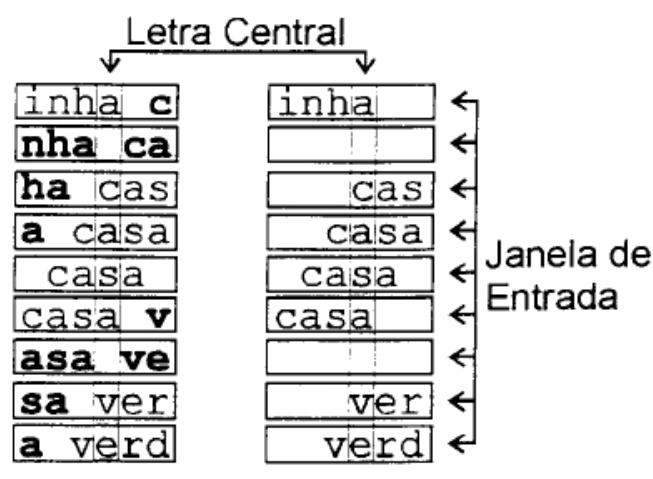

Figura 17. Módulo Pré Processador de texto

\subsubsection{Sintetizador de Voz}

Após a execução do mapeamento da letra escrita para seu fonema correspondente, é produzido através de um Sintetizador o som correspondente ao fonema determinado.

Este Sintetizador é constituído por uma biblioteca de dados para sintese, denominada Biblioteca de Voz, além de um Gerenciador de Som e uma Placa de Som acoplada ao computador, conforme pode ser visualizado na Figura 18.

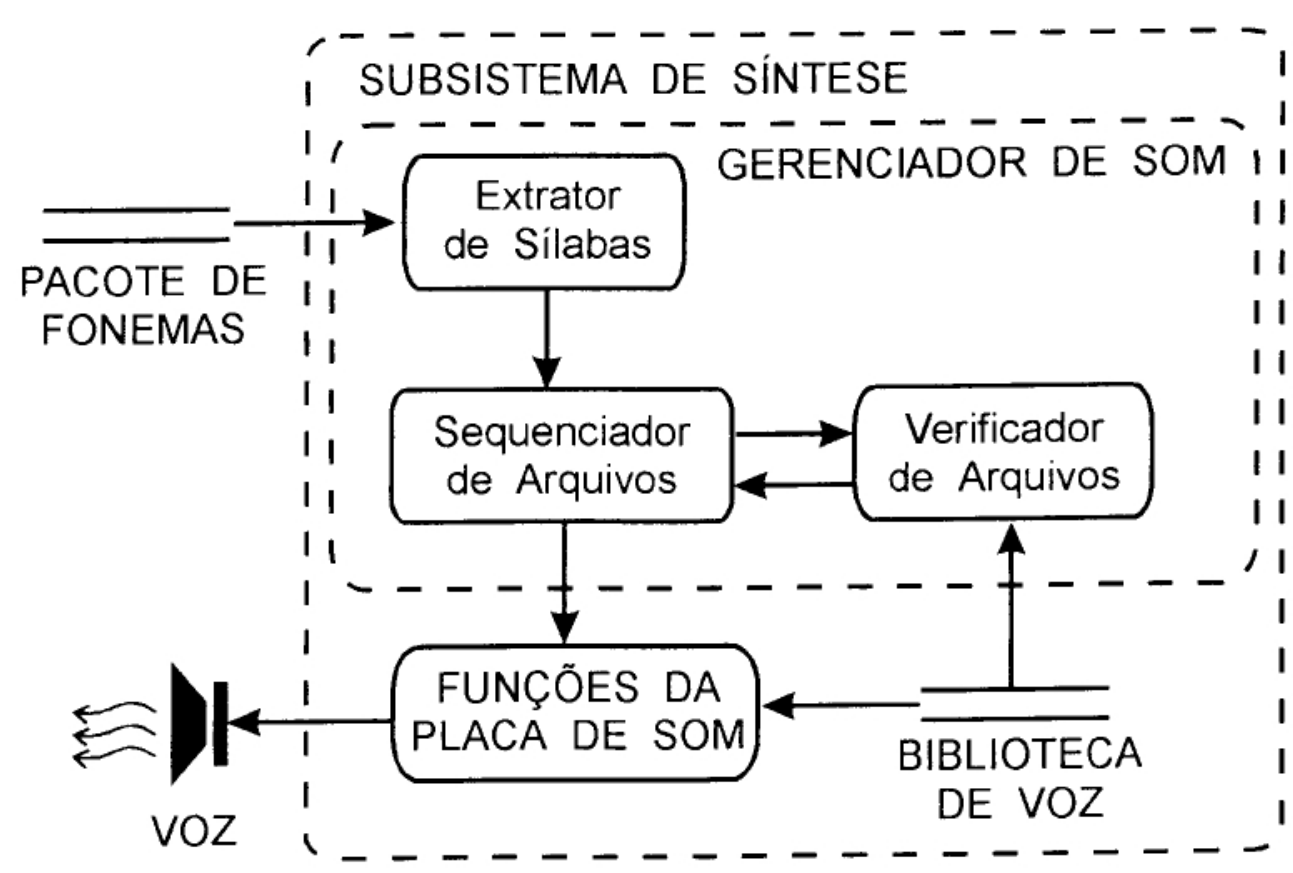

Figura 18. Subsistema de Síntese 
Funções da Placa de Som: responsável pela coletânea de funções habilitadas para ter acesso à placa de som.

Verificador de Arquivos: verifica se a sílaba extraída do pacote de fonemas existe. Caso não exista (processo de volta) o seqüenciador de arquivos fica responsável por criar uma nova seqüência utilizando os arquivos elementares da Biblioteca de voz

Seqüenciador de Arquivos: cria a seqüência de sílabas e/ou fonemas.

Extrator de Silabas: extrai do pacote de fonemas, as silabas baseadas na posição dos fonemas vocálicos (Centro). Quebra em partes distintas o pacote de fonemas.

O Gerenciador de Som recebe de um sistema de mapeamento os fonemas correspondentes ao texto que por sua vez são retransmitidos para o sistema de Síntese através de um conjunto de dados denominado Pacote de Fonemas que contém a seqüência de fonemas correspondentes a uma única palavra.

Estes dados são interpretados para determinar quais arquivos da Biblioteca de Voz serão acessados. Finalmente o Gerenciador de Som executa as tarefas pertinentes à técnica adotada na síntese da fala humana.

Esta técnica escolhida é a WaveForm, que será abordada na seção 6.3.6.

\subsubsection{Módulo de Rede Neural}

O módulo de Rede Neural, responsável pelo mapeamento Texto-Fonema, é constituído por uma única Rede Neural (RN). A rede escolhida foi a rede Perceptron Multi-Camadas.

A justificativa de utilizar a tecnologia de Redes Neurais, é baseada nas seguintes vantagens das Redes Neurais sobre tecnologias convencionais que utilizam regras explícitas e/ou dicionários fonéticos:

1) a quantidade de informação armazenada com as Redes Neurais é bem menor, pois é necessário apenas armazenar a própria rede, em específico, os pesos das conexões;

2) não há necessidade de manutenção, por parte do usuário, para novas palavras (ou pouco usadas), como acontece nos sistemas de dicionários; 
3) as Redes Neurais possuem capacidade de generalização, ou seja, com a aprendizagem de um grupo devidamente escolhido de palavras, que caracteriza o universo de discurso, pode-se englobar aproximadamente todo o dicionário clássico e coloquial.

\subsubsection{Perceptron Multi-Camadas}

\section{- Topologia Adotada}

A rede Perceptron Multi-Camadas (MLP) do Projeto Máquina Falante, possui as seguintes características descritas na Tabela 7.

\begin{tabular}{|l|c|}
\hline Número de Camadas Intermediárias & 2 \\
\hline Número de Neurônios na Camada de Entrada & 204 \\
\hline Número de Neurônios na $1^{\text {a }}$ Camada Intermediária & 70 \\
\hline Número de Neurônios na 2 $2^{\text {a }}$ Camada Intermediária & 38 \\
\hline Número de Neurônios na Camada de Saída & Sim \\
\hline Neurônios possuem o parâmetro $\theta$ (threshold $)$ & 27.518 \\
\hline Total de Pesos da Rede Neural & Função Sigmoidal \\
\hline Função de Ativação dos Neurônios & camadas intermediárias: $\lambda=1,0$ \\
\hline Parâmetro Livre da Função de Ativação & camada de saída: $\lambda=5,0$ \\
\hline
\end{tabular}

\section{Tabela 7. Caracteristicas da Rede Neural do Máquina Falante}

A topologia de rede apresentada na Tabela 7 foi escolhida variando-se o número de neurônios da primeira e segunda camada intermediária.

O processo de "Cross-Validation" (HAYKIN, 94), foi utilizado para decidir qual topologia seria a mais adequada. As redes foram treinadas com um subconjunto de treinamento constituído por 1000 palavras, selecionadas de um conjunto total de 1125 palavras. 
Os testes de validação foram feitos com as redes treinadas com o subconjunto de treinamento ( 1.000 palavras), enquanto que os testes de generalização foram feitos com as RNs retreinadas utilizando o conjunto de treinamento contendo 1.125 palavras.

Levando-se em consideração que:

a) Uma saída da RN poderia estar em uma das três situações:

1) o fonema e o acento estando corretos;

2) o fonema estando correto, mas o acento não;

3) o fonema estando incorreto, não importando se o acento estava ou não correto.

b) Um erro em acentuação não é tão importante quanto um erro de fonema, pois o acento apenas salienta a silaba tônica, sem alterar as características articulatórias dos fonemas ( $O$ sistema não fez distinção entre classes gramaticais, relevantes para distinguir os homônimos)

Assim sendo, pode-se dizer que a topologia apresentada na Tabela 7 forneceu a maior porcentagem de acerto para os dados do subconjunto de validação. A Tabela 8 destaca a porcentagem de acerto para esta rede, que é de $95,3 \%$, valor este considerado muito satisfatório.

\begin{tabular}{|c|c|c|c|}
\hline $\begin{array}{c}\text { fonemas corretos } \\
\text { (acentuação correta) }\end{array}$ & $\begin{array}{c}\text { fonemas corretos } \\
\text { (acentuação incorreta) }\end{array}$ & $\begin{array}{c}\text { fonemas } \\
\text { corretos (total) }\end{array}$ & $\begin{array}{c}\text { fonemas } \\
\text { incorretos }\end{array}$ \\
\hline $\mathbf{8 6 , 7 \%}$ & $\mathbf{8 , 6} \%$ & $\mathbf{9 5 , 3} \%$ & $\mathbf{4 , 7} \%$ \\
\hline
\end{tabular}

Tabela 8. Resultados da topologia da Rede Neural do "Máquina Falante”

Para medir o poder de generalização desta rede, realizou-se o Teste de Generalização usando um conjunto de teste, formado por 375 palavras, obtendo-se, os resultados contidos na Tabela 9 .

\begin{tabular}{|c|c|}
\hline $\begin{array}{l}\text { Fonemas } \\
\text { corretos }\end{array}$ & $\begin{array}{c}\text { fonemas } \\
\text { incorretos }\end{array}$ \\
\hline $\mathbf{9 4 , 1} \%$ & $\mathbf{5 , 9} \%$ \\
\hline
\end{tabular}

Tabela 9. Resultados de Generalização do "Máquina Falante”

Maiores detalhes sobre o sistema Máquina Falante, sobre as diferentes topologias testadas podem ser encontrados em (PROSDÓCIMO, 96). 


\subsubsection{Técnica WaveForm}

Esta seção fala sobre a técnica de WaveForm, utilizada para a criação e edição dos arquivos de áudio, demonstrando as principais vantagens e desvantagens em sua utilização.

É uma técnica de codificação em forma de onda de sinal, baseando-se na digitalização do sinal de som.

Existem outras técnicas como "Predição Linear", que são muito utilizadas, porém não superam em "qualidade humana" a técnica de WaveForm.

A técnica de WaveForm consiste em receber o sinal analógico de voz, convertê-lo em sinal digital para ser processado e armazenado, e então reconvertê-lo em sinal analógico armazenando assim o som vocal sem precisar gerá-lo, fazendo assim uma reconstrução direta.

\section{- Vantagens e Desvantagens WaveForm}

A técnica de WaveForm possui como vantagens as seguintes características:

- qualidade no Som.

- preservação das características da voz.

- não se gasta tempo com processamento de sinal pois já existe a digitalização da voz.

- o som é escutado continuamente salvo em caso de erros na criação da Biblioteca de Voz.

Por outro lado, a técnica de WaveForm também possui desvantagens em sua utilização como:

- a grande maioria dos sistemas comerciais não utiliza esta técnica pois ela requer uma enormidade de quantidade de memória para efetuar o armazenamento.

- toda digitalização tem como ponto fraco, a quantidade enorme de informação para se ter uma boa qualidade da entidade que se quer armazenar. 


\subsubsection{Biblioteca de Voz}

A Biblioteca de Voz, devido a utilização da técnica WaveForm, está constituída dos arquivos que contém as formas de ondas digitalizadas. Esta biblioteca, basicamente, é uma coletânea de fragmentos da fala humana digitalizada.

Atualmente os arquivos que formam a Biblioteca de Voz contem as silabas da língua portuguesa. No Anexo 3, encontra-se a lista das sílabas que fazem parte da Biblioteca de Voz do sistema. As silabas que obrigatoriamente compõem a biblioteca são as denominadas sílabas abertas (CV), que ocorrem com maior freqüência na língua portuguesa. Para o uso do sistema, é imprescindivel a existência dos arquivos chamados de arquivos elementares. Cada arquivo elementar correspondente a um fonema, é utilizado quando não há a silaba desejada gravada em arquivo. Forma-se uma seqüência com estes fonemas, através de simples junção, sem adaptação. Também existem 26 arquivos com os nomes das letras para o sistema poder soletrar letras isoladas no texto.

Os arquivos da fala digitalizados contêm as caracteristicas prosoidais do momento da sua gravação. Esta tarefa foi realizada com critérios para manter neutras, ou seja com a mínima mudança possivel, algumas características da fala, como ritmo e entonação.

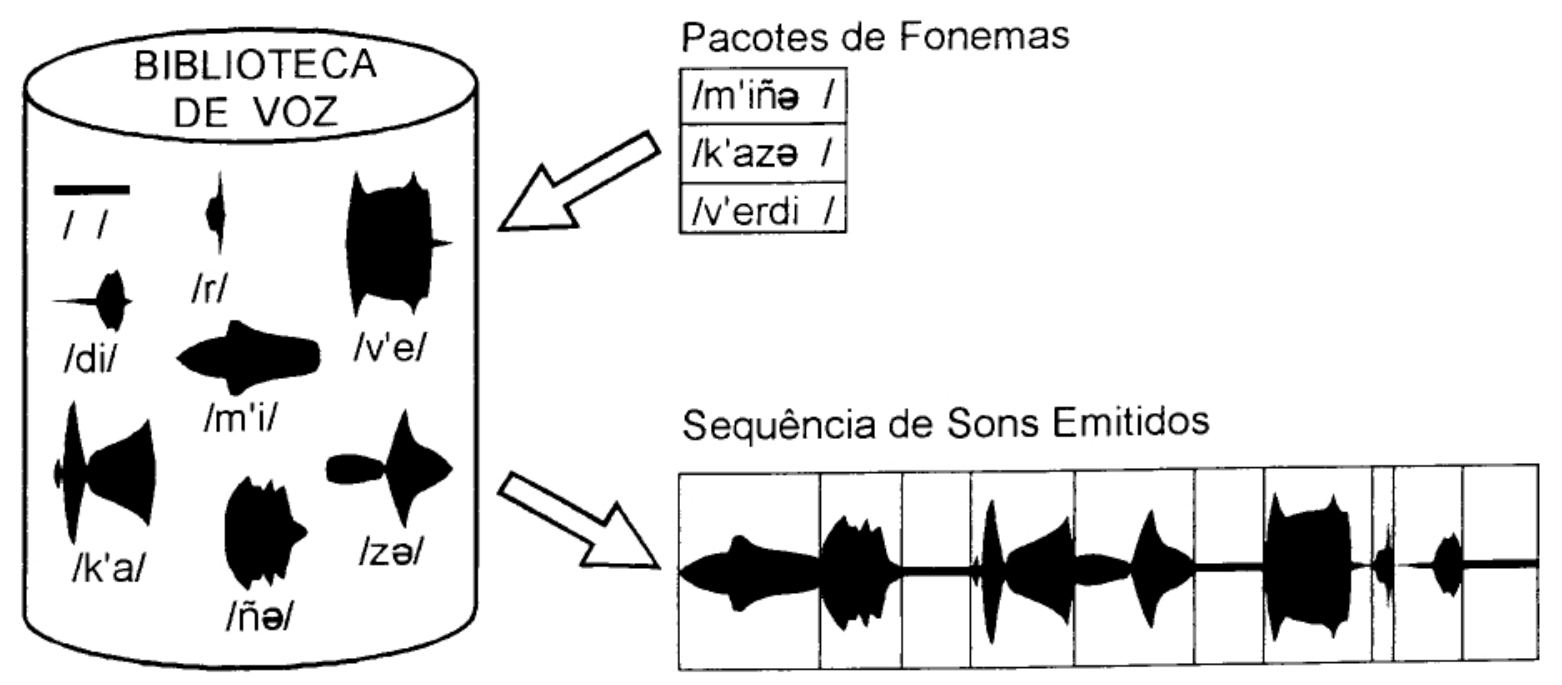

Figura 19. Dados importantes do subsistema de Síntese 
A Figura 19 apresenta, em específico, os dados utilizados na sintese do som, cujo diagrama foi apresentado na Figura 18. Dos pacotes de fonemas para a seqüência de sons emitidos, são buscados os arquivos que possuem o maior número possivel de fonemas, ou seja, busca-se sílabas completas. Se isto não for possível, a alternativa é quebrar as silabas em partes, onde existam arquivos coincidentes na Biblioteca de Voz.

Devido ao uso de arquivos que contém silabas, toda a sílaba que possuir o fonema vocálico com acentuação tem a amplitude aumentada, inclusive o declive da sílaba.

Os códigos do Pacote de Fonemas (Anexo 1) também são utilizados para criar os nomes dos arquivos da Biblioteca de Voz.

\subsection{Modificações realizadas no sistema Máquina Falante}

Nesta seção, são apresentadas as novas características que surgiram com as alterações do módulo de Conversão Texto/Noz, com o intuito de obter uma saída de áudio melhor e com caracteristicas especificas a leitura de e-mails.

A primeira modificação realizada foi na forma de se considerar as palavras para o treinamento. Decidiu-se considerar a entrada da rede, correspondente ao tamanho máximo que uma palavra pode ter em função do dicionário construido, e como saida, o tamanho máximo que uma palavra pode ter na sua transcrição fonética.

Outra alteração executada diz respeito ao aperfeiçoamento do banco de fonemas previamente criado. Foi realizado um tratamento nos arquivos de áudio com o intuito de retirar os intervalos entre os fonemas deixando a voz gerada mais próxima à falada pelo homem.

Uma terceira modificação realizada foi no código fonte que implementa o modelo da Rede Neural com o intuito de utilizar menos memória aperfeiçoando o retorno proporcionado pelo áudio na conversão, pois como o sistema Máquina Falante foi criado em 1996, não foi utilizada alocação dinâmica de memória para o armazenamento dos pesos da RNA depois de treinada acarretando em um atraso no tempo de resposta do sistema. 
Finalmente, foi também realizado um novo treinamento da Rede Neural com novos dados nas camadas de entrada, saída e intermediária, como poderá ser observado ainda nesta seção.

Assim sendo, a rede Perceptron Multi-Camadas (MLP) do Projeto de conversão Texto/Noz, para leitura de e-mails, passou a possuir as seguintes caracteristicas, detalhadas na Tabela 10.

\begin{tabular}{|l|c|}
\hline Número de Neurônios na Camada de Entrada & 686 \\
\hline Número de Neurônios na Camada Intermediária & 686 \\
\hline Número de Neurônios na Camada de Saída & Sim \\
\hline Neurônios possuem o parâmetro $\theta$ (threshold) & 39.658 \\
\hline Total de Pesos da Rede Neural & Função Sigmoidal \\
\hline Função de Ativação dos Neurônios & camadas intermediárias: $\lambda=1.0$ \\
\hline Parâmetro Livre da Função de Ativação & camada de saída: $\lambda=5.0$ \\
\hline
\end{tabular}

\section{Tabela 10. Características da Rede Neural do sistema}

A topologia de rede apresentada na Tabela 10 foi escolhida após vários testes realizados, variando-se o número de neurônios na camada intermediária, conforme apresentado na Tabela 11, a seguir.

Os 686 neurônios existentes nas camadas de entrada e saída são justificados da seguinte forma: no conjunto das 999 palavras utilizadas para treinamento e testes, a maior delas possuia 14 caracteres, e levando em consideração que cada caractere poderia ser representado por um conjunto de 49 posições, correspondente às letras, números e caracteres especiais do conjunto treinado, tem-se que $14 \times 49=686$, resultando nos 686 neurônios estabelecidos.

Já os 100 neurônios da camada intermediária, foram determinados por obter a menor taxa de erro médio $(0,0091828)$ após várias tentativas com outras configurações, conforme pode ser observado no estudo de caso a seguir. 
Para decidir qual topologia seria a mais adequada, o processo de "10 Fold CrossValidation" (HAYKIN, 94) foi utilizado. As redes foram treinadas com um subconjunto de treinamento constituído por 999 palavras.

Foram utilizadas $75 \%$ das palavras do dicionário para o treinamento, e os $25 \%$ restantes para testes, ou seja: 750 treinadas e 249 testadas.

\begin{tabular}{|l|c|c|c|c|c|}
\cline { 2 - 6 } \multicolumn{1}{c|}{} & $\begin{array}{c}\text { Neurônios } \\
\text { na Camada } \\
\text { de Entrada }\end{array}$ & $\begin{array}{c}\text { Neurônios } \\
\text { na Camada } \\
\text { Intermediária }\end{array}$ & $\begin{array}{c}\text { Neurônios } \\
\text { na Camada } \\
\text { de Saída }\end{array}$ & $\begin{array}{c}\text { Taxa mínima } \\
\text { de Erro } \\
\text { (Precisão) }\end{array}$ & $\begin{array}{c}\text { Valor do } \\
\text { Erro médio } \\
\text { encontrado }\end{array}$ \\
\hline Situação 1 & 686 & 150 & 686 & 0,001 & 0,0092893 \\
\hline Situação 2 & 686 & 686 & 686 & 0,001 & 0,0097750 \\
\hline Situação 3 & 686 & 200 & 686 & 0,001 & 0,0093482 \\
\hline Situação 4 & 686 & 1200 & 686 & 0,001 & 0,0098556 \\
\hline Situação 5 & $\mathbf{6 8 6}$ & $\mathbf{1 0 0}$ & $\mathbf{6 8 6}$ & $\mathbf{0 , 0 0 1}$ & $\mathbf{0 , 0 0 9 1 8 2 8}$ \\
\hline Situação 6 & 686 & 2 & 686 & 0,001 & 0,0099882 \\
\hline Situação 7 & 686 & 180 & 686 & 0,001 & 0,0094185 \\
\hline Situação 8 & 686 & 20 & 686 & 0,001 & 0,0099404 \\
\hline Situação 9 & 686 & 300 & 686 & 0,001 & 0,0094934 \\
\hline Situação 10 & 686 & 50 & 686 & 0,001 & 0,0098701 \\
\hline
\end{tabular}

Tabela 11. Estudo da melhor arquitetura da Rede Neural

Para determinar foram realizados testes de validação, pois assim é possível ter uma previsão do comportamento da rede com relação à capacidade de generalização. Estes testes de validação foram feitos com as RNAs treinadas com o subconjunto de treinamento composto por 750 palavras, enquanto que os testes de generalização foram feitos com as RNAs retreinadas utilizando um conjunto de treinamento formado por 249 palavras.

Os resultados encontrados foram baseados no acerto ou erro dos fonemas, sendo levada em consideração a acentuação em todos os casos apresentados. Ou seja, para o fonema ser considerado correto, ele deveria estar com sua escrita 
e acentuação corretas. Os resultados das diferentes topologias são apresentados na Tabela 12 a seguir.

\begin{tabular}{|c|c|c|}
\cline { 2 - 3 } \multicolumn{1}{c|}{} & Fonemas Corretos & Fonemas Incorretos \\
\hline Situação 1 & $95,4 \%$ & $\mathbf{4 , 6} \%$ \\
\hline Situação 2 & $90,5 \%$ & $9,5 \%$ \\
\hline Situação 3 & $95,0 \%$ & $\mathbf{5 , 0} \%$ \\
\hline Situação 4 & $90,5 \%$ & $9,5 \%$ \\
\hline Situação 5 & $96,2 \%$ & $3,8 \%$ \\
\hline Situação 6 & $90,8 \%$ & $9,2 \%$ \\
\hline Situação 7 & $94,7 \%$ & $5,3 \%$ \\
\hline Situação 8 & $90,2 \%$ & $9,8 \%$ \\
\hline Situação 9 & $94,1 \%$ & $6,9 \%$ \\
\hline Situação 10 & $92,3 \%$ & $7,7 \%$ \\
\hline
\end{tabular}

Tabela 12. Resultados da Validação

Após uma comparação entre os resultados das diferentes topologias utilizadas, foi realmente concluído que a melhor topologia é a apresentada na Situação 5 , contendo os seguintes resultados, destacados na Tabela 13.

\begin{tabular}{|c|c|c|}
\cline { 2 - 3 } \multicolumn{1}{c|}{} & Fonemas corretos & Fonemas incorretos \\
\hline Situação 5 & $\mathbf{9 6 , 2} \%$ & $\mathbf{3 , 8} \%$ \\
\hline
\end{tabular}

Tabela 13. Resultados obtidos para a topologia escolhida

\section{- O Teste de Generalização}

Para medir o poder de generalização da rede, após treinamento da MLP com 750 exemplos, realizou-se o Teste de Generalização usando um conjunto de testes, formado por 249 palavras, obtendo-se, em média, os resultados contidos na Tabela 14, gerandose o conjunto de treinamento e teste para a topologia fixada.

Para confirmar o poder de generalização desta topologia particular, apresentada na Situação 5, foi verificada a porcentagem de acerto no conjunto de testes, para ratificar que a topologia escolhida era realmente a melhor em comparação com alguma 
outra rede entre as redes testadas. As porcentagens obtidas para as topologias testadas são apresentadas na Tabela 15, onde podemos observar que a topologia correspondente à Situação 5 foi realmente a melhor.

\begin{tabular}{|c|c|c|}
\cline { 2 - 3 } \multicolumn{1}{c|}{} & Fonemas Corretos & Fonemas Incorretos \\
\hline Situação 1 & $\mathbf{9 4 , 0} \%$ & $\mathbf{6 , 0} \%$ \\
\hline Situação 2 & $\mathbf{8 9 , 7} \%$ & $\mathbf{1 0 , 3} \%$ \\
\hline Situação 3 & $\mathbf{9 3 , 1} \%$ & $\mathbf{6 , 9} \%$ \\
\hline Situação 4 & $\mathbf{8 8 , 9} \%$ & $11,1 \%$ \\
\hline Situação 5 & $\mathbf{9 5 , 4} \%$ & $\mathbf{4 , 6} \%$ \\
\hline Situação 6 & $\mathbf{8 8 , 1} \%$ & $\mathbf{1 1 , 9} \%$ \\
\hline Situação 7 & $\mathbf{9 3 , 0} \%$ & $\mathbf{7 , 0} \%$ \\
\hline Situação 8 & $\mathbf{8 8 , 4} \%$ & $11,6 \%$ \\
\hline Situação 9 & $\mathbf{9 2 , 8} \%$ & $\mathbf{7 , 2} \%$ \\
\hline Situação 10 & $\mathbf{9 0 , 9} \%$ & $\mathbf{9 , 1} \%$ \\
\hline
\end{tabular}

Tabela 14. Resultados de Generalização

Após a comparação entre os resultados das diferentes topologias utilizadas na Generalização, foi confirmado que a melhor topologia é a apresentada na Situação 5, contendo os seguintes resultados, destacados na Tabela 15.

\begin{tabular}{|c|c|c|}
\cline { 2 - 3 } \multicolumn{1}{c|}{} & Fonemas corretos & Fonemas incorretos \\
\hline Situação 5 & $\mathbf{9 5 , 4} \%$ & $\mathbf{4 . 6} \%$ \\
\hline
\end{tabular}

Tabela 15. Resultados para topologia escolhida (generalização)

\subsection{Considerações Finais}

Neste capítulo, foi apresentada a metodologia de criação do Conversor Texto/Noz do projeto "Máquina Falante" e as alterações realizadas na RNA adotada para o presente projeto, que podem ser consideradas satisfatórias visto que o sistema obteve indice de acerto de $95,4 \%$ para o conjunto de testes adotado. 


\section{Capítulo 7 \\ O Sistema Leitor de e-mails}

\subsection{Introdução}

O projeto, em sua totalidade, pode ser dividido em duas etapas. A primeira é referente ao Conversor Texto/Noz, já referenciado no capitulo 6 , e a segunda é apresentada neste capitulo, e trata do sistema leitor de e-mails. A integração das duas etapas conclui o projeto.

Serão apresentados neste capitulo dois aplicativos gerados para o uso da tecnologia de envio e recebimento de e-mails com Conversão Texto/Noz, através do uso de RNA. No primeiro é possível utilizar o Conversor Texto/Noz em um sistema especifico leitor de e-mails, e no segundo o uso da técnica de conversão criada, adaptada ao Microsoft Outlook.

A seguir são apresentadas as duas variações que ocorreram durante $\circ$ desenvolvimento deste projeto, no que se refere ao Sistema Leitor de E-mails que foram:

- a criação de um sistema especifico à leitura de e-mails, DPN Talk Mail.

- a adaptação do conversor criado a uma tecnologia de e-mails já existente, Microsoft Outlook..

\subsection{Criando um novo aplicativo leitor de e-mails}

Para a conclusão desta etapa, foi utilizado o ambiente Delphi 4. Inicialmente foi criada a interface global de um aplicativo leitor de e-mails, com o uso da linguagem de programação citada, aproveitando as caracteristicas dos já conceituados Microsoft Outlook e Eudora, em suas funções mais comuns, trazendo-as para o ambiente visual que o Delphi oferece. 
Após esta etapa inicial, foram criados um sub-menu e um novo botão de atalhos na barra de ferramentas, voltados unicamente à leitura dos e-mails. Passou então a existir a ligação entre a tecnologia de conversão e o sistema de leitura de e-mails criado.

A seguir são apresentados os passos necessários para a criação deste novo aplicativo, chamado "DPN Talk Mail".

\subsubsection{Montagem da tela}

Nesta etapa, foi gerada a tela principal de leitura de e-mails, onde foram observadas e aplicadas a maioria das funções básicas para o recebimento e envio de emails, assim como algumas funções específicas e alternativas que poderiam ainda ser criadas durante o desenvolvimento do sistema.

\subsubsection{Janela ou sub-menu de Leitura}

Um atalho em forma de um novo botão na barra de ferramentas e um sub-menu foram criados, sendo estes módulos responsáveis pela interação na conversão dos emails recebidos em texto para voz. O usuário poderia escutar os e-mails realizando tarefas alternativas simultaneamente.

\subsubsection{Tecnologia de Rede}

Esta etapa de criação do sistema foi responsável pela associação entre o sistema e o ambiente de rede. É aqui que o sistema "ganha vida" e passa a funcionar em uma rede local ou global.

Para isso foram utilizadas no Delphi as funções de um novo componente responsável pelo uso da tecnologia de rede dial-up.

\subsubsection{Teste e validação do Sistema}

Nesta última etapa foram realizados os testes de funcionamento do sistema, englobando tanto a parte de leitura quanto a parte de conexão em rede. Aqui, a dicção 
da leitura dos e-mails, a funcionalidade dos menus, assim como teclas de atalho, a conexão com a rede no recebimento e envio dos e-mails e todos os testes básicos envolvendo as funções utilizadas no sistema foram observados.

De uma maneira geral o sistema correspondeu as espectativas, porém através de pesquisas e opiniões de diversos tipos de usuários de e-mail, foi ratificada a conclusão de que seria mais cômodo fazer a adaptação do Conversor Texto/Noz em um software já existente do que forçar a migração do usuário para uma nova plataforma. Todavia o sistema foi criado e pode ser observado na Figura 20 e mais especificamente na próxima seção.

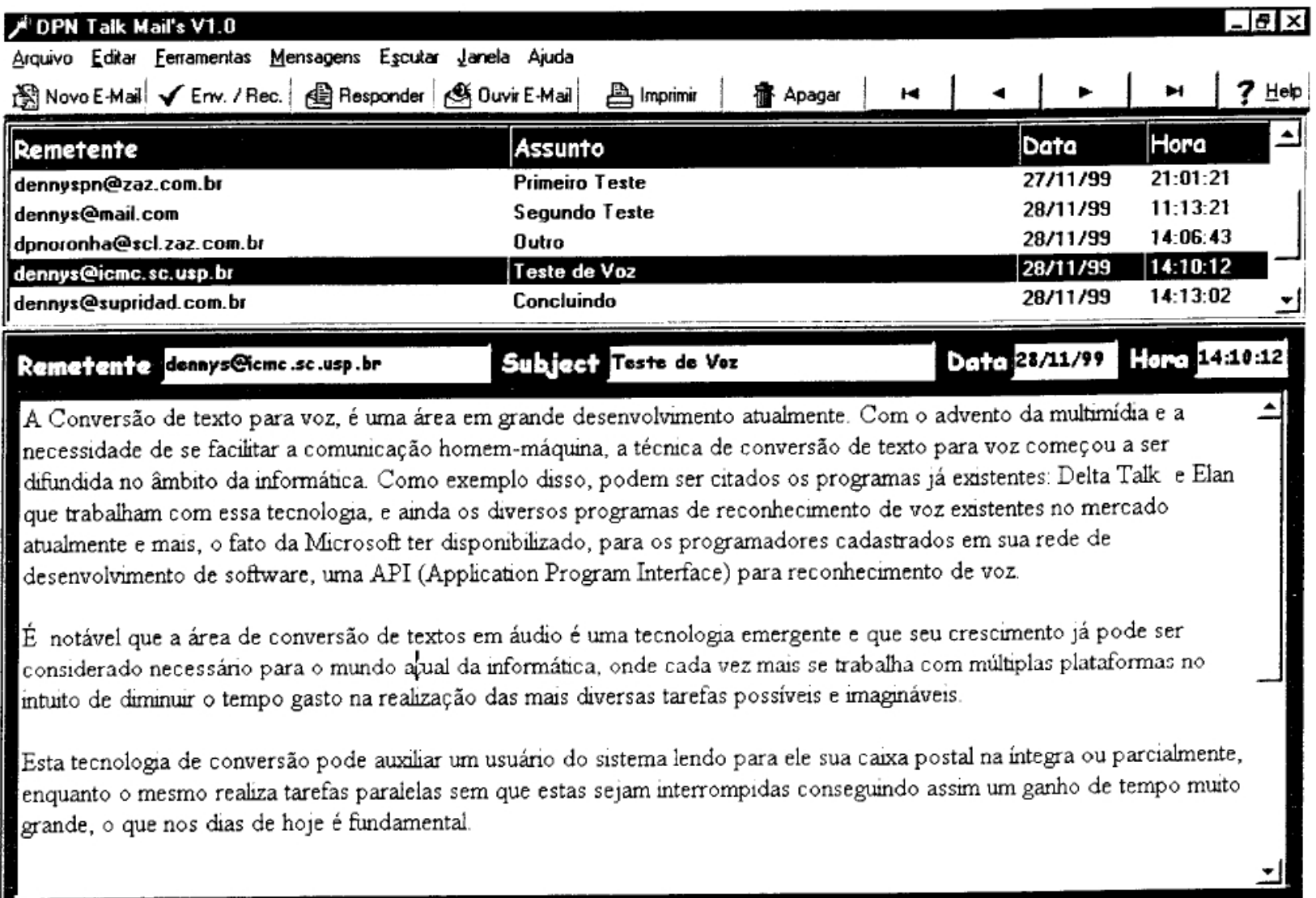

DPN Talk Mail's V1.0

Figura 20. Sistema de E-mails, Visão Geral 


\subsubsection{O Sistema Criado}

A Figura 21, apresentada a seguir, demonstra como seria o uso do sistema leitor de e-mails "DPN Talk Mail", criado especificamente para o uso da tecnologia de Conversão TextoNoz. Serão apresentandas, através de figuras, todas as funções possiveis de serem executadas no sistema.

É válido ressaltar que apenas as duas primeiras etapas foram realizadas integralmente, visto que, as funções responsáveis pela ligação com a rede não foram realizadas em sua totalidade devido à decisão de migração para o Microsoft Outlook. Foi criada apenas a ligação com a rede via protocolo dial-up e em caráter experimental, faltando ser testada e aprovada.

O sistema é constituído por uma interface experimental simples, porém funcional em relação ao que foi proposto, diferente de uma adaptação a um sistema já existente, como poderá ser observado na seção 7.3., que conta com muito mais recursos de envio e recebimento de e-mails.

Através da Figura 21, é possível observar o sistema "DPN Talk Mail", sendo visualizada apenas a caixa de entrada, com os últimos 5 e-mails recebidos.

A idéia inicial foi construir um sistema simples de recebimento e envio de e-mails, porém com funções especificas para a leitura dos mesmos, conforme será possivel observar nas próximas figuras.

O menu escutar é o responsável pela função de leitura no sistema. A partir dele, é possivel efetuar a leitura de todos os e-mails localizados na caixa de entrada, ou escutar todos os e-mails novos, ou ainda apenas o e-mail selecionado, conforme apresentado na Figura 21, a seguir. 


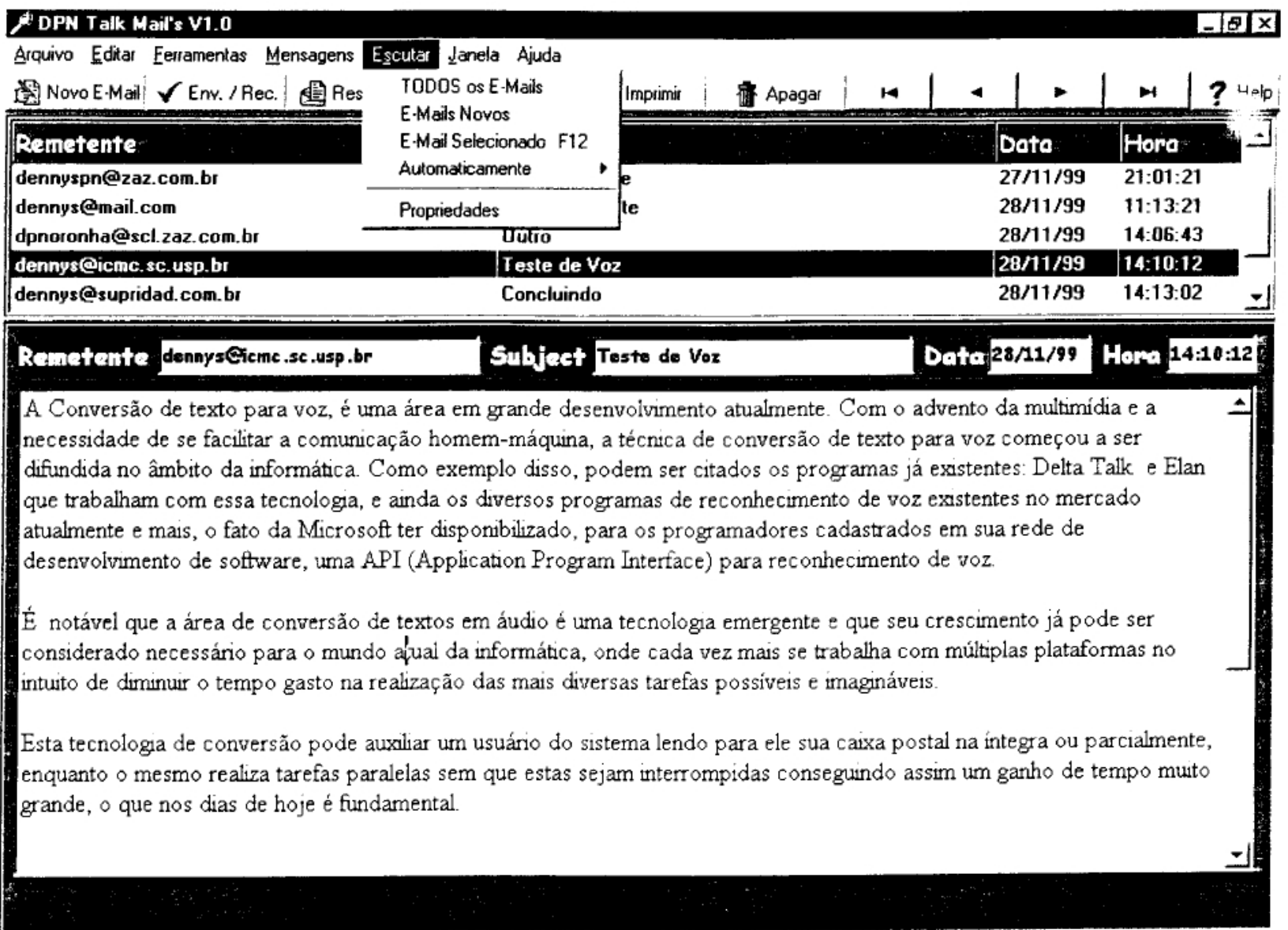

DPN Talk Mail's V1.0

Figura 21. Sistema de E-mails, Janela de Conversão

O sistema conta ainda com uma leitura automática dos e-mails que facilitaria a utilização por deficientes visuais. Estes utilizariam um teclado em braile para interagir com o sistema, que então contaria com teclas de atalho para todas as suas funções, evitando o uso do mouse como meio de interação entre o usuário e o sistema.

O sub-menu de escuta automática é o responsável pela função de leitura no sistema automaticamente. A partir dele, seria possivel efetuar a leitura automática de todos os e-mails novos, do último e-mail recebido e, ainda, do e-mail na eminência de ser enviado, conforme apresentado na Figura 22 a seguir. 


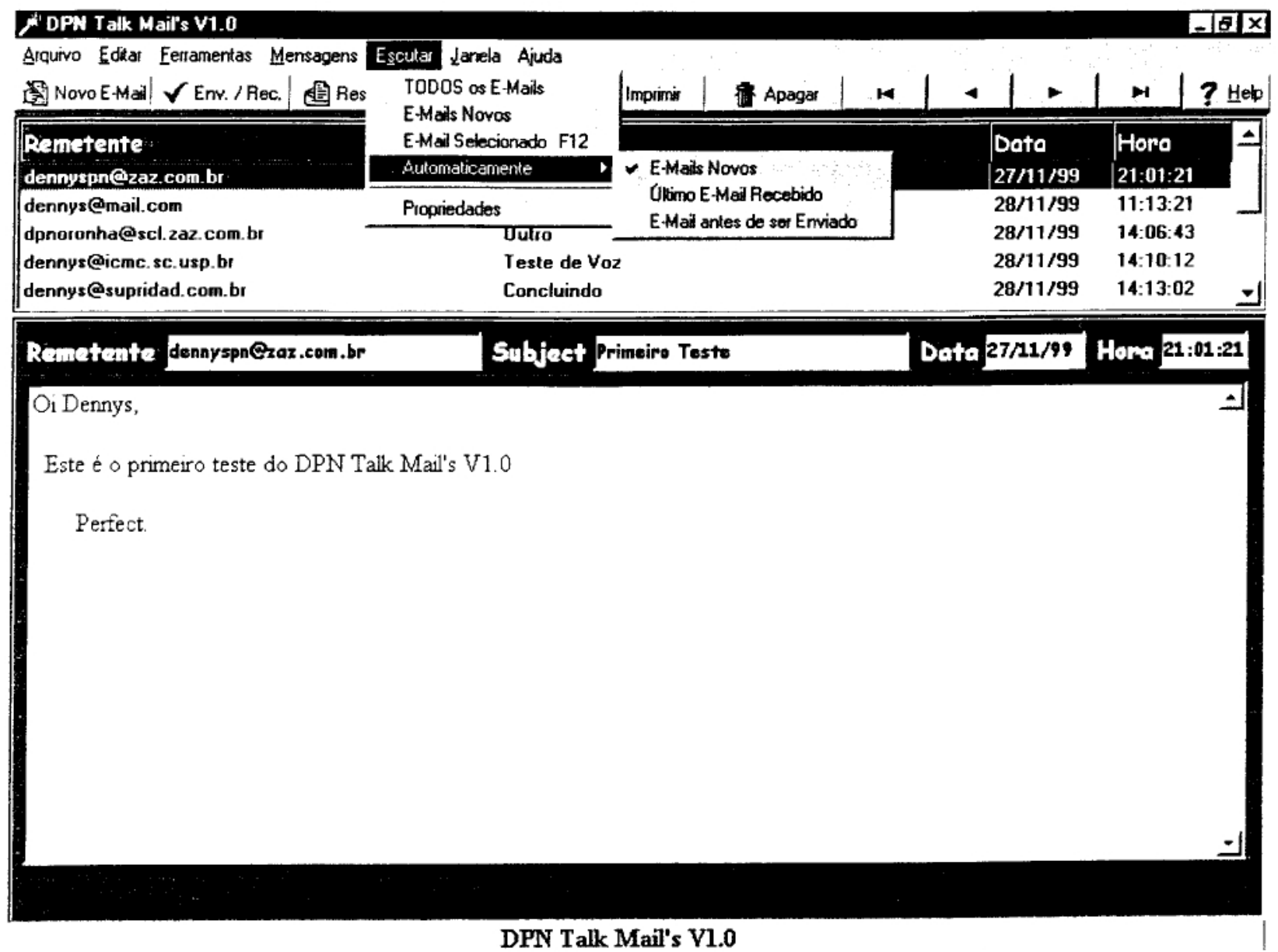

Figura 22. Sistema de E-mails, Janela de Conversão Automática

O sistema aqui apresentado possui a finalidade única de ilustrar a janela de leitura de e-mails, na forma como ela poderia ser utilizada, pois conforme mencionado, foi escolhida a utilização do Microsoft Outlook como plataforma de recebimento de emails padrão, sendo simplesmente adaptada a tecnologia de Conversão TextoNoz através de uma janela de leitura do aplicativo em questão.

Esta decisão foi tomada basicamente, conforme já mencionado, levando-se em consideração o fato de que o usuário não precisaria migrar para uma nova plataforma de envio e recebimento de e-mails. 


\subsection{Adaptando o Conversor a um sistema leitor já existente}

O uso do conversor dentro de um programa leitor de e-mails já existente tornouse mais interessante para o usuário, visto que o mesmo não precisaria migrar para uma nova plataforma de envio e recebimento de e-mails, bastando apenas a inclusão deste sub-menu ao Outlook, que é o programa leitor de e-mails mais utilizado no mercado internacional.

Assim sendo, o sistema adotado ficou constituído pela integração da tecnologia de Conversão Texto/Noz, associada a um sistema de leitura de e-mails já existente. Para isso, foi incluído no Microsoft Outlook um novo menu (Ouvir e-mail) para tratar apenas da Conversão Texto/Noz.

A seguir é apresentada a interface do Microsoft Outlook com a inclusão do menu, que foi a solução escolhida para a melhor funcionalidade do projeto.

\section{- A Integração com o Microsoft Outlook}

Para a adaptação da nova janela no Microsoft Outlook foram realizadas algumas etapas essenciais. Primeiramente, foi criado um novo menu e um novo botão de atalho na barra de ferramenta do Microsoft Outlook, os quais seriam responsáveis pela utilização do Conversor Texto/Noz.

Foi utilizado o próprio menu "personalizar" do Outlook, para a inclusão do novo menu e do novo botão na barra de ferramentas, porém para a adaptação ao Conversor Texto/Noz desenvolvido, foi criada uma macro com a finalidade de associar a nova interface do Outlook ao arquivo executável do Conversor Texto/Noz.

A forma como foi feita a ligação entre a interface criada e o Conversor Texto/Noz desenvolvido no Microsoft Outlook, deixou em aberto a possibilidade de usar no futuro, qualquer outra tecnologia de Conversão Texto/Noz no sistema. 
$\mathrm{Na}$ Figura 23, é possível observar que, além de um novo botão na barra de ferramentas com o intuito de servir como atalho na leitura do e-mail já selecionado, foi também adicionado um novo menu contendo uma opção para ouvir o e-mail Selecionado, além de um "sobre" e uma "ajuda", contendo informações sobre o sistema e sobre a sua funcionalidade.

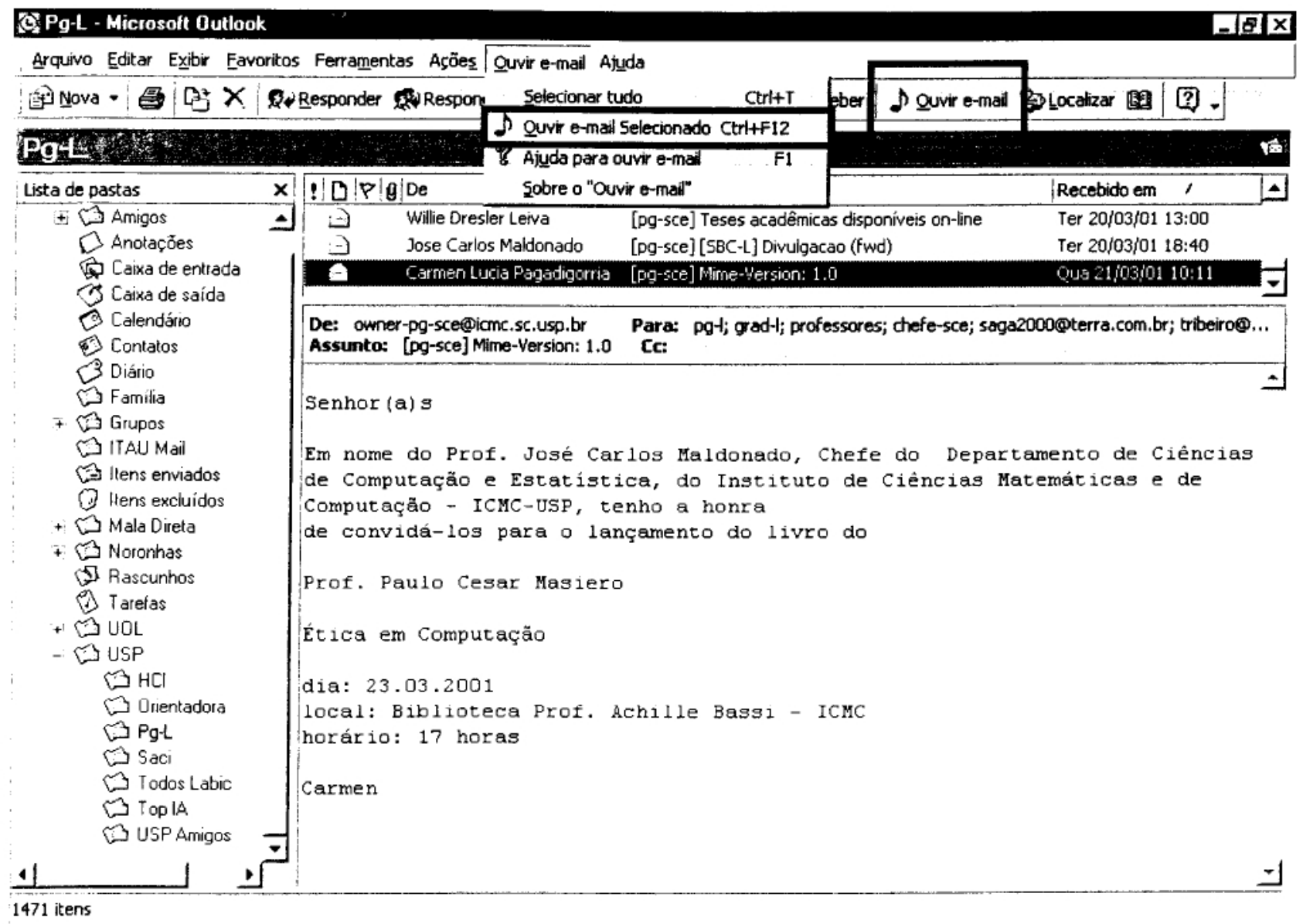

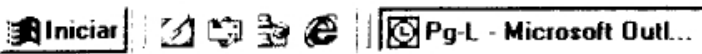

Figura 23. Integração com o Microsoft Outlook

\section{- Comparando com o DPN Talk Mail}

Conforme observado na Figura 23 , ocorreram perdas e ganhos em relação ao uso do Microsoft Outiook, como sendo uma plataforma já existente, e uma nova tecnologia criada especificamente para o projeto, que foi o caso do "DPN Talk Mail". 
Com o uso do Microsoft Outlook, como base para a leitura de e-mails, o sistema ganhou além de uma tecnologia já conhecida, com comandos familiares para o usuário, uma série de funções adicionais que a própria Microsoft disponibiliza e que o sistema especifico, DPN Talk Mail, se utilizado, não iria possuir.

Por outro lado, também é possivel observar que com o uso do Microsoft Outlook como plataforma básica, alguns comandos de leitura de e-mail não foram possíveis de ser utilizados, como é o caso da leitura automática de e-mails, que ficou inviável de ser inserida, devido a incompatibilidade na tecnologia de rede adotada pelo Microsoft Outlook, com a tecnologia de conversão utilizada no projeto.

Com a escolha em definitivo pelo uso do conversor adaptado ao Microsoft Outlook, o sistema ficou então limitado apenas à escutar os e-mails selecionados, o que torna o programa funcional, é verdade, porém sem muitas variações, o que sempre enriquece qualquer software.

A escuta dos e-mails ficou então limitada a ser executada somente em um único e-mail isolado de cada vez, e de forma manual, ou seja, o usuário necessita selecionar o e-mail que deve ser lido e então pressionar "Ouvir e-mair".

\subsection{Considerações Finais}

Neste capitulo, foi apresentado o Sistema Leitor de e-mails, baseado em duas interfaces propostas para a utilização do Conversor Texto/Voz. O capitulo foi finalizado com uma comparação entre o Sistema Leitor de e-mails, "DPN Talk Mair", criado especificamente para tal função, e o uso desta tecnologia adaptada ao Microsoft Outlook.

Com a ligação entre o Sistema Leitor de e-mails e o Conversor TextoNoz, o projeto então foi finalizado. No capitulo 8 são apresentadas algumas conclusões e sugestões de trabalhos futuros envolvendo a Tecnologia de Conversão Texto/Voz apresentada neste projeto. 


\section{Capítulo 8}

\section{Conclusões e Trabalhos Futuros}

O trabalho apresentado teve como finalidade incrementar uma tecnologia que está em grande crescimento nos dias atuais, que é o uso do correio eletrônico, e-mail, via internet da maneira mais simples possivel e sem tomar o tempo do usuário em questão, desenvolvendo um Conversor Texto/Noz, baseado em fonemas com Redes Neurais Artificiais.

A opção pelo uso de fonemas no projeto foi, entre outros fatores já discutidos neste trabalho, devido a facilidade de aprendizado na construção de palavras ditas novas, assim como na busca de um retorno de áudio agradável ao usuário do sistema leitor de e-mails.

A utilização de Redes Neurais no mapeamento do sistema Conversor Texto/Noz ocorreu devido a duas características básicas: o aprendizado, com o objetivo de absorver, a partir do conjunto de treinamento, o mapeamento Texto-Fonemas e a generalização que é responsável pela característica das RNA de permitir cobrir o vocabulário da língua portuguesa a partir de um pequeno e significativo subconjunto do universo de discurso.

O projeto, após ser concluído, obteve um retorno satisfatório. Os dois subsistemas, Mapeamento e Síntese, corresponderam as expectativas de desempenho. A Rede Neural adotada no sistema teve indice de acerto de 95,4\% para o conjunto de testes adotado, o que pode ser considerado um bom desempenho.

A biblioteca de voz foi reeditada com o intuito de tornar a saida de áudio mais agradável, retirando espaços em branco no início e no final de cada arquivo, assim como, controlando, sempre que possível, o volume dos arquivos, para que não houvessem oscilações muito grandes durante a junção dos fonemas.

A integração com o Microsoft Outlook possibilitou uma facilidade maior no tocante a adaptação de um possível usuário do sistema à tecnologia de Conversão Texto/Noz, 
visto que o mesmo não precisaria migrar para um novo sistema leitor de e-mails, podendo manter a sua plataforma atual, inserindo apenas um novo menu na mesma.

É válido ressaltar que com a criação deste projeto, a migração do mesmo para outras aplicações que utilizem a tecnologia de Conversão Texto/Noz, tornar-se-á possivel, podendo ser empregada em diferentes situações como: comunicação alternativa para os deficientes visuais e da fala, leitura de programas para jovens, crianças e demais pessoas interessadas, multi-media CD ROMS, sistemas em balcões de informações (Ex.: Extra, Shoppings SP), tecnologia de voz em páginas World Wide $W e b$, sistemas de guias veiculares e muitas outras atividades alternativas.

Com base neste vasto leque de alternativas de uso da tecnologia de Conversão TextoNoz, existiu uma maior motivação para a realização deste projeto.

Como trabalho futuro, poderá ser possível o desenvolvimento de um protótipo de sistema de apoio vocal para pessoas com deficiência motora, visual e de fala, baseado num editor de texto com saída vocal, capaz de fornecer uma voz artificial com qualidade suficiente para poder ser utilizada em diferentes situações de interação verbal, e especificamente durante a leitura de e-mails.

Esta tecnologia de conversão poderá auxiliar um usuário do sistema, lendo para ele sua caixa postal na integra ou parcialmente, enquanto o mesmo realiza tarefas paralelas sem que estas sejam interrompidas, conseguindo assim um ganho de tempo muito grande, o que nos dias de hoje é fundamental.

A análise sintática das frases, também seria uma ótima idéia de trabalho futuro, pois o uso da mesma, iria terminar com os já conhecidos problemas de entonação de palavras sem o uso do acento tônico.

O uso da tecnologia FPGA (Field Programmable Gate Array) com computação reconfigurável também seria uma abordagem interessante a ser investigada, pois, o tempo de processamento requerido para uma RNA, utilizando esta técnica, é centenas de vezes menor que utilizando um microprocessador comum. Isto propiciaria um tempo de resposta do sistema de leitura de e-mails muito menor, tornando a voz produzida mais parecida com a voz humana. Além disso, o uso da tecnologia de FPGA também propiciaria que o hardware construido fosse utilizado com a finalidade de ajudar o deficiente visual. 


\section{Referências Bibliográficas}

> (AINSWORTH, 1973) Ainsworth,W.A. A System for Converting English Text into Speech. IEEE Transactions on Audio and Electroacoustics, v. 21, n. 3, p. 28890, June 1973.

> (ALLEN, 1973) Allen, J. Reading Machines for the Blind: The Technical Problems and the Methods Adopted for Their Solution. IEEE Transactions on Audio and Electroacoustics, v. 21, n. 3, p. 259-64, June 1973.

> (ALLEN, 1976) Allen,J. Synthesis of Speech from Unrestricted Text. Proceedings of the IEEE, v. 64, n. 4, p. 433-42, Apr. 1976.

> (ALLIANDRO, 1974) Alliandro, H. The Portuguese-English Dictionary. 10 ed. New York, Pocket Book. 1974

> (ATAL \& RABINER, 1986) Atal,B.S.; Rabiner,L.R. Speech Research Directions. AT \& T Technical Journal, v. 65, n. 5, p. 75-88, Sept./Oct. 1986.

> (BORBA, 1972) Borba, F. S., Introdução aos Estudos Lingüísticos, Cia. Ed. Nacional, 1972.

- (CALlOU \& LEITE, 1990) Callou,D.; Leite,Y. Iniciação à Fonética e à Fonologia. 1 ed. Rio de Janeiro, São Paulo, Jorge Zahar Editor Ltda. 1990.

> (CAMPOS, 1980) Campos,G.L. Síntese de Voz para o Idioma Português. São Paulo,. Tese (Doutorado) - Escola Politécnica, Universidade de São Paulo. 1980.

- (CARTER, 1983) Carter, J. P., Electronically Speaking: Computer Speech Generation, Howard W. Sams \& Co. 1983.

- (CEgALLA, 1977) Cegalla, D.P. Novissima Gramática da Língua Portuguesa. 16 ed. São Paulo, Companhia Editora Nacional. 1977.

> (CROCHIERE \& FLANAGAN, 1990) Crochiere,R.E.; Flanagan,J.L. Speech Processing: an Evolving Technology. AT \& T Technical Journal, v. 65, n. 5, p. 211, Sept./Oct. 1990.

- (CUNHA \& CINTRA, 1985) Cunha,C.; Cintra,L. Nova Gramática do Português Comtemporâneo. 2 ed. Rio de Janeiro, Editora Nova Fronteira. 1985. 
> (DIVAY \& VITALE, 1997) Divay, M.; Vitale, A.J. Algorithms for grapheme-phoneme translation for English and French: Applications for database searches and speech synthesis. Computational Linguistics 23,4, p. 495-523, Dec. 1997.

> (EDGINGTON et. al., 1996a) Edgington, M.; Lowry, A.; Jackson, P.; Breen, A.P.; Minnis, S. Overview of current text-to-speech techniques .1. Text and linguistic analysis. Bt Technology Journal 14,1, p. 68-83, Jan. 1996.

> (EDGINGTON et. al., 1996b) Edgington, M.; Lowry, A.; Jackson, P.; Breen, A.P.; Minnis, S. Overview of current text-to-speech techniques .2. Prosody and speech generation. BT Technology Journal 14,1, p. 84-99, Jan. 1996.

(EGASHIRA \& VIOLARO, 1992) Egashira,F.; Violaro,F. Sintese de Voz a Partir de Texto. Campinas, Faculdade de Engenharia Elétrica da Universidade Estadual de Campinas, 1992.

> (EL-IMAN, 1989) El-Iman,Y.A. An Unrestricted Vocabulary Arabic Speech Synthesis System. IEEE Transactions on Acoustics, Speech and Signal Processing, v. 37, n.12, p.1829-45, Dec. 1989.

r (ELOVITZ et al., 1976) Elovitz,H.S.; Johnson,R.; McHugh,A.; Shore,J.E. Letter-toSound Rules for Automatic Translation of English Text to Phonetics. IEEE Transactions on Acoustics, Speech and Signal Processing, v. 24, n. 6, p. 446-59, Dec. 1976.

> (ENDRES, 1983) Endres,W.K. Problems of Speech Analysis and Synthesis. In: H.W. Schüssler, ed. EURASIP Signal Processing: Theories and Applications, Erlangen, 1983. Proceedings. North-Holland, Elsevier Science Publishers B.V., C 1.0, p. 315-22, 1983.

- (ESQUIVEL, 1985) Esquivel,A.S. Um Sistema de Síntese de Voz. Congresso Nacional de Informática, 18., São Paulo, 1985. Anais. São Paulo, Sucesu, p. 776-82, 1985.

> (FERREIRA, 1986) Ferreira, A.B.H. Novo Dicionário da Língua Portuguesa. 2 ed. Rio de Janeiro, Editora Nova Fronteira, 1986.

- (HAYKIN, 1994) Haykin, S., Neural Networks A Comprehensive Foundation, Macmillan Publishing Co. / IEEE Press, 1994. 
- (HERTZ, 1982) Hertz, S.R.; From Text to Speech with SRS. Journal of the Acoustical Society of America, v. 74, n. 4, p. 1155-70, Oct. 1982.

- (HERTZ, 1985) Hertz,S.R.; Kadin,J; Karplus,K.J. The Delta Rule Development System for Speech Synthesis from Text. Proceedings of the IEEE, v. 73, n. 11, p. 1589601, Nov. 1985.

- (HERTZ, 1994) Hertz,S.R.; The Delta Programming Language: An Integrated Approach to Non-Linear Phonology, Phonetics, and Speech Synthesis. Ithaca, Phonetics Laboratory, 1994.

- (HIRSCHBERG et al., 1990) Hirschberg,J.B.; Riederer, S.A.; Rowley,J.E.; Syrdal,A.K. Voice Response Systems: Technologies and Applications. AT \& T Technical Journal, v. 65, n. 5, p. 42-51, Sept./Oct. 1990.

- (JAVKIN, 1989) Javkin,H. et al., A Multi-Lingual Text-to-Speech System. IEEE International Conference on Acoustics, Speech and Signal Processing, 5.8. p. 242-5, 1989.

- (KAPLAN \& LERNER, 1985) Kaplan,G.; Lerner,E.J. Realism in Synthetic Speech. IEEE Spectrum, v. 22, p. 32-7, Apr. 1985.

- (KITAI et. al., 1997) Kitai, M.; Hakoda, K.; Sagayama, S.; Yamada, T.; Tsukada, H.; Takahashi, S.; Noda, Y.; Takahashi, J.; Yoshida, Y.; Arai, K.; Imoto, T.; Hirokawa, T. ASR and TTS telecommunications applications in Japan. Speech Communication 23,1-2 p. 17-30, Oct. 1997.

- (KLATT, 1987) Klatt,D.H. Review of Text-to-Speech Conversion for English. Journal of Acoustical Society of America, v. 82, n. 3, p. 737-93, Sept. 1987.

- (LAPORTE, 1989) Laporte,E. Applications of Phonetic Description. M. Gross and D. Perrin, ed. Eletronic Dictionaries and Automata in Computational Linguistics. Berlin, Springer-Verlag, Berlin, (Lectures Notes in Computer Science 377) p. 6578, 1989.

- (LAU, 1992) Lau, C., Neural Networks Theoretical Foundations and Analysis, IEEE Press, 1992.

- (LEE et al., 1989) Lee,L.S.; Tseng,C.H,; Ouh-Young,M. The Synthesis Rules in a Chinese Text-to-Speech System. IEEE Transactions on Acoustics, Speech, and Signal Processing, v. 37, n. 9, p. 1309-20, Sept. 1989. 
(LIPPMANN, 1987) Lippmann, R. P., An Introduction to Computing with Neural Nets, IEEE ASSP Magazine, vol. 4 (2), p. 4-22, 1987.

- (OLABE et al., 1983) Olabe,J.C.; Santos,A.; Martínez,R.; Muñoz,E.; Martinez, M.; Quilis,A.; Bernstein,J. Real Time Text to Speech Conversion System for Spanish. In: H.W. Schüssler, ed. EURASIP Signal Processing: Theories and Applications, 2., Erlangen, 1983. Proceedings. North-Holland, Elsevier Science Publishers B.V. C 1.3, p. 331-3, 1983.

- (OLIVEIRA et al., 1994) Oliveira,L.C.; Viana,M.C.; Trancoso,I.M. A Rule-Based Textto-Speech System for Portuguese. Lisboa, INESC/IST/CLUL, 1994.

> (O'MALLEY, 1990) O'Malley,M.H. Text-To-Speech Conversion Technology. IEEE Computer, p. 17-23, Aug. 1990.

- (O'SHAUGHNESSY, 1998) O'Shaughnessy, D., Multilingual text-to-speech synthesis: The Bell Labs approach by Sproat, $R$. Computational Linguistics, 24, 4, p. 656658, Dec. 1998.

- (PAGE e BREEN, 1996) Page, J.H; Breen, A.P. The Laureate text-to-speech system Architecture and applications. BT Technology Journal. 14,1, p. 57-67, Jan. 1996. - (PROSDócimo, 1996) Prosdócimo, M.Z. Sistema para transformar Texto em Voz utilizando Redes Neurais para a lingua Portuguesa. Dissertação de Mestrado. Instituto de Ciências Matemáticas e de Computação, Universidade de São Paulo, 1996.

- (RUMELHART, 1986) Rumelhart, D. E., Hinton, G. E. e Willians, R. J., Learning Internal Representations by Error Propagation, Parallel Distributed Processing vol.1, p. 318-362, MIT Press, 1986.

- (SALZA et. al., 1996) Salza, P.L.; Foti, E.; Nebbia, L.; Oreglia, M. Mos and pair comparison combined methods for quality evaluation of text-to-speech systems. Acustica. 82, 4, p. 650-656, Jul./Aug. 1996.

- (SEJNOWSKI \& ROSENBERG, 1987) Sejnowski, T. J. \& Rosenberg, C. R., Parallel Networks That Learn to Pronounce English Text. Complex Systems Publication, 1987.

- (SORIN et. al., 1995) Sorin, C.; Jouvet, D.; Gagnoulet, C.; Dubois, D.; Sadek, D.; Toularhoat, M. Operational and Experimental French Telecommunication 
Services Using Cnet Speech Recognition And Text-To-Speech Synthesis. Speech Communication. 17,3, p.273-286, Nov. 1995.

- (TAKEDA e ICHIKAWA, 1S 34) Takeda, S.; Ichikawa. A. Analysis of Prominence in Spoken Japanese Sentences and Application to Text-To-Speech Synthesis. Speech Communication. 14, 2, p.171-196, Apr. 1994.

- (UMEDA, 1976) Umeda, N. Linguistic Rules for Text-to-Speech Synthesis. Proceedings of the IEEE, v. 64, n. 4, p. 443-51, Apr. 1976.

- (VAN COILE, 1989) Van Coile,B.M.J. The DEPES Development System for Text-toSpeech Synthesis. IEEE International Conference on Acoustics, Speech and Signal Processing, 1989. Proceedings.IEEE, 1989. S 5.10. p. 250-3, 1989.

> (VIANA et al., 1991) Viana,M.C.; Andrade,E; Oliveira,L.C.;Trancoso,I.M. Ler_PE: Um Utensilio para o Estudo da Ortografia do Português. Encontro da Associação Portuguesa Lingüística, 7., Lisboa, 1991. Anais. Lisboa, p. 474-89, Apr. 1991.

r (YOUNG e FALLSIDE, 1989) Young,S.J.; Fallside,F. Speech Synthesis from Concept: A Method for Speech Output from Information Systems. Journal of Acoustical Society of America, v. 66, n. 3, p. 685-95, Sept. 1989. 


\section{ANEXO 1 - Tabela de Códigos}

Códigos de Controle e Fonemas Especiais:

\begin{tabular}{|l|l|l|l|}
\hline 00 pausa & 36 nulo & 37 duplo $/ \mathrm{ks} /$ & 38 soletrar \\
\hline
\end{tabular}

Códigos para Fonemas Vocálicos:

\begin{tabular}{|cc|cc|cc|cc|cc|cc|cc|}
\hline 01 & $\mathbf{i}$ & 02 & $\tilde{\mathbf{i}}$ & 03 & $\mathbf{e}$ & 04 & $\tilde{\mathbf{e}}$ & 05 & $\boldsymbol{\varepsilon}$ & 06 & $\mathbf{a}$ & 07 & $\tilde{\mathbf{a}}$ \\
\hline 08 & $\Lambda$ & 09 & $\boldsymbol{\partial}$ & 10 & $\mathbf{o}$ & 11 & $\tilde{\mathbf{o}}$ & 12 & $\jmath$ & 13 & $\mathbf{u}$ & 14 & $\tilde{\mathbf{u}}$ \\
\hline
\end{tabular}

Códigos para Fonemas Semi-consonantais (Semi-vocálicos):

\section{\begin{tabular}{ll|ll}
15 & $\mathbf{j}$ & 16 & $\mathbf{w}$
\end{tabular}}

Códigos para Fonemas Consonantais:

\begin{tabular}{|cc|cc|cc|cc|cc|cc|cc|}
\hline 17 & $\mathbf{b}$ & 18 & $\mathbf{d}$ & 19 & $\mathbf{f}$ & 20 & $\mathbf{g}$ & 21 & $\mathbf{3}$ & 22 & $\mathbf{k}$ & 23 & $\mathbf{I}$ \\
\hline 24 & $\boldsymbol{\lambda}$ & 25 & $\mathbf{m}$ & 26 & $\mathbf{n}$ & 27 & $\tilde{\mathbf{n}}$ & 28 & $\mathbf{p}$ & 29 & $\mathbf{r}$ & 30 & $\overline{\mathbf{r}}$ \\
\hline 31 & $\mathbf{s}$ & 32 & $\boldsymbol{J}$ & 33 & $\mathbf{t}$ & 34 & $\mathbf{v}$ & 35 & $\mathbf{z}$ & & & & \\
\cline { 1 - 9 } & & &
\end{tabular}




\section{ANEXO 2 - Lista de Palavras}

- LISTA DE PAlaVRAS DO CONJUNTO DE TREINAMENTO

1.125 palavras $(100 \%)$

- LISTA DE PAlaVRAS DO SUBCONJUNTO DE TREINAMENTO

1.000 palavras $(88,9 \%)$

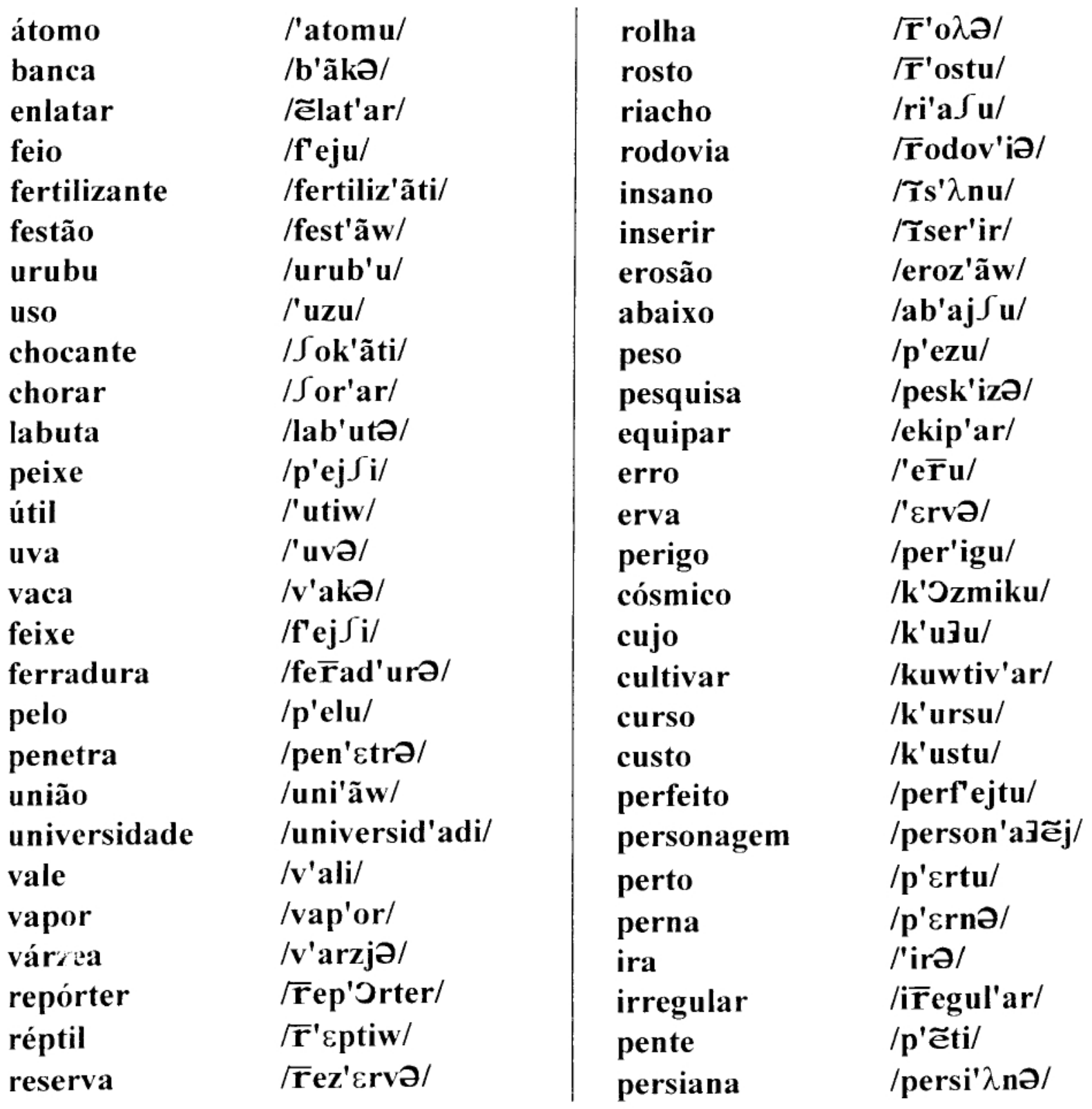




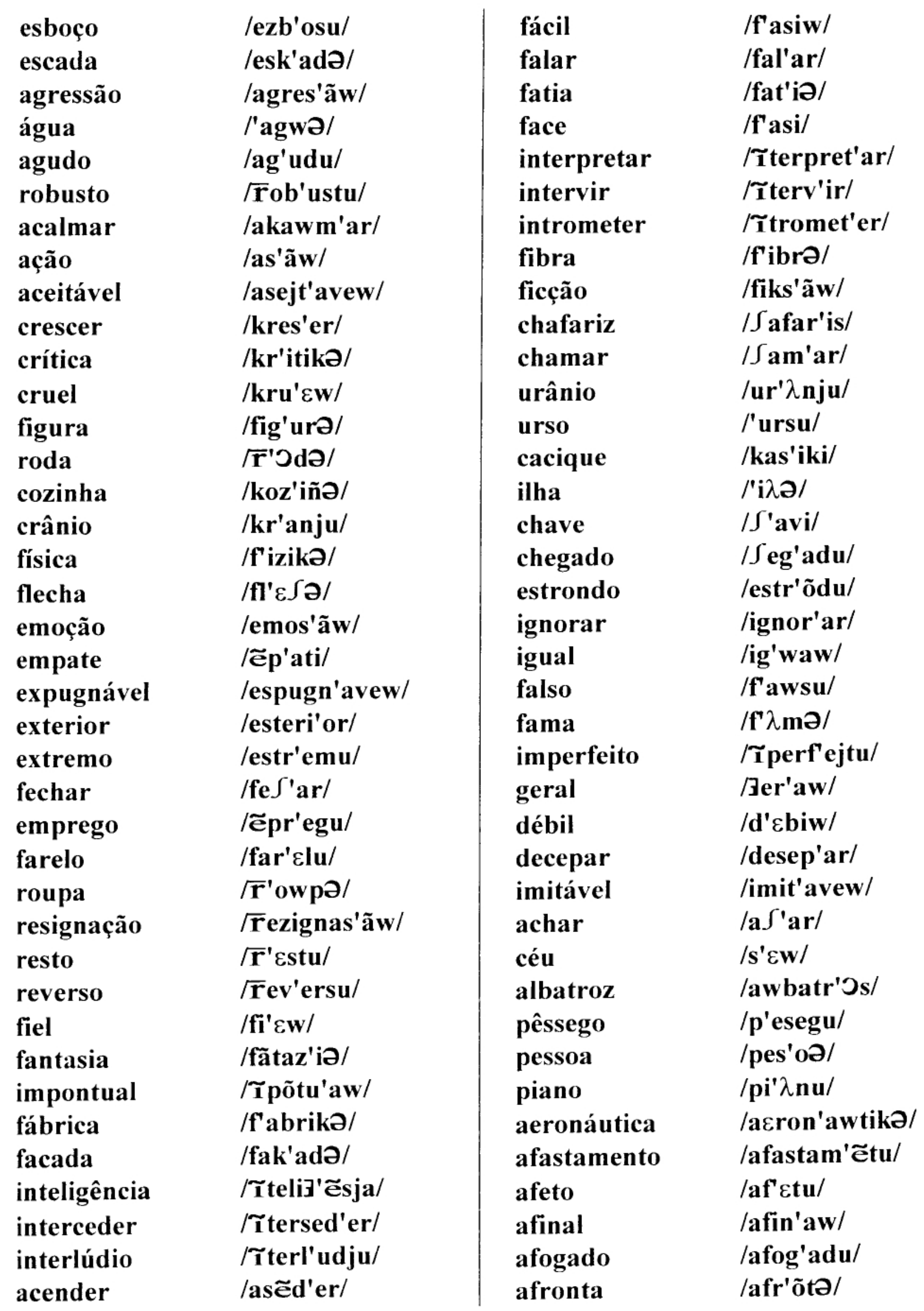




\begin{tabular}{|c|c|c|c|}
\hline afugentar & /afußẽt'ar/ & amor & /am'or/ \\
\hline coluna & /kol'unə/ & amplo & /'ãplu/ \\
\hline comandante & /komãd'ãti/ & análise & /an'alizi/ \\
\hline combustão & /kõbust'ãw/ & ângulo & /'ãgulu/ \\
\hline comer & /kom'er/ & carnaval & /karnav'aw/ \\
\hline agência & /aق'ésjo/ & carne & /k'arni/ \\
\hline gir & /az'ir/ & caroço & /kar'osu/ \\
\hline gora & /ag'Ora/ & carreteiro & /kā̄ret'ejru/ \\
\hline gradável & /agrad'avew/ & cavaleiro & /kaval'ejru/ \\
\hline arícia & /kar'isjə/ & alisar & /aliz'ar/ \\
\hline Iternação & /awternas'ãw/ & alma & /'awmə/ \\
\hline & $/ \widetilde{\mathbf{e}}_{\mathbf{j}} /$ & almoço & /awm'osu/ \\
\hline bsoluto & /absol'utu/ & ajudar & /aJud'ar/ \\
\hline heiro & / S'ejru/ & alaranjado & /alarãz'adu/ \\
\hline hinelo & /Sin'clu/ & abonar & /abon'ar/ \\
\hline létron & /el'Etrõw/ & abraço & /abr'asu/ \\
\hline nflamável & /Tflam'avew/ & fino & /f'inu/ \\
\hline nfringir & /Tfrö'ir/ & alô & /al'o/ \\
\hline ustre & /il'ustri/ & animal & /anim'aw/ \\
\hline xplosão & /esploz'ãw/ & cascavel & /kaskav'єw/ \\
\hline bundância & /abũd'ãsjə/ & casual & /kazu'aw/ \\
\hline mbaixo & $/ \tilde{e}_{b} \mathbf{a j} \int_{\mathbf{u}} /$ & causa & /k'awzə/ \\
\hline nda & /a'Tdə/ & inferno & /Tf'ernu/ \\
\hline sada & /riz'ade/ & infinito & /Tfin'itu/ \\
\hline tual & Гritu'aw/ & aparelho & /apar' $\varepsilon \lambda \mathbf{u} /$ \\
\hline arroceria & /kā̄oser'iə/ & apêndice & /ap'ẽdisi/ \\
\hline & $\sqrt{\mathbf{r}} \cdot \mathbf{i u} /$ & picada & /pik'adə/ \\
\hline brir & /abr'ir/ & pinga & /p'тga/ \\
\hline mburrar & /ébu $\overline{\mathbf{r}}^{\prime} \mathbf{a r} /$ & abuso & /ab'uzu/ \\
\hline arato & /bar'atu/ & ano & $/ \lambda \mathbf{n u} /$ \\
\hline arco & /b'arku/ & antes & /'ãtis/ \\
\hline arra & /b'a $\overline{\mathbf{r}} \boldsymbol{\theta} /$ & ao & /aw/ \\
\hline ivilização & /sivilizas'ãw/ & inveja & 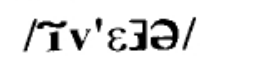 \\
\hline bacaxi & /abaka $\int^{\prime} i /$ & apagador & /apagad'or/ \\
\hline nexpugnável & /inespugn'avew/ & infalível & /Tfal'ivew/ \\
\hline tura & /awt'ura/ & infecto & / $\mathbf{\mathbf { 1 }} \mathbf{f}^{\top} \varepsilon \mathbf{k t u} /$ \\
\hline 1anhã & /amañ'ã/ & cartão & /kart'ãw/ \\
\hline arelo & /amar'clu/ & casaco & /kaz'aku/ \\
\hline bulância & /ãbul'ãsjə/ & filha & $/ \mathbf{f}^{\prime} \mathbf{i} \lambda \boldsymbol{\theta} /$ \\
\hline
\end{tabular}




\begin{tabular}{|c|c|c|c|}
\hline filial & /fili'aw/ & porque & /pork'e/ \\
\hline fim & $/ \mathbf{f} \mathbf{1} /$ & porta & /p'Orta/ \\
\hline inverno & /T̃v'Ernu/ & posição & /pozis'ãw/ \\
\hline dedo & /d'edu/ & posta & /p'Osta/ \\
\hline encéfalo & /ẽs'cfalu/ & junho & / \\
\hline encomenda & /ฮ̃kom'ẽdə/ & justiça & /Bust'isa/ \\
\hline pois & /p'ojs/ & potência & /pot'ẽsja/ \\
\hline polar & /pol'ar/ & puxa & /p'uSa/ \\
\hline polícia & /pol'isjə/ & encaixe & 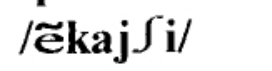 \\
\hline polvilho & /powv'i $\lambda \mathbf{u} /$ & julho & $/ \mathbf{J}^{\prime} \mathbf{u} \lambda \mathbf{u} /$ \\
\hline vir & /v'ir/ & pirralho & $/ \mathbf{p i} \overline{\mathbf{r}}^{\prime} \mathbf{a} \lambda \mathbf{u} /$ \\
\hline vírgula & /v'irgulə/ & piso & /p'izu/ \\
\hline volta & $/ v^{\prime O w t \partial /}$ & plano & /pl'anu/ \\
\hline vôo & /v'ou/ & pouco & /p'owku/ \\
\hline voz & $/ \mathbf{v}^{\prime}$ Os/ & povo & /p'ovu/ \\
\hline endereço & /ẽder'esu/ & prataria & /pratar'iə/ \\
\hline enfim & 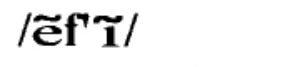 & precipício & /presip'isju/ \\
\hline engano & $/ \tilde{\mathbf{e g}}{ }^{\prime} \lambda \mathbf{n u} /$ & fazenda & /faz'ẽdə/ \\
\hline engenharia & /ฮ્łeñar'iə/ & quando & /k'wãdu/ \\
\hline flor & /fl'or/ & quatro & /k'watru/ \\
\hline flutuar & /flutu'ar/ & pior & /pi'Or/ \\
\hline foco & /f'כku/ & piquete & /pik'eti/ \\
\hline fogo & /f'ogu/ & juiz & /Bu'is/ \\
\hline gênero & /a'eneru/ & caravana & $/ \operatorname{karav}^{\prime} \lambda$ nə/ \\
\hline gente & / $\mathbf{y}^{\prime}$ ẽti/ & cárcere & /k'arseri/ \\
\hline caneta & /kan'etO/ & jovem & /ł'כvẽj/ \\
\hline canteiro & /kãt'ejru/ & canal & /kan'aw/ \\
\hline capim & $/ \operatorname{kap}^{\prime} \mathbf{\mathbf { 1 }} /$ & xodó & / sod'O/ \\
\hline capitão & /kapit'ãw/ & zanga & /z'ãgə/ \\
\hline caqui & /kak'i/ & instantâneo & $/$ istãt' $\lambda \mathbf{n j u} /$ \\
\hline caranguejo & /karãg'ełu/ & integral & /Ttegr'aw/ \\
\hline vulgo & /v'uwgu/ & incêndio & /T̃s'ẽdju/ \\
\hline xadrez & / Jadr'es/ & zero & /z'eru/ \\
\hline xereta & / Ser'eta/ & zinco & /z'T ku/ \\
\hline xícara & / S'ikara/ & zona & /z'one/ \\
\hline pulmonar & /puwmon'ar/ & zurrar & /zun'rar/ \\
\hline platéia & /plat'єjə/ & ponto & /p'õtu/ \\
\hline poder & /pod'er/ & inércia & /in'Ersjə/ \\
\hline porém & /por' $\tilde{\mathbf{e j}} /$ & insolvente & /Tsowv'ẽti/ \\
\hline
\end{tabular}




\begin{tabular}{|c|c|c|c|}
\hline inspetor & /Tspet'or/ & quinze & $/ \mathbf{k}^{\prime} \mathbf{\mathbf { z }} \mathbf{i} /$ \\
\hline índio & / Tdju/ & raça & /厂' asə/ \\
\hline que & $/ \mathbf{k e} /$ & rádio & $\sqrt{\mathbf{r}} \mathbf{a d j u} /$ \\
\hline quebrar & /kebr'ar/ & ramo & $\sqrt{\mathbf{r}}{ }^{\prime} \lambda \mathbf{m u} /$ \\
\hline inteiro & /Tt'ejru/ & reboco & / Teb'oku/ \\
\hline propriedade & /proprjed'adi/ & regra & /厂'́gra/ \\
\hline prova & /pr'כva/ & relâmpago & /rel'ãpagu/ \\
\hline psicopata & /psikop'atə/ & tinto & $/ t^{\prime} \tilde{\mathbf{T}} \mathbf{t u} /$ \\
\hline queijo & /k'ejłu/ & toalha & $/$ to'a $\lambda \partial /$ \\
\hline quem & $/ \mathbf{k}^{\prime} \tilde{\mathbf{e j}} /$ & todo & $/ t^{\prime}$ odu/ \\
\hline quieto & /k'jetu/ & receptador & / \\
\hline inauguração & /inawguras'ãw/ & recheio & Гree $\int^{\prime} \mathbf{e j u} /$ \\
\hline Irdinal & /kardin'aw/ & recreação & / Trekreas'ãw/ \\
\hline arga & /k'argə/ & impureza & /Tpur'eza/ \\
\hline quadra & /k'wadre/ & inadequado & /inadek'wadu/ \\
\hline rançoso & / rãa'ozu/ & salsa & /s'awsə/ \\
\hline rapaz & /rap'as/ & santo & /s'ãtu/ \\
\hline rasgo & /厂r'azgu/ & saúde & /sa'udi/ \\
\hline real & /re'aw/ & ora & /'Ora/ \\
\hline qual & /k'waw/ & ordem & /'Ord $\tilde{\mathbf{e j}} /$ \\
\hline qualquer & /kwawk'єr/ & órgão & /'Orgãw/ \\
\hline rede & $\sqrt{\mathbf{r}^{\prime}}$ edi/ & origem & /or'i] $\mathbf{e j} /$ \\
\hline redondo & /red'õdu/ & orquestra & /ork'Estra/ \\
\hline reeditar & /reedit'ar/ & orvalho & /orv'a $\lambda \mathbf{u} /$ \\
\hline banha & $/ \mathbf{b}^{\prime} \lambda \tilde{\mathbf{n}} \boldsymbol{\theta} /$ & oscilar & /osil'ar/ \\
\hline dado & /d'adu/ & osso & $/ \operatorname{osu} /$ \\
\hline daí & $/ \mathbf{d a}^{\prime} \mathrm{i} /$ & ouro & /'owru/ \\
\hline dança & /d'ãsə/ & outro & /'owtru/ \\
\hline data & /d'ate/ & inclusive & /Tkluz'ivi/ \\
\hline ética & /'etikə/ & incômodo & /Tk'omodu/ \\
\hline eu & /'ew/ & refrigerante & /refriłer'ãti/ \\
\hline evoluir & /evolu'ir/ & região & /reJi'ãw/ \\
\hline exame & $/ \mathbf{e z}^{\prime} \lambda \mathbf{m i} /$ & torre & /t'o $\overline{\mathbf{r}} \mathrm{i} /$ \\
\hline exceção & /eses'ãw/ & torta & /t'Orta/ \\
\hline excluir & /esklu'ir/ & compreensível & /kõpreẽs'ivew/ \\
\hline exilar & /ezil'ar/ & cedo & /s'edu/ \\
\hline decimal & /desim'aw/ & óxido & /'OKidu/ \\
\hline transformar & /trãsform'ar/ & aplicar & /aplik'ar/ \\
\hline verdura & /verd'ura/ & aposta & /ap'Oste/ \\
\hline
\end{tabular}




\begin{tabular}{|c|c|c|c|}
\hline $\begin{array}{l}\text { como } \\
\text { compaixão } \\
\text { trabalho } \\
\text { tragédia } \\
\text { incompleto } \\
\text { indeciso } \\
\text { celeiro } \\
\text { cena } \\
\text { cento } \\
\text { cereal } \\
\text { certo } \\
\text { alegre } \\
\text { além } \\
\text { alforje } \\
\text { alguém } \\
\text { algum } \\
\text { alho } \\
\text { ingrato } \\
\text { início } \\
\text { argila } \\
\text { cebola } \\
\text { ovo } \\
\text { aqui } \\
\text { aquilo } \\
\text { arco } \\
\text { arredor } \\
\text { arroio } \\
\text { artificial } \\
\text { árvore } \\
\text { asa } \\
\text { completo } \\
\text { comprápico } \\
\text { inóspito } \\
\text { trazer } \\
\text { trecho } \\
\text { três } \\
\text { tributo } \\
\text { trilho } \\
\text { tró }\end{array}$ & 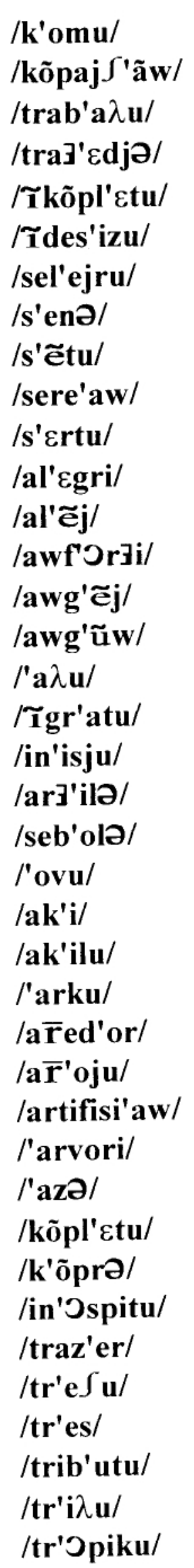 & $\begin{array}{l}\text { tudo } \\
\text { uivar } \\
\text { último } \\
\text { ultraje } \\
\text { um } \\
\text { dono } \\
\text { doutrina } \\
\text { computação } \\
\text { comum } \\
\text { calha } \\
\text { bugre } \\
\text { buraco } \\
\text { burrice } \\
\text { até } \\
\text { globo } \\
\text { golfo } \\
\text { gordo } \\
\text { gostosura } \\
\text { enredo } \\
\text { enxofre } \\
\text { eterno } \\
\text { governo } \\
\text { ativo } \\
\text { atlas } \\
\text { infundado } \\
\text { açucar } \\
\text { acústica } \\
\text { guaraná } \\
\text { guarda } \\
\text { guerra } \\
\text { guia } \\
\text { guri } \\
\text { relógio } \\
\text { remédio } \\
\text { renda } \\
\text { acordar } \\
\text { açougue } \\
\text { acreditar } \\
\text { alimentar }\end{array}$ & 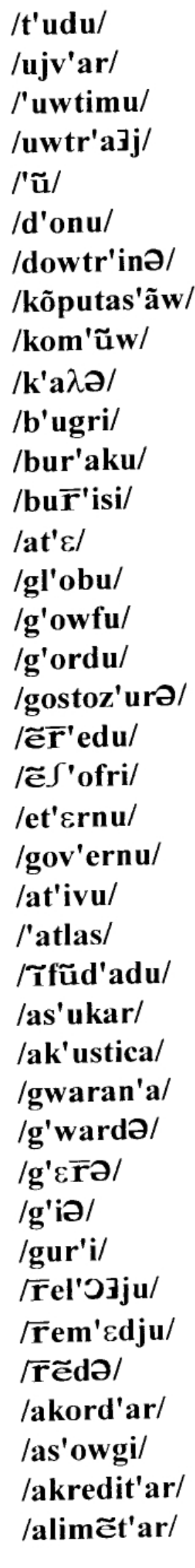 \\
\hline
\end{tabular}




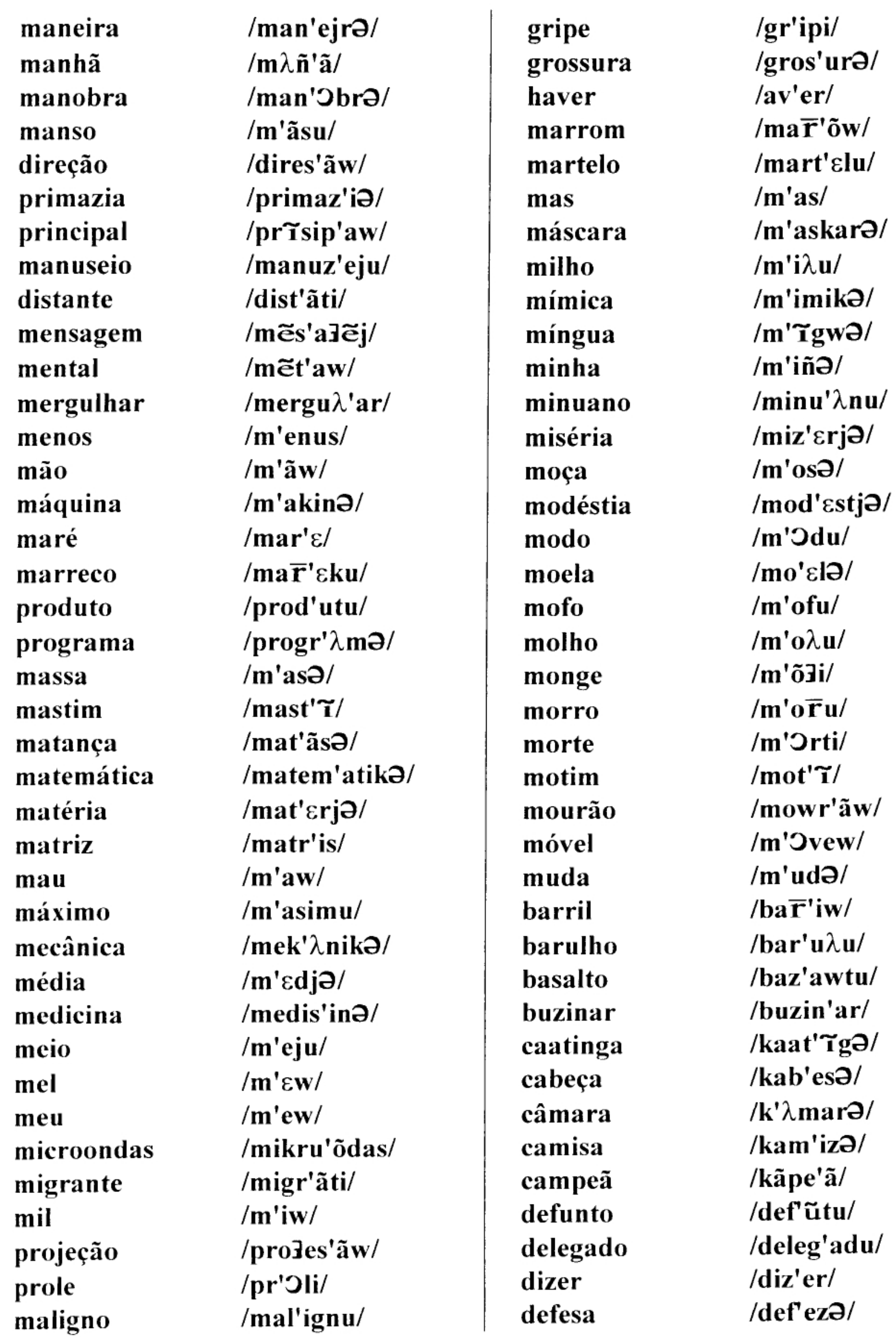




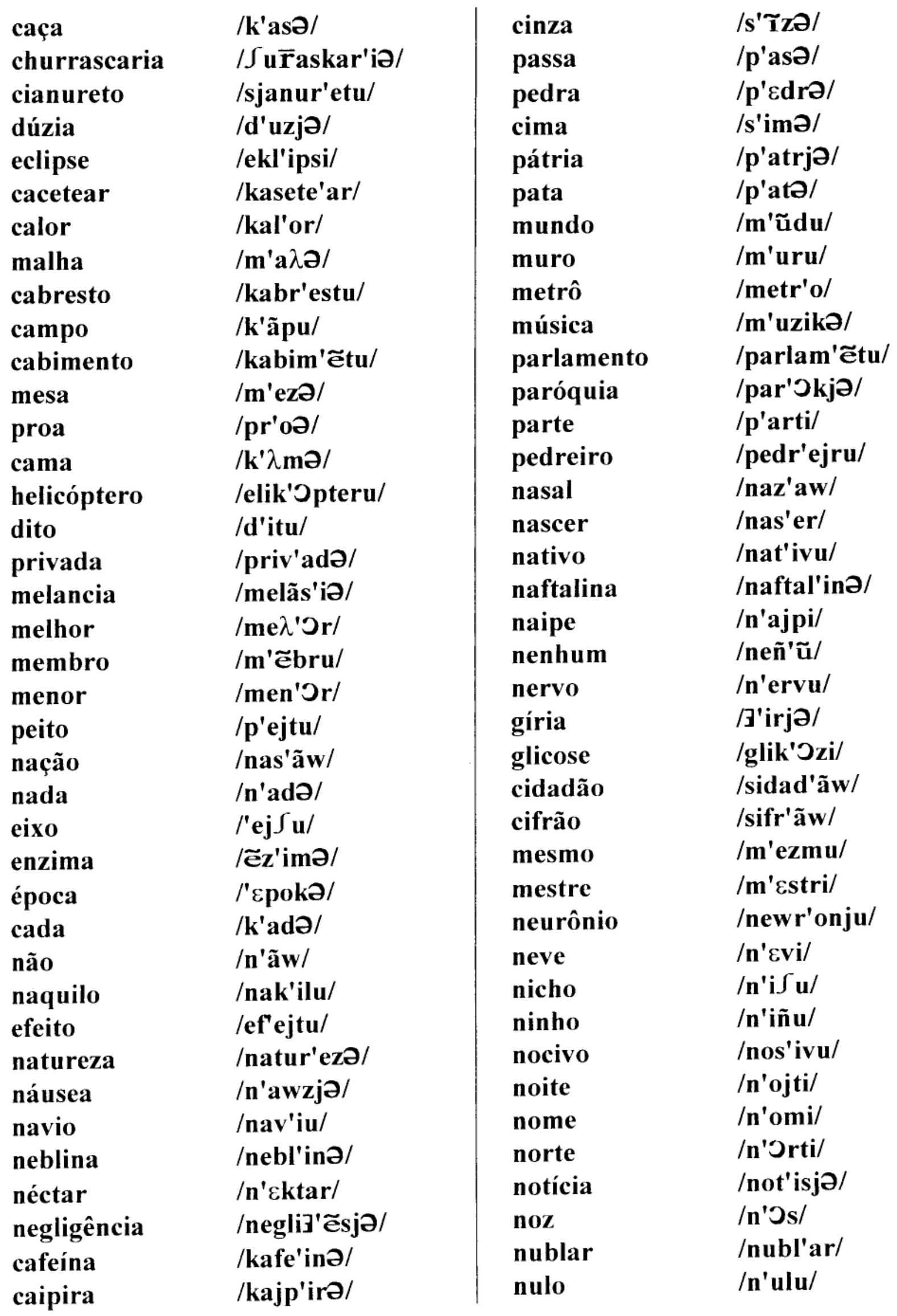




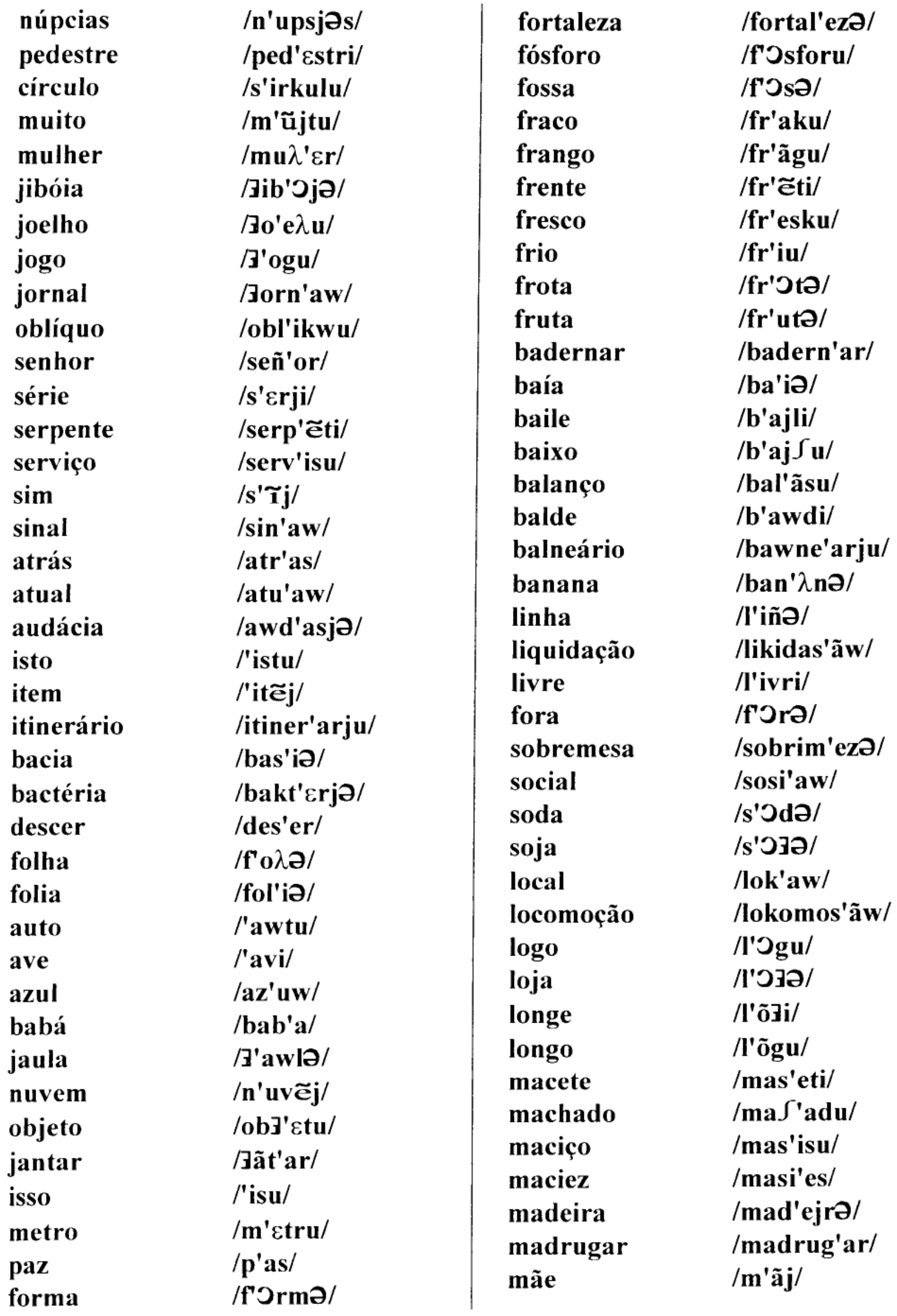




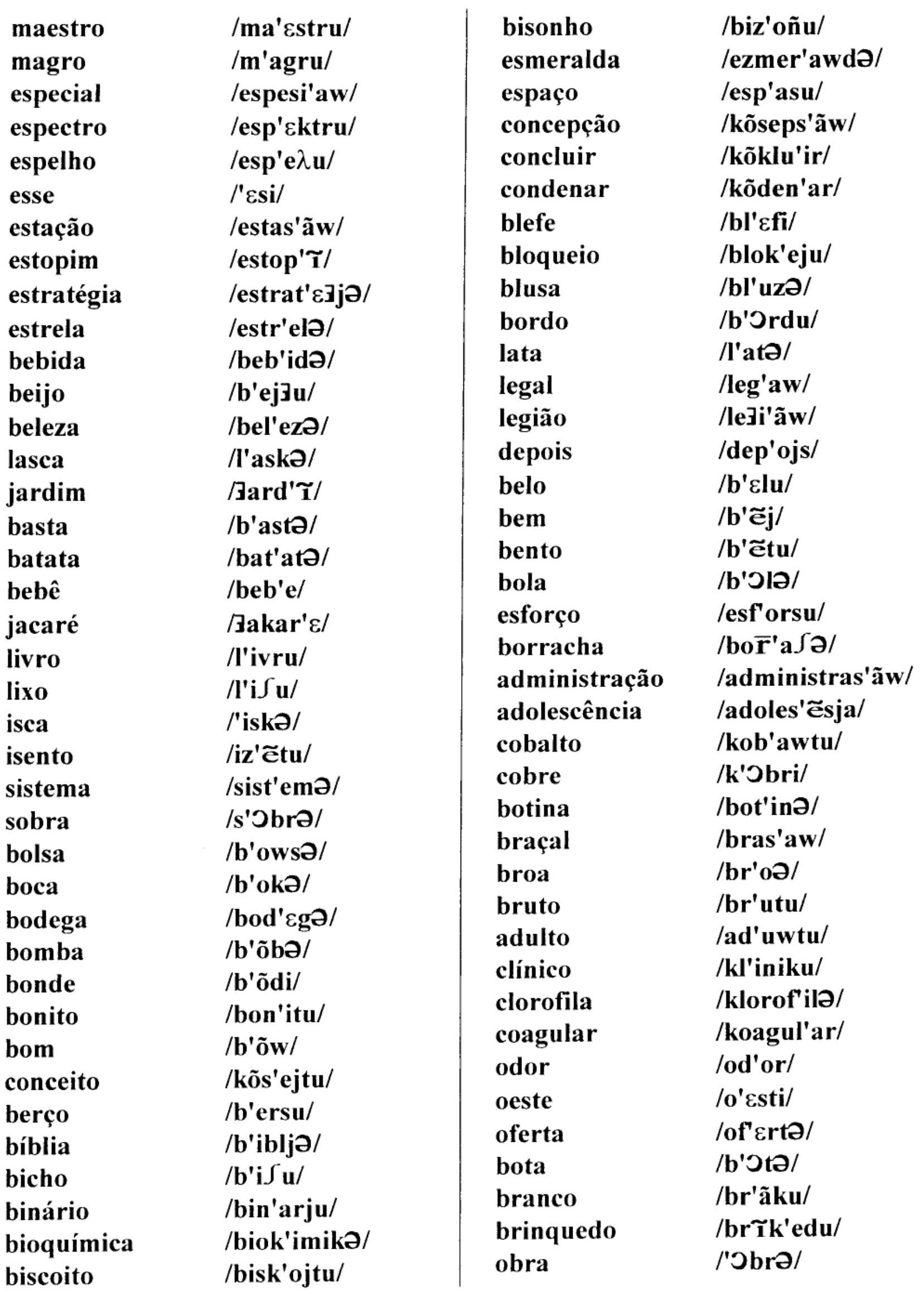




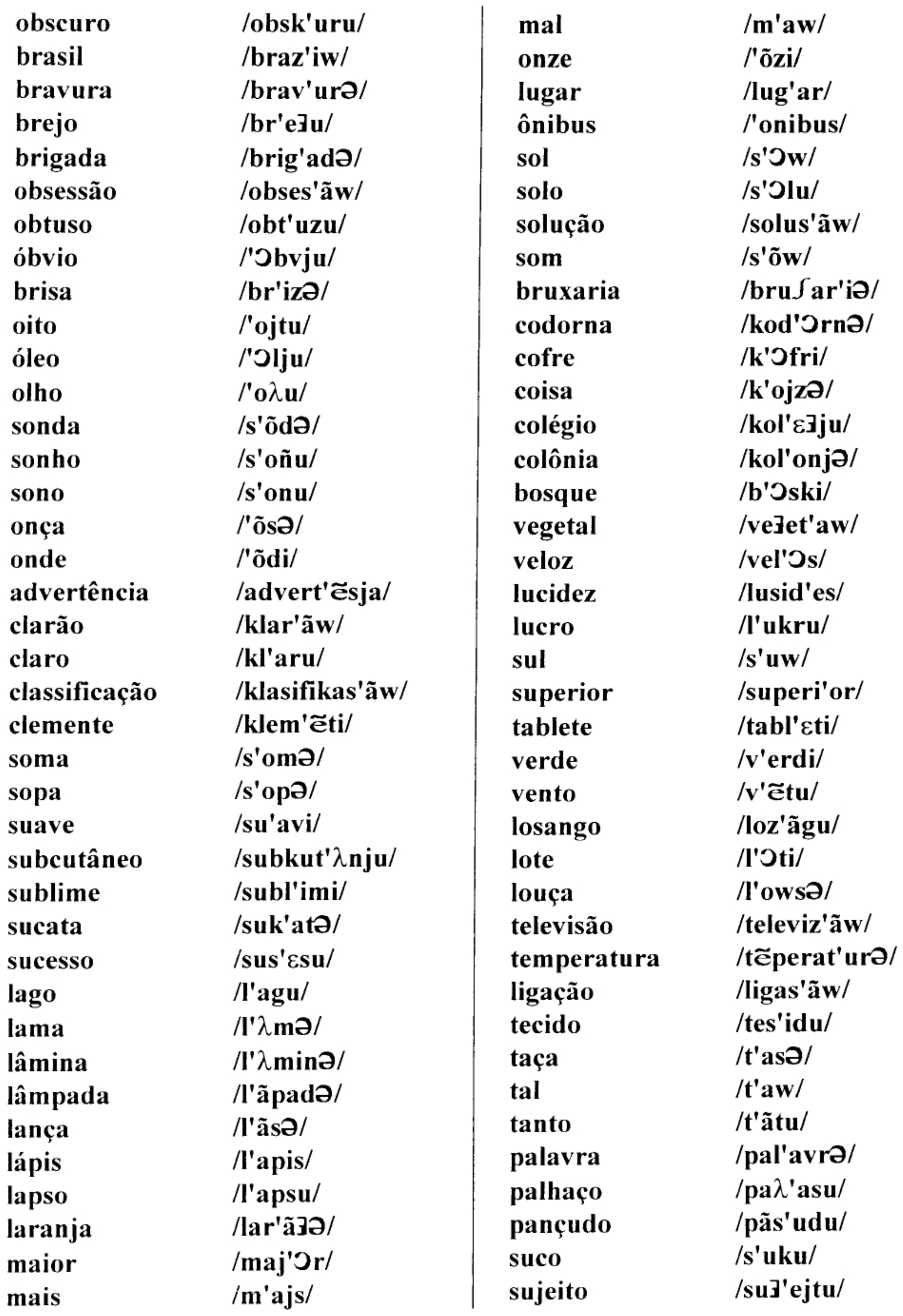




\begin{tabular}{|c|c|c|c|}
\hline sabão & /sab'ãw/ & libélula & /lib'clulə/ \\
\hline sabiá & /sabi'a/ & doceiro & /dos'ejru/ \\
\hline vazio & /va'ziu/ & escarpa & /esk'arpə/ \\
\hline parada & /par'adə/ & escolher & /esko $\lambda$ 'er/ \\
\hline paralisia & /paraliz'iə/ & escravo & /eskr'avu/ \\
\hline parede & /par'edi/ & esfera & /esf'Erə/ \\
\hline padrão & /padr'ãw/ & confecção & /kõfeks'ãw/ \\
\hline página & /p'ajina/ & lição & /lis'ãw/ \\
\hline pai & $/ p^{\prime} \mathbf{a j} /$ & lacre & /l'akri/ \\
\hline tempo & /t'êpu/ & abismo & /ab'izmu/ \\
\hline corja & /k'Orłə/ & limpo & /l'трu/ \\
\hline coronel & /koron'Ew/ & tapete & /tap'eti/ \\
\hline tentação & /tẽtas'ãw/ & tara & /t'ara/ \\
\hline teoria & /teor'iə/ & $\operatorname{tax} a$ & /t'aSa/ \\
\hline vermelho & /verm'e $\lambda \mathbf{u} /$ & pane & $/ \mathbf{p}^{\prime} \lambda \mathbf{n i} /$ \\
\hline viagem & /vi'a] ejj/ & correio & /kor'eju/ \\
\hline vida & /v'idə/ & transpirar & /trãspir'ar/ \\
\hline laço & /l'asu/ & savana & $/ \mathbf{s a v}^{\prime} \lambda \mathbf{n} \boldsymbol{} /$ \\
\hline corte & /k'Orti/ & teatro & /te'atru/ \\
\hline corvo & /k'orvu/ & conhecimento & /koñesim'ẽtu/ \\
\hline cachecol & $/ \mathbf{k a} \int \mathbf{e k}^{\prime} \bigcirc \mathbf{w} /$ & ladrão & /ladr'ãu/ \\
\hline limão & /lim'ãw/ & seco & /s'eku/ \\
\hline abdicar & /abdik'ar/ & século & /s'ckulu/ \\
\hline aberto & /ab'crtu/ & parente & /par'êti/ \\
\hline painel & /pajn'Ew/ & leite & /l'ejti/ \\
\hline paisano & $/$ pajz'$\lambda \mathbf{n u} /$ & lenha & /l'eñə/ \\
\hline ruim & $\sqrt{\mathbf{r}} \mathbf{u} \tilde{\mathbf{x}} /$ & língua & /l'Tgwə/ \\
\hline rural & / $\mathbf{r} u r^{\prime} \mathbf{a w} /$ & pacto & /p'aktu/ \\
\hline sábado & /s'abadu/ & segundo & /seg'ũdu/ \\
\hline luxo & $/ \mathbf{l}^{\prime} \mathbf{u} \int \mathbf{u} /$ & seis & /s'ejs/ \\
\hline luz & /l'us/ & adaptável & /adapt'avew/ \\
\hline maçã & $/ \mathbf{m a s} \mathbf{a}^{\prime} /$ & demais & /dem'ajs/ \\
\hline macarrão & /maka $\overline{\mathbf{r}}^{\prime} \mathbf{a} \mathbf{o} /$ & dentro & /d'ẽtru/ \\
\hline corrupiar & /kō̄upi'ar/ & pantanal & /pãtan'aw/ \\
\hline luta & /l'uta/ & pão & /p'ãw/ \\
\hline luneta & /lun'etə/ & consoante & /kõso'ãti/ \\
\hline lento & /l'etu/ & constranger & /kõstrãz'er/ \\
\hline leque & /l'cki/ & adeus & /ad'ews/ \\
\hline leste & /l'esti/ & adiante & /adj'ãti/ \\
\hline
\end{tabular}




\begin{tabular}{|c|c|c|c|}
\hline $\begin{array}{l}\text { adjetivo } \\
\text { colóquio } \\
\text { lácteo } \\
\text { lado } \\
\text { contra }\end{array}$ & $\begin{array}{l}\text { /adJet'ivu/ } \\
\text { /kol'Okju/ } \\
\text { /l'aktju/ } \\
\text { /l'adu/ } \\
\text { /k'õtrə/ }\end{array}$ & $\begin{array}{l}\text { copa } \\
\text { coração } \\
\text { contexto } \\
\text { sem } \\
\text { sempre }\end{array}$ & $\begin{array}{l}\text { /k'Opə/ } \\
\text { /koras'ãw/ } \\
\text { /kõt'estu/ } \\
\text { /s'ẽj/ } \\
\text { /s'ẽpri/ }\end{array}$ \\
\hline
\end{tabular}




\section{ANEXO 3 - Lista de Sílabas}

- Lista das sílabas contidas na Biblioteca de Voz (1.077 sílabas):

- Padrão silábico CV (266 sílabas):

$/ \mathrm{b} \mathbf{i} / \mathrm{b} \tilde{\mathbf{i}} / \quad / \mathrm{be} / \quad / \mathrm{b} \tilde{\mathbf{e}} / \quad / \mathrm{b} \boldsymbol{b} / \quad / \mathrm{b} \mathbf{a} / \quad / \mathrm{b} \tilde{\mathbf{a}} / \mathrm{b} \Lambda /$

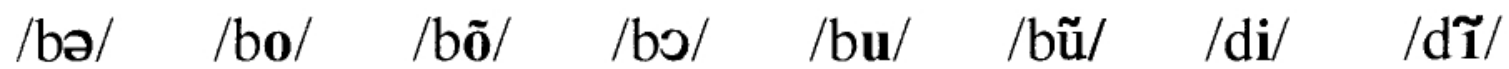
$/ \mathrm{de} / \quad / \mathrm{d} \tilde{\mathbf{e}} / \quad / \mathrm{d} \boldsymbol{e} / \quad / \mathrm{d} \mathbf{a} / \quad / \mathrm{d} \tilde{\mathbf{a}} / \quad / \mathrm{d} \Lambda / \quad / \mathrm{d} \boldsymbol{\Xi} / \quad / \mathrm{d} \mathbf{0} /$ $/ \mathrm{d} \tilde{\mathbf{o}} / \mathrm{d} / \mathrm{do} / \mathrm{du} / \mathrm{d} \tilde{\mathbf{u}} / \quad / \mathrm{fi} / \quad / \mathrm{f} \tilde{\mathbf{i}} / \quad / \mathrm{fe} / \quad / \mathrm{f} \tilde{\mathbf{e}} /$ $/ \mathrm{fE} / \quad / \mathrm{fa} / \quad / \mathrm{fa \tilde {a }} / \quad / \mathrm{f} \Lambda / \quad / \mathrm{fa} / \quad / \mathrm{fo} / / \mathrm{f} \tilde{\mathbf{o}} / \quad / \mathrm{fo} /$ $/ \mathrm{fu} / \quad / \mathrm{fu} / / \mathrm{gi} / \mathrm{g} \tilde{\mathbf{i}} / \mathrm{g} \mathbf{g} / \mathrm{g} \tilde{\mathbf{e}} / \mathrm{g} \boldsymbol{g} / \mathrm{ga} /$ $/ \mathrm{g} \tilde{\mathbf{a}} / \mathrm{g} / \mathrm{g} / \mathrm{g} / \mathrm{g} / \mathrm{go} / \mathrm{g} \tilde{\mathbf{o}} / \mathrm{g} / \mathrm{g} / \mathrm{gu} / \mathrm{gu \tilde { }} /$

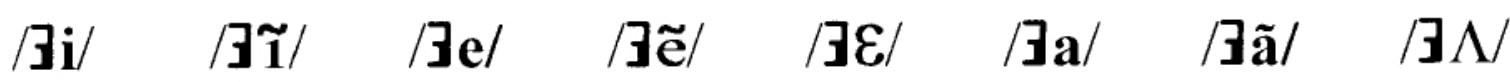

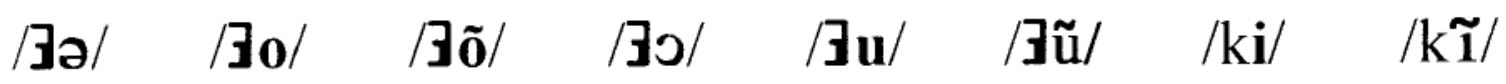
$/ \mathrm{ke} / \quad / \mathrm{k} \tilde{\mathbf{e}} / \quad / \mathrm{k} \boldsymbol{\varepsilon} \quad / \mathrm{ka} / \quad / \mathrm{k} \tilde{\mathbf{a}} / \quad / \mathrm{k} \Lambda / \quad / \mathrm{kə} / \quad / \mathrm{ko} /$

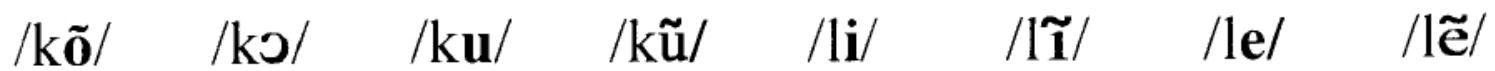
$/ 1 \mathbb{E} / \quad / \mathbf{a} / \quad / \mathbf{a} / \quad / 1 \Lambda / \quad / \mathbf{a} / \quad / 1 \mathbf{o} / \quad / l \tilde{\mathbf{o}} / \quad / 1 \mathrm{l} /$ $/ l \mathbf{u} / / \operatorname{u} / / \quad / \lambda \mathbf{i} / \quad / \lambda \tilde{\mathbf{i}} / \quad / \lambda \mathbf{e} / \quad / \lambda \tilde{\mathbf{e}} / \quad / \lambda \varepsilon / \quad / \lambda \mathbf{a} /$

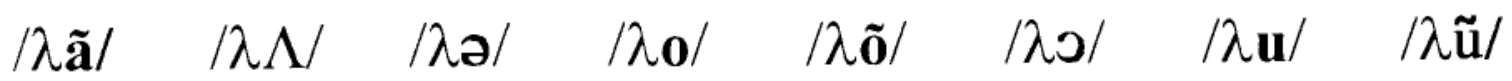
$/ \mathrm{mi} / / \mathrm{m} \tilde{\mathbf{1}} / \quad / \mathrm{me} / \quad / \mathrm{m} \tilde{\mathbf{e}} / \quad / \mathrm{m} \boldsymbol{l} / \quad / \mathrm{ma} / \quad / \mathrm{m} \tilde{\mathbf{a}} / \quad / \mathrm{m} \Lambda /$ 
"Um Sistema para Leitura de e-mail, com Conversão Texto/Voz, utilizando Redes Neurais" $/ \mathrm{ma} / \mathrm{mo} / \mathrm{m} \tilde{\mathbf{o}} / \mathrm{mo} / \mathrm{mu} / \mathrm{mu} / \mathrm{ni} / \mathrm{n} \tilde{\mathbf{i}} /$

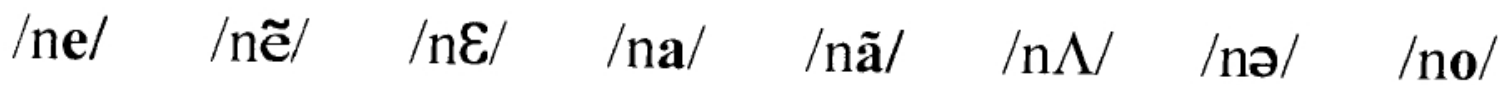

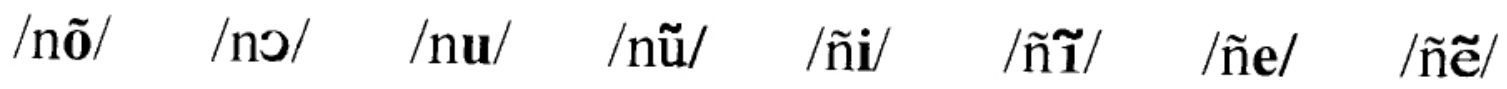

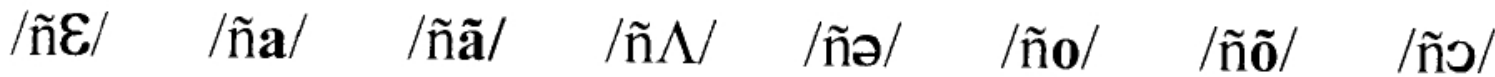
$/ \tilde{\mathbf{n}} / / \tilde{\mathrm{n}} / / \mathrm{p} \mathbf{i} / \mathrm{p} \tilde{\mathbf{i}} / / \mathrm{pe} / \quad / \mathrm{p} \tilde{\mathbf{e}} / \quad / \mathrm{p} \boldsymbol{l} / \mathrm{pa} /$ $/ \mathrm{p} \tilde{\mathbf{a}} / \mathrm{p} \Lambda / \mathrm{p} \boldsymbol{\mathrm { p }} / / \mathrm{p} \mathbf{\mathrm { m }} / \mathrm{p} \tilde{\mathbf{o}} / \mathrm{p} / \mathrm{p} / \mathrm{pu} / / \mathrm{p} \tilde{\mathbf{u}} /$ $/ \mathrm{ri} / \mathrm{r} \tilde{\mathbf{i}} / \quad / \mathrm{re} / \quad / \mathrm{r} \tilde{\mathbf{e}} / \quad / \mathrm{r} \boldsymbol{E} / \quad / \mathrm{ra} / \quad / \mathrm{ra} / \quad / \mathrm{r} \Lambda /$ $/ \mathrm{ra} / \quad / \mathrm{ro} / \quad / \mathrm{r} \tilde{\mathbf{o}} / \quad / \mathrm{rJ} / \quad / \mathrm{ru} / \quad / \mathrm{ru} / \quad / \overline{\mathbf{r}} \mathbf{i} / / \overline{\mathbf{r}} \mathbf{\mathbf { 1 }} /$

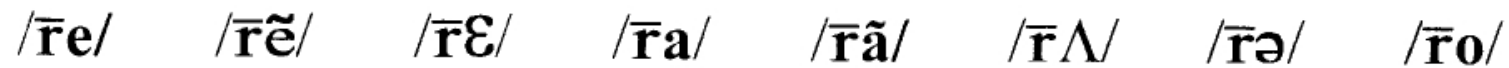
$/ \overline{\mathbf{r}} \tilde{\mathbf{o}} / \quad / \overline{\mathbf{r}} / \quad / \overline{\mathbf{r}} / \quad / \overline{\mathbf{r}} \tilde{u} / \quad / \mathrm{si} / \quad / \mathrm{s} \tilde{\mathbf{i}} / \quad / \mathrm{se} / \quad / \mathrm{s} \tilde{\mathbf{e}} /$ $/ \mathrm{s} \boldsymbol{L} / \quad / \mathrm{sa} / \quad / \mathrm{s} \mathbf{a} / \quad / \mathrm{s} \Lambda / \quad / \mathrm{s} \boldsymbol{l} / \mathrm{s} \mathbf{s} / \quad / \mathrm{s} \tilde{\mathbf{o}} / \quad / \mathrm{s} \boldsymbol{l} /$ $/ \mathrm{su} / \quad / \mathrm{s} \tilde{\mathbf{u}} / \quad / \int \mathbf{i} / \quad / \int \tilde{\mathbf{i}} / \quad / \int \mathbf{e} / \quad / \int \tilde{\mathbf{e}} / \quad / \delta \boldsymbol{E} / \quad / \int \mathbf{a} /$ $/ \int \tilde{\mathbf{a}} / \quad / \int \Lambda / \quad / \int_{\boldsymbol{\theta}} / \quad / \int_{\mathbf{0}} / \quad / \int \tilde{\mathbf{o}} / \quad / \int^{\mathrm{O}} / \quad / \int_{\mathbf{u}} / \quad / \int \tilde{\mathbf{u}} /$ $/ \mathrm{ti} / \mathrm{t} \tilde{\mathbf{1}} / \quad / \mathrm{te} / \quad / \mathrm{t} \tilde{\mathbf{e}} / \quad / \mathrm{t} \boldsymbol{E} / \quad / \mathrm{ta} / \quad / \mathrm{t} \tilde{\mathbf{a}} / \quad / \mathrm{t} \Lambda /$ $/$ tə/ $/$ to $/ \quad /$ to $/ \quad /$ ol $/ \mathrm{tu} / \quad / \mathrm{tu} / \quad / \mathrm{vi} / \mathrm{V} \tilde{\mathbf{i}} /$ $/ \mathrm{ve} / \mathrm{v} \tilde{\mathbf{e}} / \quad / \mathrm{v} \boldsymbol{E} / \quad / \mathrm{va} / \quad / \mathrm{v} \tilde{\mathbf{a}} / \quad / \mathrm{v} \Lambda / \quad / \mathrm{v} \boldsymbol{l} / \mathrm{vo} /$ $/ \mathrm{v} \tilde{\mathbf{o}} / \mathrm{ho} / \mathrm{v} \mathbf{u} / \mathrm{v} \tilde{\mathbf{u}} / \mathrm{z} \mathbf{\mathbf { i }} / \mathrm{z} \tilde{\mathbf{i}} / \mathrm{zze} / \mathrm{z} \tilde{\mathbf{e}} /$ $/ \mathrm{z} \boldsymbol{E} / \quad / \mathrm{za} / \quad / \mathrm{z} \tilde{\mathbf{a}} / \quad / \mathrm{z} \Lambda / \quad / \mathrm{z} \mathbf{} / \quad / \mathrm{zo} / \quad / \mathrm{z} \tilde{\mathbf{0}} / \quad / \mathrm{ZO} /$ /zu/ /zũ / 
- Padrão silábico CVC* e CC*V (269 sillabas): observação: $C^{*}$ representa fonemas semi-consonantais (semi-vocálicos)

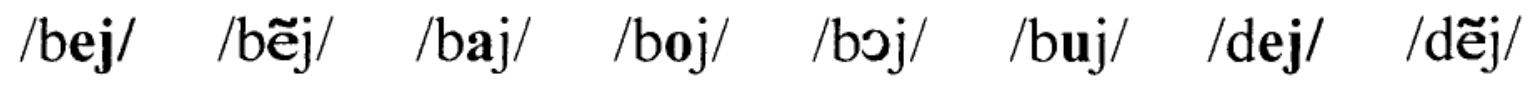
$/ \mathrm{d} \varepsilon \mathrm{j} / \quad / \mathrm{daj} / \quad / \mathrm{doj} / \quad / \mathrm{d} \mathrm{jj} / \quad / \mathrm{fej} / \quad / \mathrm{f} \tilde{\mathrm{ej}} / \quad / \mathrm{f} \varepsilon \mathrm{j} / \quad / \mathrm{faj} /$

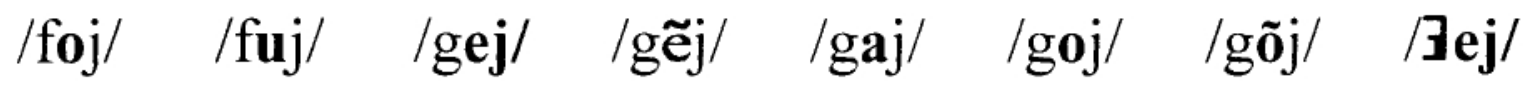

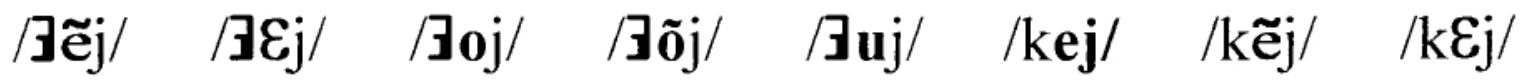
$/ \mathrm{kaj} / \quad / \mathrm{koj} / \quad / \mathrm{k} \tilde{\mathbf{o j}} / \quad / \mathrm{kuj} / \quad / \mathrm{lej} / \quad / \mathrm{l} \mathrm{jj} / \quad / \mathrm{laj} / \quad / \mathrm{loj} /$ $/ \mathbf{l o j} / / / \mathrm{loj} / \quad / \lambda \mathrm{ej} / \quad / \lambda \tilde{\mathbf{o j}} / \quad / \mathrm{mej} / \quad / \mathrm{me \tilde {j }} / \quad / \mathrm{maj} / \quad / \mathrm{moj} /$ $/ \mathrm{m} \tilde{\mathbf{o j}} / \quad / \mathrm{moj} / \quad / \mathrm{mu \tilde {j }} / \quad / \mathrm{nej} / \quad / \mathrm{n} \tilde{\mathbf{e j}} / \quad / \mathrm{n} \varepsilon \mathrm{j} / \quad / \mathrm{noj} / \quad / \mathrm{n} \tilde{\mathbf{o j}} /$ $/ \mathrm{noj} / \quad / \tilde{\mathbf{n e j}} / \quad / \tilde{\mathbf{n}} \mathbf{0 j} / \quad / \mathrm{pej} / \quad / \mathrm{pẽj} / \quad / \mathrm{p} \varepsilon \mathrm{j} / \quad / \mathrm{paj} / \quad / \mathrm{poj} /$

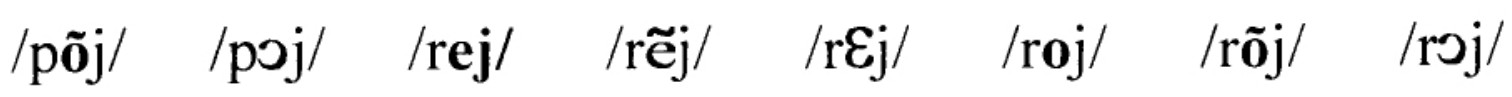

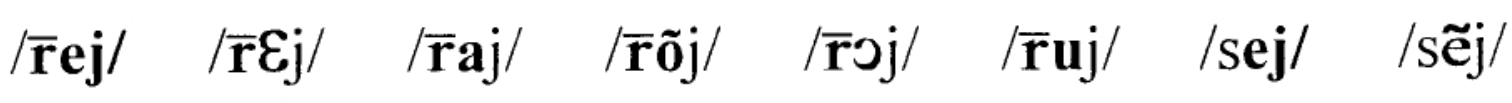

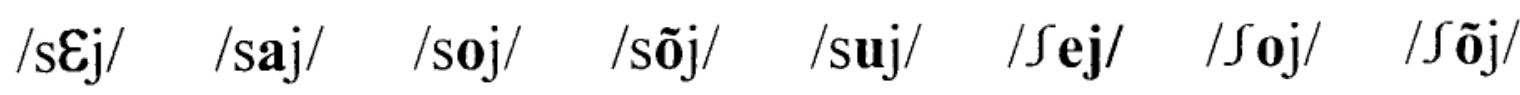
$/$ tej/ /tẽj/ /tEj/ /tõj/ /toj/ /vej/ /vẽj/ /vaj/ $/ \mathrm{vo \tilde {j }} / \quad / z \mathbf{z e j} / \quad / z \tilde{\mathrm{ej}} / \quad / z \mathbf{a j} / \quad / z \mathbf{o j} / \quad / z \tilde{\mathbf{o j}} / / \quad / z o j / \quad / \mathrm{biw} /$ /bEw/ /baw/ /bow/ /bõw/ /dew/ /daw/ /dãw/ /dow/ $/ \mathrm{do \tilde {w }} / /$ fiw/ /few/ /fEw/ /faw/ /fãw/ /fow/ /gEw/ /gaw/ /gãw/ /gow/ /Jiw/ /Jaw/ / Jãw/ /kew/ /kaw/ /kãw/ /kow/ /kow/ /lew/ /law/ /lãw/ /low/ / $/ \lambda \mathbf{a w} /$

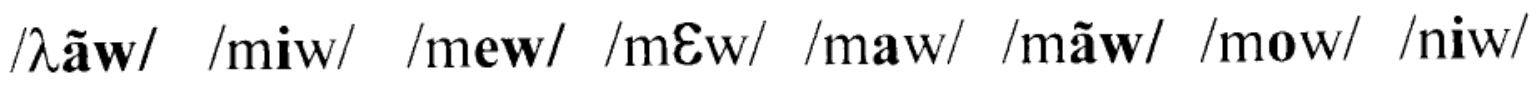


"Um Sistema para Leitura de e-mail, com Conversão Texto/Voz, utilizando Redes Neurais" /new/ /nEw/ /naw/ /nãw/ /now/ /ñ̃w/ /now/ /ñaw/ /ñaw/ /ñow/ /pew/ /pEw/ /paw/ /pãw/ /pow/ /raw/

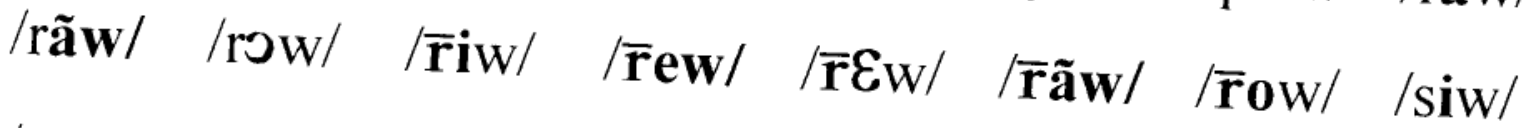
/sew/ /sEw/ /saw/ /sãw/ /sow/ /sõw/ /sow/ / $/$ aw/ $/ \mathrm{s}$ ãw/ /tiw/ /tew/ /tEw/ /taw/ /tãw/ /tow/ /tõw/

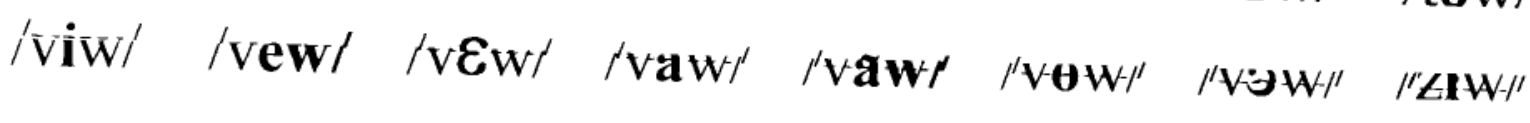
/zew/ /zaw/ /zãw/ /zow/ /zõw/ /bja/ /bju/ /dja/

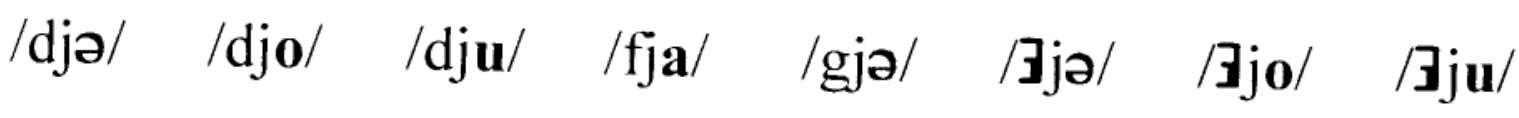
$/ \mathrm{kje} / \mathrm{kja} / \mathrm{kja} / \mathrm{kju} / / \mathrm{lja} / / \mathrm{lja} / / \mathrm{ljo} / / \mathrm{lju} /$ /mjə/ /mju/ /nja/ /njə/ /nju/ /pje/ /pjə/ /pjo/ $/ \mathrm{pju} / / \mathrm{rj} \mathbf{\mathbf { i }} / \mathrm{rje} / \mathrm{rja} / \mathrm{rja} / \quad / \mathrm{rjo} / \quad / \mathrm{rju} / / \mathrm{sje} /$ $/$ sja/ /sja/ /sjo/ /sju/ /tja/ /tjo/ /tju/ /vje/ /vja/ /vjə/ /vju/ /zja/ /zja/ /zjo/ /bwi/ /bwə/ /dwa/ /gwe/ /gwẽ//gwa/ /gwã/ /gwa/ /kwi/ /kwe/ /kwẽ/ /kwE/ /kwa/ /kwã/ /kwo/ /lwa/ /nwo/ /swa/ /twi/ /twa/ /two/ /vwa/ /zwa/ 
- Padrão silábico CCV (105 sílabas):

/blĩ / /ble/ /ble/ /bla/ /blo/ /blo/ /blu/ /bri/

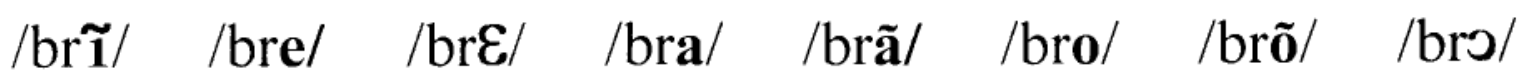
/bru/ /dri/ /dre/ /dra/ /dr $\Lambda / \quad /$ dro/ $/ \mathrm{dro} / \quad / \mathrm{fle} /$ $/ \mathrm{fl} / / \mathrm{fla} / \quad / \mathrm{fla} / / \mathrm{fl} \Lambda / \mathrm{flo} / \quad / \mathrm{flo} / \quad / \mathrm{flu} / \quad / \mathrm{fri} /$ $/$ fre/ $/$ frẽ $/ \quad /$ frE/ $/$ fra/ $/$ frãa $/$ fro/ $/$ frõ $/ /$ fro/ $/ \mathrm{fru} / \mathrm{gli} / \mathrm{gla} / \mathrm{gla \tilde {a }} / \mathrm{glo} / \mathrm{glo} / \mathrm{glu} / \mathrm{gri} /$

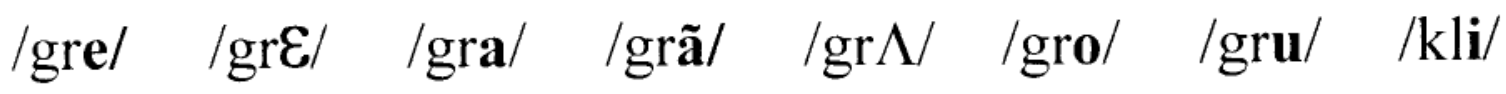
$/ \mathrm{kle} / \quad / \mathrm{klE} / \quad / \mathrm{kla} / \quad / \mathrm{kla \tilde {a }} / \quad / \mathrm{klo} / \quad / \mathrm{klo} / \quad / \mathrm{klu} / \quad / \mathrm{kri} /$ $/ \mathrm{kre} / \mathrm{krE} / \quad / \mathrm{kra} / \quad / \mathrm{kro} / \quad / \mathrm{kro} / \quad / \mathrm{kru} / \quad / \mathrm{ple} / \quad / \mathrm{pl} /$

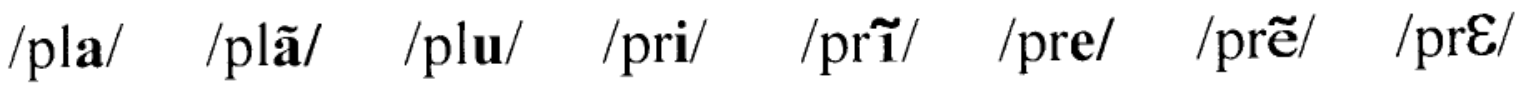
$/ \mathrm{pra} / / \mathrm{pra} / / \mathrm{pro} / \mathrm{pr} \tilde{\mathbf{o}} / \mathrm{pro} / \mathrm{pru} / / \operatorname{tri} / \quad / \operatorname{tr} \mathbf{\mathbf { i }} /$ $/ \operatorname{tre} / / \operatorname{tr} \tilde{\mathbf{e}} / \quad / \operatorname{tr} \boldsymbol{l} / \quad / \operatorname{tra} / \quad / \operatorname{tra} / / 2 / \operatorname{tr} \Lambda / \quad / \operatorname{tro} / \quad / \operatorname{tr} \tilde{\mathbf{o}} /$

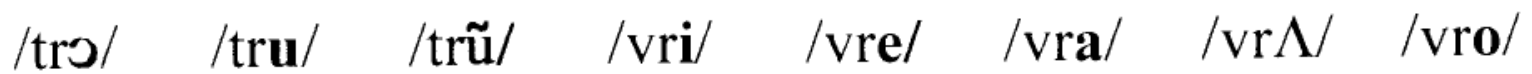
/vru/ 
- Padrão silábico CVC** (437 silabas): observação: $C^{* \star}$ representa apenas os fonemas $/ r /$ e /s/ principalmente utilizados, respectivamente, em forma infinitiva dos verbos e plural das palavras.

/bir/ /ber/ /bEr/ /bar/ /b $\Lambda \mathrm{r} /$ /bər/ /bor/ /bor/ /bur/ /dir/ /der/ /dEr/ /dar/ /d $\Lambda \mathrm{r} / \quad / \mathrm{d} ə \mathrm{r} / \quad / \mathrm{dor} /$ /dor/ /dur/ /fir/ /fer/ /fEr/ /far/ /f $\Lambda \mathrm{r} /$ /fər/ /for/ /for/ /fur/ /gir/ /ger/ /gEr/ /gar/ /g $\Lambda \mathrm{r} /$ /gər/ /gor/ /gor/ /gur/ /Bir/ Ber/ /JEr/ /Jar/ \} \Lambda \mathrm { r } / \text { Jər/ Jor/ Jor/ /Jur/ /kir/ /ker/ /kEr/ } /kar/ /k $\Lambda \mathrm{r} / \quad$ kər/ /kor/ /kor/ /kur/ /lir/ /ler/ $/ \mathrm{lEr} / \quad / \operatorname{lar} / \quad / 1 \Lambda \mathrm{r} / \quad / \mathrm{lar} / \quad /$ lor/ $/$ lor/ $/ \mathrm{lur} / \quad / \lambda \mathbf{i r} /$

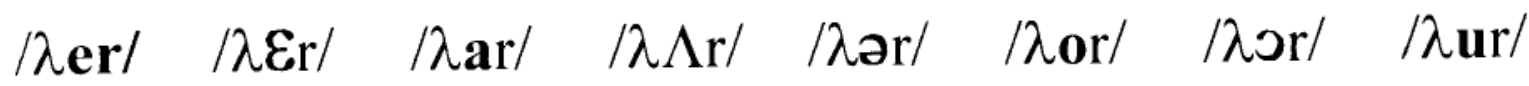
$/ \mathrm{mir} / \mathrm{mer} / \mathrm{m \varepsilon r} / \mathrm{mar} / \mathrm{m} \Lambda \mathrm{r} /$ /mər/ $/ \mathrm{mor} /$ /mor/ /mur/ /nir/ /ner/ /nEr/ /nar/ /n $\Lambda \mathrm{r} /$ /nər/ /nor/

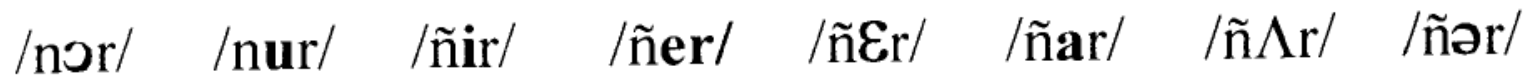
/ñor/ /ñor/ /ñur/ /pir/ /per/ /pEr/ /par/ /p $\Lambda \mathrm{r} /$ /por/ /por/ /por/ /pur/ /rir/ /rer/ /rEr/ /rar/ /r $\Lambda \mathrm{r} / \quad$ /rər/ $/$ ror/ $/$ ror/ $/$ rur/ $/ \overline{\mathbf{r i r}} / \quad / \overline{\mathbf{r} e r} / \quad / \overline{\mathbf{r}} \varepsilon \mathrm{r} /$

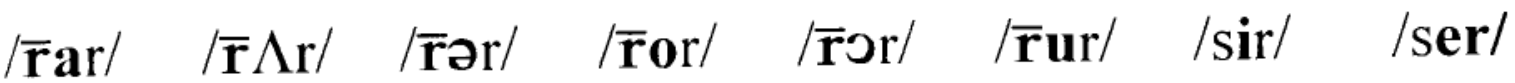
/ser/ /sar/ /s $\Lambda \mathrm{r} /$ /sər/ /sor/ /sor/ /sur/ / / ir/ 
/mũs/ /nis/ /ñ̃s/ /nes/ /nẽs/ /nछs/ /nas/ /nãs/ /n $\Lambda$ s/ /nəs/ /nos/ /nõs/ /nos/ /nus/ /nũs/ /ñis/

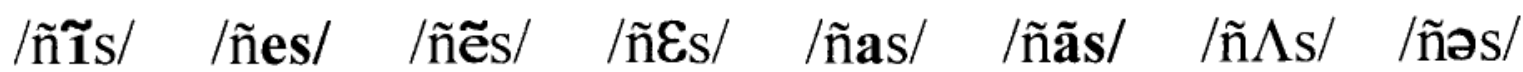

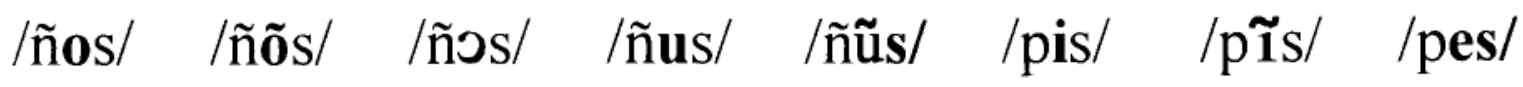
/pẽs/ /pEs/ /pas/ /pãs/ /p $\Lambda \mathrm{s} / \quad$ /pəs/ $/ \mathrm{pos} / \quad / \mathrm{põs} /$ /pos/ /pus/ /pũs/ /ris/ /rĩs/ /res/ /rẽs/ $/$ rEs/ /ras/ $\quad /$ rãs/ $\quad / \mathrm{r} \Lambda \mathrm{s} / \quad$ /rəs/ $\quad /$ ros/ $\quad /$ ross/ $/$ ros/ $/$ rus/

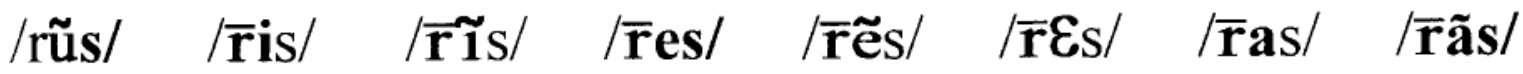

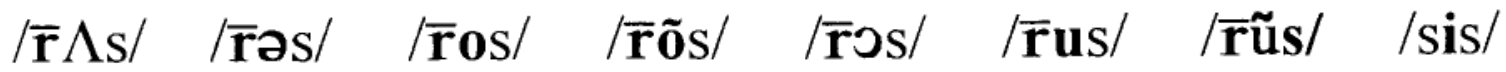

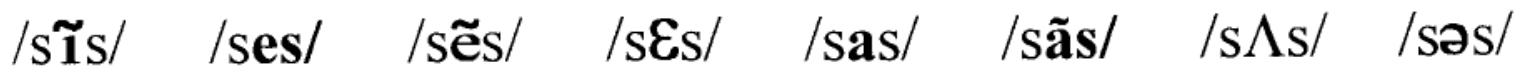

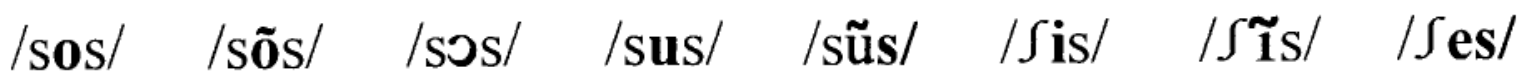

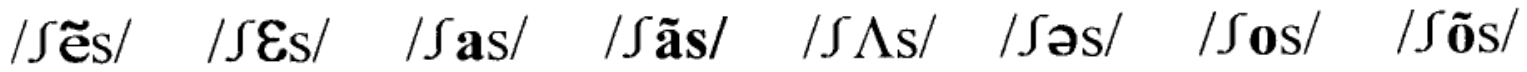

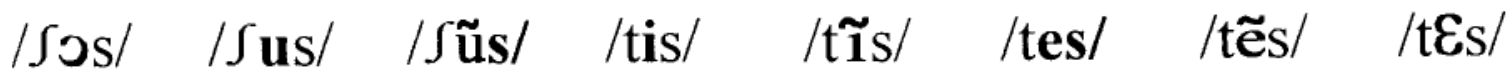
/tas/ $/$ tãs/ $/$ t $\Lambda \mathrm{s} / \quad /$ tas/ $\quad /$ tos/ $/$ tõs/ $/$ tos/ $\quad /$ tus/ /tũs/ /vis/ /ṽ̃s/ /ves/ /vẽs/ /vEs/ /vas/ /vãs/

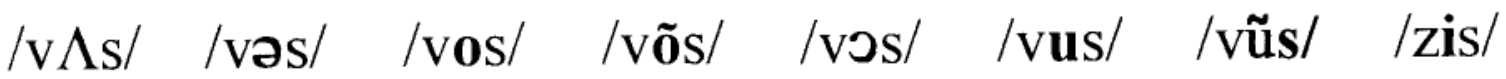

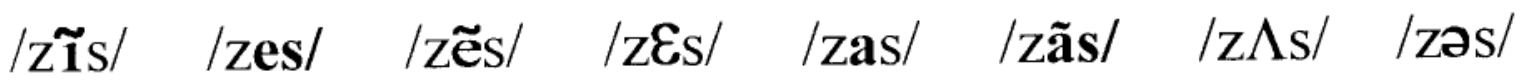
/zos/ /zõs/ /zOs/ /zus/ /zũs/ 